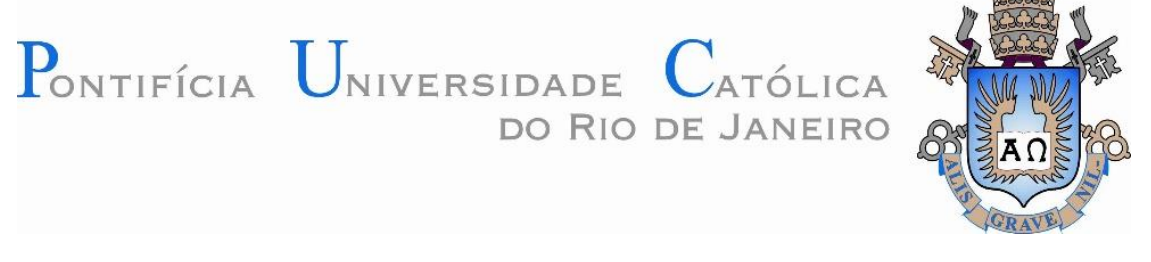

Matheus Ferreira de Barros

\title{
Análise e Previsão de Séries Temporais Utilizando Amortecimento Exponencial com Múltiplos Ciclos e Técnicas de Simulação na Produção de Energia Eólica
}

Dissertação apresentada como requisito parcial para obtenção do grau de Mestre pelo Programa de PósGraduação em Metrologia (Área de concentração: Metrologia para Qualidade e Inovação) da PUC-Rio.

Orientador: Prof. Reinaldo Castro Souza Coorientador. Prof. Fernando Luiz Cyrino Oliveira 
Matheus Ferreira de Barros

\section{Análise e Previsão de Séries Temporais Utilizando Amortecimento Exponencial com Múltiplos Ciclos e Técnicas de Simulação na Produção de Energia Eólica}

Dissertação apresentada como requisito parcial para obtenção do grau de Mestre pelo Programa de Pós-Graduação em Metrologia (Área de concentração: Metrologia para Qualidade e Inovação) da PUC-Rio.

Prof. Reinaldo Castro Souza

Orientador

Departamento de Engenharia Elétrica - PUC-Rio

Prof. Fernando Luiz Cyrino Oliveira

Coorientador

Departamento de Engenharia Industrial - PUC-Rio

Prof.- Ana Paula Barbosa Sobral UFF

Prof. José Francisco Moreira Pessanha

UERJ

Prof. Jose Eugênio Leal

Coordenador Setorial do Centro Técnico Científico - PUC-Rio

Rio de Janeiro, 18 de setembro de 2015 
Todos os direitos reservados. É proibida a reprodução total ou parcial do trabalho sem autorização da universidade, do autor e do orientador.

\section{Matheus Ferreira de Barros}

Graduado em Engenharia de Produção pela Universidade Federal Fluminense em 2013.

Ficha Catalográfica

Barros, Matheus Ferreira de
Análise e previsão de séries temporais utilizando
amortecimento exponencial com múltiplos ciclos e técnicas
de simulação na produção de energia eólica / Matheus
Ferreira de Barros ; orientador: Reinaldo Castro Souza ;
co-orientador: Fernando Luiz Cyrino Oliveira. - 2015.
74 f. : il. (color.); 30 cm
Dissertação (mestrado)-Pontifícia Universidade
Católica do Rio de Janeiro, Centro Técnico Científico,
Programa de Pós-Graduação em Metrologia para a
Qualidade e Inovação, 2015.
Inclui bibliografia
1. Metrologia - Teses. 2. Séries temporais. 3.
Técnico Científico. Programa de Pós-Graduação em
Metrologia para a Qualidade e Inovação. IV. Título.
Pontifícia Universidade Católica do Rio de Janeiro. Centro
Castro. II. Oliveira, Fernando Luiz Cyrino. III.


Take this kiss upon the brow! And, in parting from you now,

Thus much let me avowYou are not wrong, who deem That my days have been a dream Yet if hope has flown away In a night, or in a day, In a vision, or in none, Is it therefore the less gone? All that we see or seem Is but a dream within a dream.

I stand amid the roar Of a surf-tormented shore, And I hold within my hand Grains of the golden sandHow few! Yet how they creep Through my fingers to the deep,

While I weep- while I weep! Oh God! Can I not grasp Them with a tighter clasp? Oh God! Can I not save One from the pitiless wave?

Is all that we see or seem But a dream within a dream? 


\section{Agradecimentos}

Esse trabalho representa o fim de um ciclo de muito aprendizado em minha trajetória, e não poderia esquecer de deixar aqui o meu agradecimento a pessoas que foram fundamentais nesse caminho.

A minha família e meus amigos, por toda compreensão da minha ausência em muitos momentos devido ao mestrado. Nomear todos aqui seria uma tarefa muito difícil, mas isso seria impossível sem o apoio e carinho deles.

Ao meu orientador, Reinaldo Castro, por todas as portas abertas e pela confiança de sempre.

Ao meu coorientador, Fernando Cyrino, pela contribuição inestimável e pela paciência.

À Ana Paula Barbosa Sobral, por ser um grande exemplo, por todo incentivo e por aceitar participar da banca de avaliação.

Ao professor José Francisco, por aceitar participar da banca de avaliação.

A todos os professores da PUC-Rio, com que tive o prazer de aprender muito durante esses dois anos.

Ao CNPq e à PUC-Rio, pelos auxílios concedidos, sem os quais este trabalho não poderia ter sido realizado. 


\section{Resumo}

Barros, Matheus Ferreira de; Souza, Reinaldo Castro; Oliveira, Fernando Luiz Cyrino. Análise e Previsão de Séries Temporais Utilizando Amortecimento Exponencial com Múltiplos Ciclos e Técnicas de Simulação na Produção de Energia Eólica. Rio de Janeiro, 2015. 74p. Dissertação de Mestrado - Programa de Pós-Graduação em Metrologia (Área de concentração: Metrologia para Qualidade e Inovação), Pontifícia Universidade Católica do Rio de Janeiro.

A presente dissertação se insere no contexto da energia eólica, que é a fonte de energia que mais cresce na matriz elétrica brasileira, segundo dados da Empresa de Pesquisa de Energia (EPE), com projeções para que esse crescimento se mantenha. Com isso, a principal motivação do presente trabalho é o fato de que desenvolver e aplicar métodos de previsão cada vez mais precisos para as variáveis determinantes na produção de energia eólica em um aerogerador, como a velocidade do vento, é de crucial importância para o planejamento da operação do sistema elétrico nacional. Logo, o objetivo principal do trabalho é adaptar e aplicar uma metodologia de previsão de séries temporais em um banco de dados formado por medições de velocidade de vento. A metodologia se constrói a partir da análise exploratória dos dados, onde pode se observar características importantes, como estacionariedade na média e uma estrutura sazonal complexa, que envolve um ciclo diário e uma sazonalidade mensal. Com isso, foi adaptado um modelo de amortecimento exponencial com múltiplos ciclos que incorpora simulação de Monte Carlo e decomposição da série através do método TBATS, para realizar as previsões. Como resultados e conclusões, é possível observar que modelo adaptado se mostrou adequado para tratar o problema proposto, quando comparado com os modelos de previsão estabelecidos pela literatura, resultando em um aumento na precisão das previsões realizadas.

\section{Palavras-chave}

Metrologia; Séries Temporais; Energia Eólica; Amortecimento Exponencial. 


\section{Abstract}

Barros, Matheus Ferreira de; Souza, Reinaldo Castro (Advisor); Oliveira, Fernando Luiz Cyrino (Coadvisor). Analysis and forecasting of time series using multiple seasonal exponential smoothing and simulation techniques in the wind energy production. Rio de Janeiro, 2015. 74p. MSc.Dissertation - Programa de Pós-Graduação em Metrologia (Área de concentração: Metrologia para Qualidade e Inovação), Pontifícia Universidade Católica do Rio de Janeiro.

This work is in the context of wind energy, which is the energy source that grows more in the Brazilian energy matrix, according to the Energy Research Company (EPE), with projections that this growth will continue. Thus, the main motivation of this work is the fact that developing and implementing increasingly precise forecasting methods for the key variables in the production of wind energy in a wind turbine, such as wind speed, is of crucial importance for planning of the national electric system operation. Therefore, the main objective of this work is to adapt and apply a time series forecasting methodology in a database formed by wind speed measurements. The methodology is built from the exploratory analysis of data, which can be observed important features such as stationary mean and a complex seasonal structure, which involves a daily cycle and monthly seasonality. Thus, it was adapted an exponential smoothing model that incorporates multiple cycles, Monte Carlo simulation and decomposition of the series through the TBATS method, to make forecasts. As results and conclusions, it is possible to observe that model adapted was adequate to address the proposed issue, compared with the forecast models established in the literature, resulting in an increase in the accuracy of forecasts made.

\section{Keywords}

Metrology; Time Series; Wind Energy; Exponential Smoothing. 


\section{Sumário}

1 Introdução 13

1.1. Escopo da pesquisa e formulação da situação problema 13

1.2. Objetivo geral 13

$\begin{array}{ll}\text { 1.3. Objetivos específicos } & 13\end{array}$

1.4. Importância da pesquisa 14

1.5. Organização do trabalho 14

2 Séries temporais e amortecimento exponencial 16

2.1. Conceitos básicos de séries temporais 16

2.2. Modelos de Amortecimento Exponencial 18

2.2.1. O desenvolvimento do amortecimento exponencial 18

2.2.2. Classificação e formulação dos modelos de amortecimento $\begin{array}{lr}\text { exponencial } & 19\end{array}$

2.2.3. O modelo de amortecimento exponencial de múltiplos ciclos 26

2.3. A decomposição de séries temporais pelo método TBATS 28

3 Energia Eólica 31

3.1. Histórico da Energia Eólica 31

3.2. A Energia Eólica no Mundo e no Brasil 33

3.3. O Panorama do Setor Elétrico Nacional e a Energia Eólica 37

3.4. Fundamentos de Energia Eólica 40

3.5. Modelos de previsão aplicados a energia eólica 42

4 Análise Exploratória dos Dados 44

4.1. Dados de velocidade de vento 44

4.2. Dados de potência 48

5 Aplicação do Método de Previsão 56

6 Conclusão $\quad 68$ 
6.1. Principais resultados

6.2. Trabalhos futuros

68

Referências Bibliograficas 


\section{Lista de figuras}

Figura 1 - Exemplo de série temporal $\quad 17$

Figura 2 - Decomposição da série temporal 17

Figura 3 - Exemplos dos modelos de tendência 21

Figura 4 - Exemplos dos modelos de tendência multiplicativa 21

Figura 5 - Exemplo de modelo comtendência aditiva e sazonalidade aditiva

Figura 6 - Exemplo de modelo com tendência aditiva e sazonalidade multiplicativa

Figura 7 - Exemplo de série temporal com dois ciclos 27

Figura 8 - Decomposição com TBATS 30

Figura 9 - Modelo de aerogerador 32

Figura 10 - Evolução da potência e da área dos aerogeradores

Figura 11 - Projeção da capacidade total instalada de geração de energia eólica no mundo até 2020

Figura 12 - Ranking dos países segundo a capacidade instalada de geração de energia eólica

Figura 13 - Projeção da capacidade total instalada de geração de energia eólica do Brasil até 2018

Figura 14 - Capacidade instalada de geração de energia eólica por estado no Brasil em 2014

Figura 15 - Capacidade em construção de geração de energia eólica por estado no Brasil em 2014

Figura 16 - Mapa eólico do Brasil 37

Fonte: Atlas eólico do Brasil 37

Figura 17 - Matriz elétrica do Brasil por tipo de fonte 37

Figura 18 - Projeção da matriz elétrica brasileira por fonte até $2020 \quad 38$

Figura 19 - Produção de energia eólica e energia

hidroelétrica acumulada 38

Figura 20 - Processo de decisão do despacho hidrotérmico do ONS $\quad 39$

Figura 21 - Curva de Potência 40 
Figura 22 - Histograma dos dados $\quad 44$

Figura 23 - Boxplot dos dados por hora $\quad 45$

Figura 24 - Bloxplot dos dados por mês $\quad 45$

Figura 25 - Histograma e distribuição ajustada nos meses de maio e outubro 48

Figura 26 - Curva de potência do aerogerador utilizado 50

Figura 27 - Gráfico de pareto da produção média horária - janeiro a abril

Figura 28 - Gráfico de pareto da produção média horária - maio a agosto

Figura 29 - Gráfico de pareto da produção média horária - setembro a dezembro

Figura 30 - Potência média horária percentual nos meses de maio e outubro

Figura 31 - Gráfico de radar da potência média horária percentual nos meses de maio e outubro

Figura 32 - Regressão linear entre o coeficiente de variação e a média da produção média horária

Figura 33 - Evolução da potência média mensal às $8 \mathrm{~h}$ e às $21 \mathrm{~h}$. 53

Figura 34 - Potência média de acordo com o horário e o mês 54

Figura 35 - Média horária por mês da potência 55

Figura 36 - Decomposição da série com duas componentes sazonais 55

Figura 37 - Fluxograma do modelo de previsão 57

Figura 38 - Decomposição pelo TBATS 58

Figura 39 - Resíduo da decomposição 58

Figura 40 - Teste de Ljung-Box nos resíduos $\quad 59$

Figura 41 - Histograma e função de probabilidade $\quad 59$

Figura 42 - Previsão com o modelo proposto 60

Figura 43 - Gráfico do MAPE por modelo de previsão 66

Figura 44 - Perfis de velocidade por dia 66 


\section{Lista de tabelas}

Tabela 1 - Classificação dos modelos de amortecimento exponencial 23

Tabela 2 - Horizontes de previsão por aplicações 42

Tabela 4 - Relação entre velocidade e potência 49

Tabela 5 - Valores do MAPE para previsões utilizando média

e mediana 61

Tabela 6 - Teste de hipótese para diferença de variâncias 62

Tabela 7 - Teste T para diferença de médias assumindo variâncias diferentes 62

Tabela 8 - Valores do MAPE utilizando 30 e 100 séries sintéticas $\quad 63$

Tabela 9 - Teste F para diferença de variâncias 64

Tabela 10 - Teste T para diferença de médias assumindo variâncias

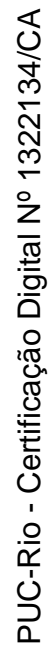
diferentes 64

Tabela 11 - MAPE dos modelos de previsão por dia 65

Tabela 12 - Alternativas para futuros desenvolvimentos 69 


\section{Introdução}

\subsection{Escopo da pesquisa e formulação da situação problema}

A energia eólica, é a fonte de energia que mais cresce na matriz elétrica brasileira, segundo dados da Empresa de Pesquisa de Energia (EPE), subindo de 25 MW instalados em 2005 para 5610 MW em outubro de 2014, com projeções para que esse crescimento se mantenha. Paralelamente a isso, existe a questão da complexidade do sistema elétrico nacional, que conta em sua grande parcela com fontes de natureza hidroelétrica e térmica, gerando um cenário complexo de tomada de decisão no que se refere ao despacho da produção de energia para atender a demanda de consumo do país, conhecido como problema do despacho hidrotérmico. Com o crescimento da produção de energia eólica, a operação do sistema elétrico se torna ainda mais complexo.

Mediante esse cenário, é de suma importância que se possa: a) conhecer as características da produção de energia eólica em uma determinada localidade, a partir de uma análise exploratória de dados profunda e consistente, e; b) elaborar e adaptar da literatura existente modelos de previsão que sejam robustos e que tenham cada vez mais precisão para as séries temporais de velocidade de vento.

Ambos os motivos levantados anteriormente procuram auxiliar e avançar na compreensão de um problema que se torna cada vez mais relevante, que é de como e quais são os impactos da inserção da crescente produção de energia eólica no problema do despacho hidrotérmico.

\subsection{Objetivos}

O objetivo principal do trabalho é adaptar e aplicar uma metodologia de previsão de séries temporais em um banco de dados formado por medições de velocidade de vento e realizar uma análise exploratória de dados de produção de energia eólica.

Para isso, é necessário alcançar os seguintes objetivos secundários, como: 
- Coleta de medições de velocidade do vento de uma estação anemométrica.

- Conversão dos dados de velocidade em potência.

- Análise exploratória dos dados.

- Elaboração de um panorama do estado da energia eólica na matriz elétrica nacional e da caracterização de fundamentos básicos de energia eólica.

- A formulação de um modelo de previsão que se adeque à complexidade dos dados.

\subsection{Importância da pesquisa}

Com isso, a principal motivação do presente trabalho é o fato de desenvolver e aplicar métodos de previsão cada vez mais precisos em variáveis determinantes na produção de energia eólica de um aerogerador, como a velocidade do vento, é de crucial importância para o planejamento da operação do sistema elétrico nacional. Além de um avanço no estado da arte dos modelos de previsão de séries temporais devido à exploração de modelos recentes de previsão, que combinam uma série de técnicas estatísticas, como a decomposição de séries temporais e simulação de Monte Carlo, com modelos de amortecimento exponencial.

\subsection{Organização do trabalho}

O trabalho está dividido na seguinte estrutura

Capítulo 1 - Introdução: Contextualiza a pesquisa, traça suas principais motivações e define seus objetivos principais e secundários

Capítulo 2 - Séries temporais e amortecimento exponencial: Propõe uma conceituação de séries temporais e uma revisão da literatura sobre os modelos de amortecimento exponencial, além dos aspectos básicos do método de decomposição TBATS

Capítulo 3 - Energia eólica: Aborda a energia eólica, em sua evolução como fonte de energia na matriz elétrica brasileira e mundial e seus fundamentos, além das principais abordagens de previsão que são adotadas referentes a ela. 
Capítulo 4 - Análise exploratória dos dados: Apresenta uma análise estatística descritiva dos dados de velocidade de vento e de potência que são utilizados no modelo de previsão do capítulo 5.

Capítulo 5 - Modelo de previsão: Detalha o modelo de previsão proposto e mostra seus resultados quando comparados com outros modelos de amortecimento exponencial.

Capítulo 6 - Conclusões: Sintetiza os resultados da pesquisa e propõe desenvolvimentos futuros.

Ainda está incluído depois das referências bibliográficas um anexo sobre o teste de aderência e o processo de simulação de Monte Carlo. 


\section{Séries temporais e amortecimento exponencial}

\subsection{Conceitos básicos de séries temporais}

Conforme observa (Hyndman et al., 2008), uma série temporal surge sempre que uma variável é observada ao longo do tempo, sendo essa variável contínua ou discreta. Delimitando o escopo da abordagem que será feita aqui, as séries temporais serão sempre discretas e com espaçamento de tempo igual entre as observações. Por exemplo, a velocidade do vento em uma determinada localidade quando observada ao longo do tempo é uma variável de natureza contínua, mas o tratamento dado aqui pode ser da observação pontual feita de 10 em 10 minutos, ou da média diária da velocidade.

Um método de previsão de séries temporais pode ser definido como algum procedimento que dado um conjunto de observações $y_{1}, y_{2}, \ldots y_{n}$, onde $y_{n}$ é o valor da série temporal no instante $n$, fornece um valor para $y_{n+h}$, onde $n$ é o tamanho da série e $h$ é a quantidade de passos à frente que se deseja prever. No entanto, para realizar a previsão de séries temporais, é útil que seja entendido o seu padrão de comportamento, para que então possa ser utilizado um método de previsão adequado. Tradicionalmente, uma série temporal pode ser decomposta em três tipos de componentes, que são:

Tendência: É o comportamento de longo prazo da série, indicando estacionariedade, crescimento ou decrescimento, podendo ser linear, parabólico, exponencial, entre outros.

Sazonalidade: A repetição de um padrão com período definido.

Irregular ou Ruído: Um comportamento de natureza aleatória, que não pode ser definido como sazonalidade ou tendência. 
A seguir é mostrado um exemplo de decomposição ${ }^{1}$ na série de consumo de energia elétrica no Brasil em $\mathrm{MWh}^{2}$, de janeiro de 2004 a dezembro de 2014 com frequência mensal.

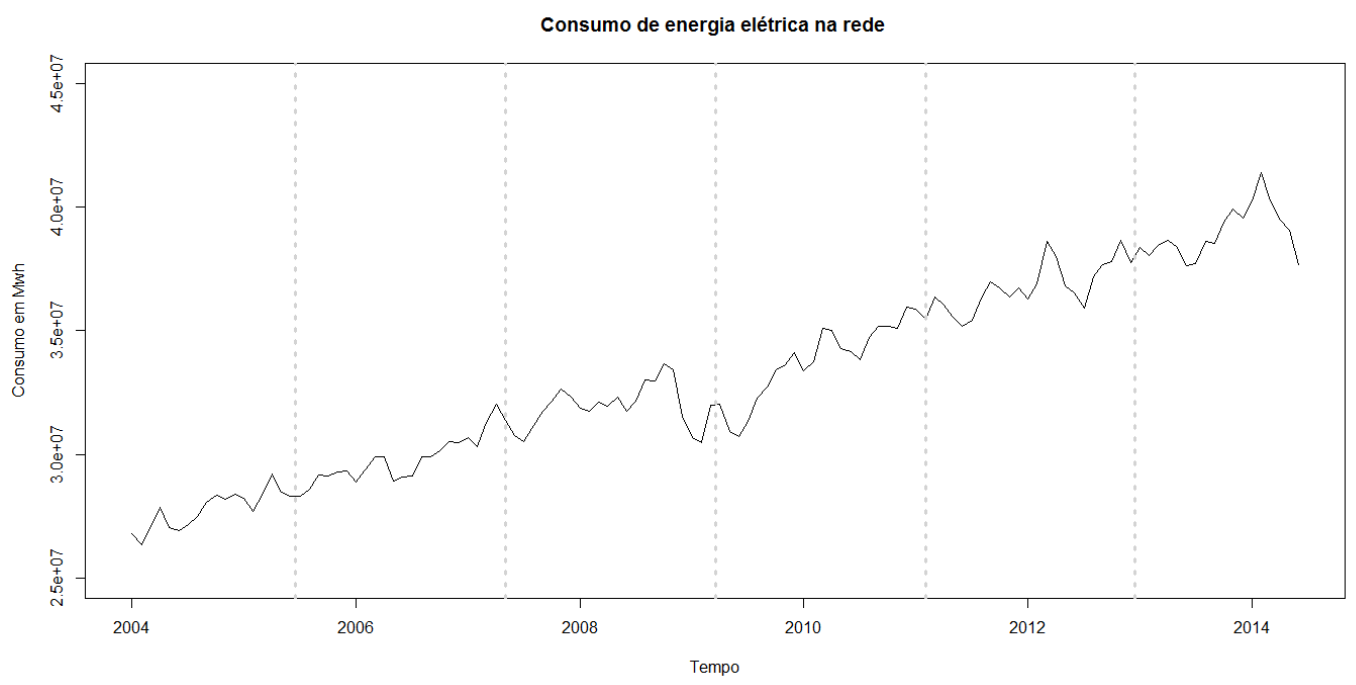

Figura 1 - Exemplo de série temporal

Pela observação gráfica da série, fica clara uma tendência linear de crescimento, além da presença de uma sazonalidade mensal dentro do período de um ano.

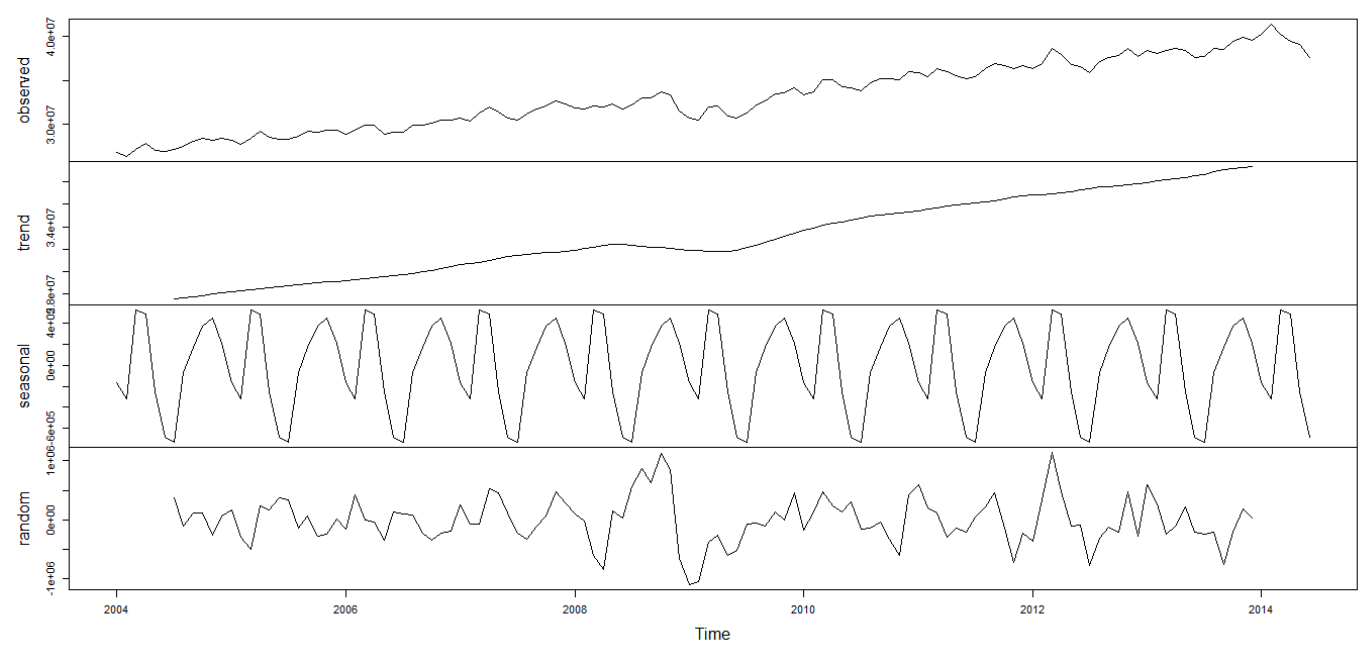

Figura 2 - Decomposição da série temporal

Pela decomposição utilizada, a série $y_{t}$ pode ser expressa como:

$$
y_{t}=\hat{T}_{t}+\hat{S}_{t}+\hat{E}_{t}
$$

${ }^{1}$ Aqui foi usada uma decomposição do tipo aditiva pelo método de decomposição clássica por médias móveis. Detalhes do método podem ser consultados em (Hyndman e Athanasopoulos, 2014)

${ }^{2}$ Dados disponíveis em www.epe.gov.br 
Onde $\widehat{T}_{t}$ é a tendência, $\hat{S}_{t}$ é a sazonalidade e $\widehat{E}_{t}$ é o ruído. Vale lembrar que a decomposição pode ser usada com uma formulação multiplicativa, que é uma alternativa quando a variância da série não é constante, com a seguinte formulação:

$$
y_{t}=\widehat{T}_{t} \times \hat{S}_{t} \times \hat{E}_{t}
$$

\subsection{Modelos de Amortecimento Exponencial}

\subsubsection{O desenvolvimento do amortecimento exponencial}

Os primeiros trabalhos que serviram de base para toda uma classe de modelos de previsão chamados de modelos de Amortecimento Exponencial conforme observa (Gardner, 1985), foram os trabalhos de (Brown, 1959), (Holt, 1957) e (Winters, 1960), que surgiram no contexto do nascimento da pesquisa operacional e de suas aplicações principalmente na otimização de recursos militares e posteriormente para o setor de vendas. A partir disso, esses modelos se difundiram muito devido a sua aplicação nos mais variados setores industriais, e sofreram diversos aprimoramentos teóricos. Dentre eles se destacam (Pegels, 1969), onde foram incorporadas alternativas para o amortecimento da tendência, (Harvey, 1986) para a generalização do amortecimento em séries multivariadas, (Ord, Koehler e Snyder, 1997) e (Hyndman et al., 2002) para a formulação dos métodos de amortecimento para o contexto de espaço de estados, (Taylor, 2003a) com o aprimoramento das tendências amortecidas, (Taylor, 2003b) com a formulação que lida com dois ou mais padrões sazonais simultaneamente e (Billah et al., 2006) para a seleção do modelo de amortecimento exponencial.

Além disso, os modelos de amortecimento exponencial continuam a ser extensivamente utilizados tanto em aplicações práticas como em desenvolvimentos teóricos de novos modelos de previsão, que combinam os modelos clássicos de amortecimento com outras técnicas estatísticas e de inteligência computacional, conforme se pode observar em (De Livera, Hyndman e Snyder, 2011), (Beaumont, 2014), (Bergmeir, Hyndman e Benitez, 2014) e (Sudheer e Suseelatha, 2015). 


\subsubsection{Classificação e formulação dos modelos de amortecimento exponencial $^{3}$}

A maneira que os modelos de Amortecimento Exponencial trabalham é basicamente alimentando uma equação de previsão que conta com alguns parâmetros que são estimados inicialmente e posteriormente atualizados quando novos dados são incorporados a série temporal em que o modelo está instalado.

Para ilustrar, consideremos o modelo de formulação teórica mais básica, chamado Amortecimento Exponencial Simples. Nele, temos duas equações, que são:

$$
\begin{gathered}
\hat{y}_{t+h \mid t}=l_{t} \\
l_{t}=\alpha y_{t}+(1-\alpha) l_{t-1}
\end{gathered}
$$

Ou seja, a primeira equação diz que a previsão da série no instante $t, h$ passos à frente vai ser somente igual a um parâmetro $l_{t}$, que é o nível da série. Este parâmetro por sua vez é igual ao último dado da série multiplicado por uma constante $^{4} \alpha$, mais $(1-\alpha)$ multiplicado pelo parâmetro de nível no instante anterior. Desenvolvendo a equação 2, temos:

$$
\begin{gathered}
l_{t}=\alpha y_{t}+(1-\alpha) l_{t-1} \\
l_{t}=\alpha y_{t}+(1-\alpha)\left(\alpha y_{t-1}+(1-\alpha) l_{t-2}\right) \\
l_{t}=\alpha y_{t}+\alpha(1-\alpha) y_{t-1}+(1-\alpha)^{2} l_{t-2} \\
l_{t}=\alpha y_{t}+\alpha(1-\alpha) y_{t-1}+(1-\alpha)^{2}\left(\alpha y_{t-2}+(1-\alpha) l_{t-3}\right) \\
l_{t}=\alpha y_{t}+\alpha(1-\alpha) y_{t-1}+\alpha(1-\alpha)^{2} y_{t-2}+(1-\alpha)^{3} l_{t-3} \\
\vdots \\
l_{t}=\alpha y_{t}+\alpha(1-\alpha) y_{t-1}+\alpha(1-\alpha)^{2} y_{t-2}+\cdots+\alpha(1-\alpha)^{T} y_{0}
\end{gathered}
$$

\footnotetext{
${ }^{3}$ Cabe ressaltar que a notação das equações aqui utilizadas se aproxima muito da utilizada por (Gardner, 2006) e (Hyndman et al., 2008), pois estes foram trabalhos que balizaram em grande parte a revisão bibliográfica feita sobre o estado da arte dos modelos de amortecimento exponencial.

4 Essas constantes que são introduzidas na formulação dos modelos de Amortecimento Exponencial com letra grega minúscula $\alpha, \beta, \gamma, \varphi$, são valores fixados entre 0 e 1 denominados geralmente como hiperparâmetros ou constantes de amortecimento. Tem a função de estabelecer o quão sensível será o modelo aos dados mais recentes, pois quando mais próximo de 1, mais peso os últimos dados terão na previsão. O modo como esses valores são calculados geralmente é formulado como um problema de otimização onde se escolhe o conjunto de valores que minimizam o erro médio das previsões 1 passo à frente.
} 
Logo, a previsão do próximo valor da série será uma combinação dos valores passados, com pesos que decaem exponencialmente ${ }^{5}$ com o tempo, pois por definição $\alpha$ e $1-\alpha$ estão sempre entre 0 e 1 .

A partir dessa formulação, mais um parâmetro que descreve o crescimento pode ser acrescentado, dando origem ao seguinte modelo.

$$
\begin{gathered}
\hat{y}_{t+h \mid t}=l_{t}+h b_{t} \\
l_{t}=\alpha y_{t}+(1-\alpha)\left(l_{t-1}+b_{t-1}\right) \\
b_{t}=\beta\left(l_{t}-l_{t-1}\right)+(1-\beta) b_{t-1}
\end{gathered}
$$

Logo, temos a previsão como soma de um parâmetro de nível e um parâmetro de crescimento da tendência, dando origem a um modelo de tendência linear aditiva, descrito pelas equações 4 a 6 . Esse é também chamado modelo de Holt aditivo. Porém, como é descrito em (Hyndman et al., 2008), existem cinco formas de se modelar a tendência $\left(T_{h}\right), h$ passos à frente, pela combinação dos parâmetros de nível $\left(l_{t}\right)$, crescimento $\left(b_{t}\right)$ e amortecimento da tendência $(\varphi){ }^{6}$ Consideremos aqui os cinco casos sem a presença de sazonalidade.

Sem tendência

$$
T_{h}=l_{t}
$$

Tendência aditiva

$$
T_{h}=l_{t}+h b_{t}
$$

Tendência aditiva amortecida

$$
T_{h}=l_{t}+\varphi_{h} b_{t}
$$

Tendência multiplicativa

$$
T_{h}=l_{t} b_{t}^{h}
$$

Tendência multiplicativa amortecida

$$
T_{h}=l_{t}+b_{t}^{\varphi_{h}}
$$

Os modelos das equações 7 e 8 já foram apresentados anteriormente, e o modelo da equação 10 é o caso multiplicativo do modelo de Holt. Já o modelo de

\footnotetext{
${ }^{5}$ Daí a origem do nome da classe de modelos

${ }^{6}$ Para simplificar a notação nos modelos com amortecimento da tendência, consideraremos:
}

$$
\varphi+\varphi^{2}+\cdots+\varphi^{m}=\sum_{i=1}^{h} \varphi^{i}=\varphi_{h}
$$


tendência aditiva amortecida, presente na equação 9 foi desenvolvido em (Pegels, 1969), sendo desdobrado posteriormente em (Taylor, 2003a), levando ao modelo de tendência multiplicativa amortecida, que está descrito na equação 11 .

Conforme pode se observar na figura 3, o modelo sem tendência faz com que as previsões se mantenham constantes ao longo do tempo, enquanto a tendência aditiva dá origem a um comportamento linear. Uma alternativa a esses dois modelos é a tendência aditiva amortecida, que faz com que as previsões tenham um caráter assintótico ao longo do tempo.

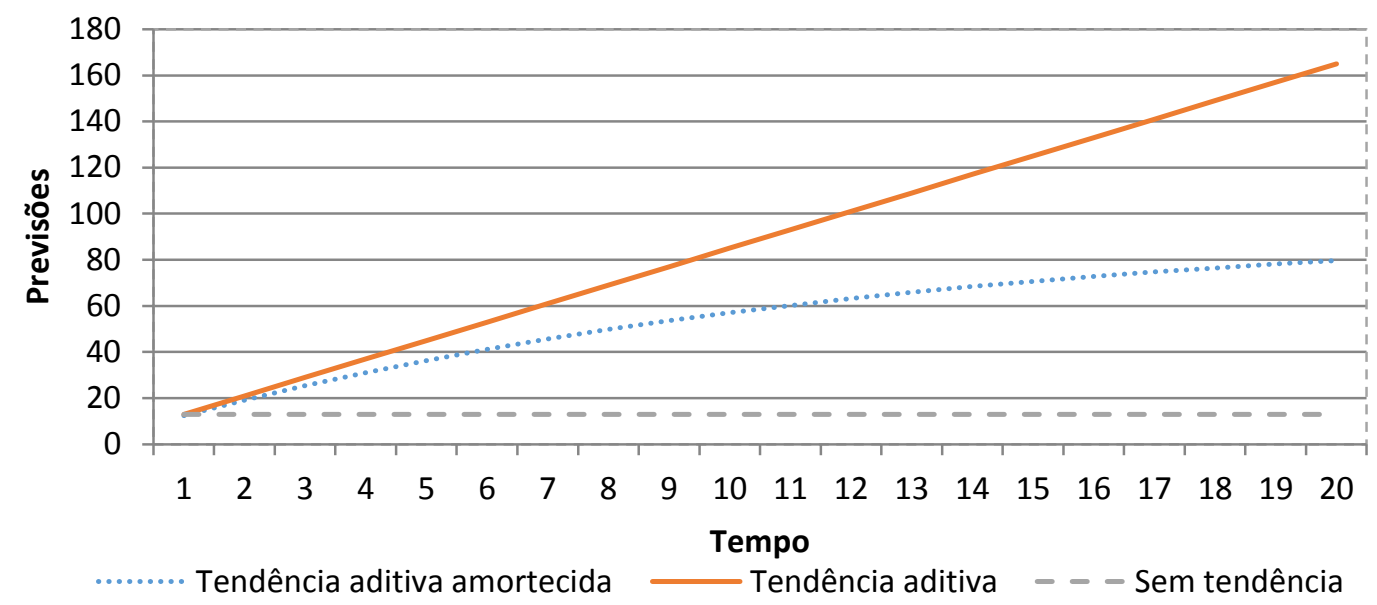

Figura 3 - Exemplos dos modelos de tendência

Já no caso da tendência multiplicativa, ilustrado na figura 4, temos um comportamento exponencial das previsões, e a alternativa de amortecimento que diminui a taxa de crescimento do modelo multiplicativo.

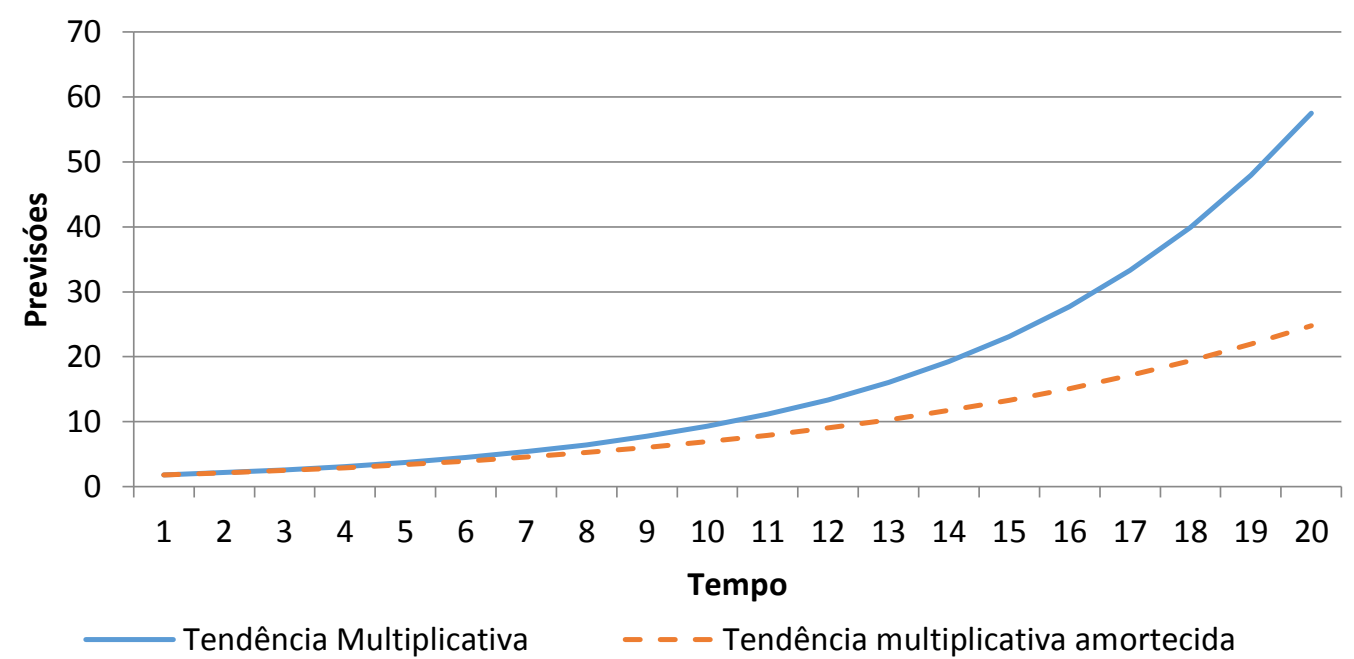

Figura 4 - Exemplos dos modelos de tendência multiplicativa 
Agora, podemos adicionar o parâmetro de sazonalidade, tendo ele a sua versão aditiva e multiplicativa, como é ilustrado nas equações 12 a 15 e 16 a 19, respectivamente, que combinam o modelo de tendência aditiva com a sazonalidade aditiva e multiplicativa.

$$
\begin{gathered}
\hat{y}_{t+h \mid t}=l_{t}+h b_{t}+s_{t-m+h_{m}^{+}} \\
l_{t}=\alpha\left(y_{t}-s_{t-m}\right)+(1-\alpha)\left(l_{t-1}+b_{t-1}\right) \\
b_{t}=\beta\left(l_{t}-l_{t-1}\right)+(1-\beta) b_{t-1} \\
s_{t}=\gamma\left(y_{t}-l_{t}\right)+(1-\gamma) s_{t-m} \\
l_{t}=\alpha\left(\frac{y_{t}}{s_{t-p}}\right)+(1-\alpha)\left(l_{t-1}+b_{t-1}\right) \\
b_{t}=\beta\left(l_{t}-l_{t-1}\right)+(1-\beta) b_{t-1} \\
s_{t}=\gamma\left(\frac{y_{t}}{l_{t}}\right)+(1-\gamma) s_{t-m}
\end{gathered}
$$

Conforme se pode observar na figura 5, o modelo de sazonalidade aditiva mantém a amplitude da variação sazonal constante ao longo do tempo, o que também é chamado de homocedasticidade .

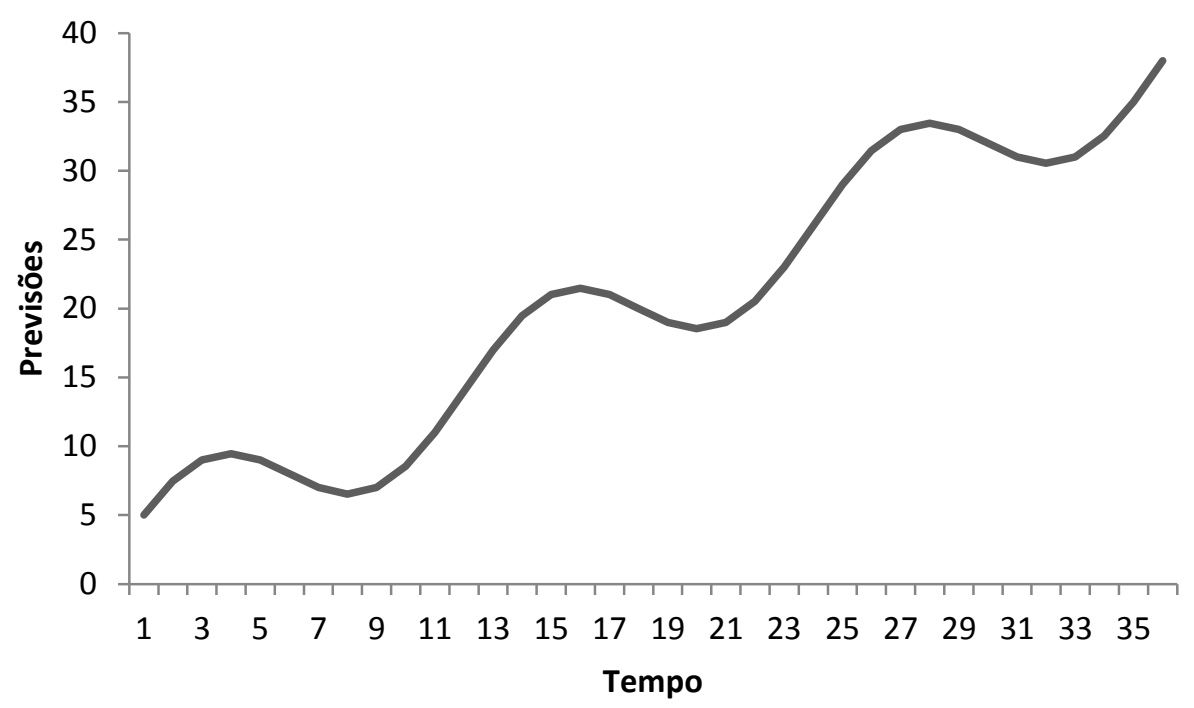

Figura 5 - Exemplo de modelo comtendência aditiva e sazonalidade aditiva

Já no modelo de sazonalidade multiplicativa presente na figura 6 , a amplitude da sazonalidade varia com o tempo, podendo crescer ou diminuir 
conforme o comportamento da série temporal em que o modelo está analisando, o que é denominado heterocedasticidade.

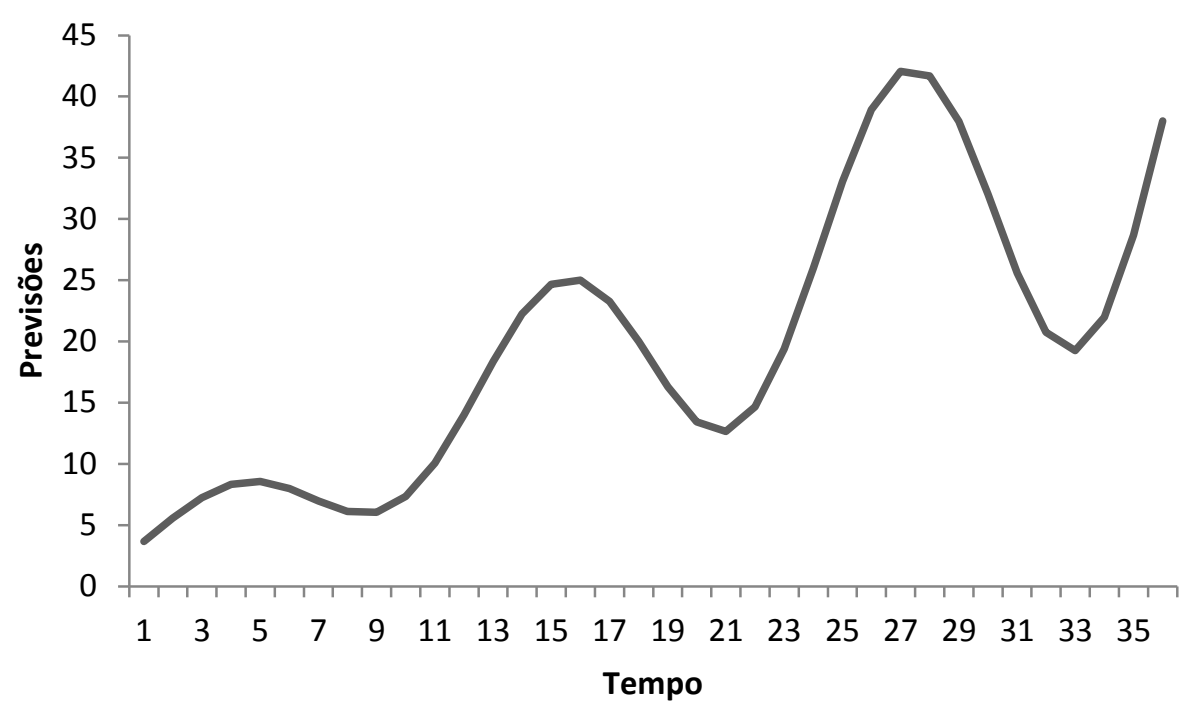

Figura 6 - Exemplo de modelo com tendência aditiva e sazonalidade multiplicativa

Logo, combinando as 5 formas da tendência e as 3 da sazonalidade, temos de acordo com (Gardner Jr, 2006) e (Hyndman et al., 2008), 15 modelos padrão de amortecimento exponencial. Abaixo, a tabela 1 apresenta todas as possibilidades de acordo com a forma da tendência e da sazonalidade.

\begin{tabular}{|c|c|c|c|}
\hline \multirow[t]{2}{*}{ Componente de tendência } & \multicolumn{3}{|c|}{ Componente sazonal } \\
\hline & $\mathrm{N}$ (Nenhum) & A (Aditivo) & M (Multiplicativo) \\
\hline $\mathrm{N}$ (Nenhum) & $\mathrm{N} \mathrm{N}$ & $\mathrm{NA}$ & $\mathrm{N} \mathrm{M}$ \\
\hline A (Aditivo) & $\mathrm{AN}$ & A A & A M \\
\hline $\mathrm{A}_{\mathrm{am}}$ (Aditivo amortecido) & $\mathrm{A}_{\mathrm{am}} \mathrm{N}$ & $\mathrm{A}_{\mathrm{am}} \mathrm{A}$ & $\mathrm{A}_{\mathrm{am}} \mathrm{M}$ \\
\hline M (Multiplicativo) & $\mathrm{M} \mathrm{N}$ & M A & M M \\
\hline $\mathrm{M}_{\mathrm{am}}$ (Multiplicativo amortecido) & $\mathrm{M}_{\mathrm{am}} \mathrm{N}$ & $\mathrm{M}_{\mathrm{am}} \mathrm{A}$ & $\mathrm{M}_{\mathrm{am}} \mathrm{M}$ \\
\hline
\end{tabular}

Tabela 1 - Classificação dos modelos de amortecimento exponencial

Com isso, é apresentado o conjunto de equações (previsão e parâmetros) que descrevem cada um dos modelos, de acordo com a classificação estabelecida, presentes nas equações 20 a 71 .

- $\quad \mathrm{NN}$ (Sem tendência e sem sazonalidade)

$$
\begin{gathered}
\hat{y}_{t+h \mid t}=l_{t} \\
l_{t}=\alpha y_{t}+(1-\alpha) l_{t-1}
\end{gathered}
$$


- $\quad$ AN (Tendência aditiva e sem sazonalidade)

$$
\begin{gathered}
\hat{y}_{t+h \mid t}=l_{t}+h b_{t} \\
l_{t}=\alpha y_{t}+(1-\alpha)\left(l_{t-1}+b_{t-1}\right) \\
b_{t}=\beta\left(l_{t}-l_{t-1}\right)+(1-\beta) b_{t-1}
\end{gathered}
$$

- $\quad \mathrm{A}_{\mathrm{am}} \mathrm{N}$ (Tendência aditiva amortecida e sem sazonalidade)

$$
\begin{gathered}
\hat{y}_{t+h \mid t}=l_{t}+\varphi_{h} b_{t} \\
l_{t}=\alpha y_{t}+(1-\alpha)\left(l_{t-1}+\varphi b_{t-1}\right) \\
b_{t}=\beta\left(l_{t}-l_{t-1}\right)+(1-\beta) \varphi b_{t-1}
\end{gathered}
$$

- $\quad$ MN (Tendência multiplicativa e sem sazonalidade)

$$
\begin{gathered}
\hat{y}_{t+h \mid t}=l_{t} b_{t}{ }^{h} \\
l_{t}=\alpha y_{t}+(1-\alpha)\left(l_{t-1} b_{t-1}\right) \\
b_{t}=\beta\left(\frac{l_{t}}{l_{t-1}}\right)+(1-\beta) b_{t-1}
\end{gathered}
$$

- $\mathrm{M}_{\mathrm{am}} \mathrm{N}$ (Tendência multiplicativa amortecida e sem sazonalidade)

$$
\begin{gathered}
\hat{y}_{t+h \mid t}=l_{t}{b_{t}}^{\varphi_{h}} \\
l_{t}=\alpha y_{t}+(1-\alpha)\left(l_{t-1} b_{t-1}{ }^{\varphi}\right) \\
b_{t}=\beta\left(\frac{l_{t}}{l_{t-1}}\right)+(1-\beta) b_{t-1}^{\varphi}
\end{gathered}
$$

- NA (Sem tendência e sazonalidade aditiva) ${ }^{7}$

$$
\begin{gathered}
\hat{y}_{t+h \mid t}=l_{t}+s_{t-m+h_{m}^{+}} \\
l_{t}=\alpha\left(y_{t}-I_{t}\right)+(1-\alpha)\left(l_{t-1}\right) \\
s_{t}=\gamma\left(y_{t}-l_{t}\right)+(1-\gamma) s_{t-m}
\end{gathered}
$$

- AA (Tendência aditiva e sazonalidade aditiva)

$$
\begin{gathered}
\hat{y}_{t+h \mid t}=l_{t}+m b_{t}+s_{t-m+h_{m}^{+}} \\
l_{t}=\alpha\left(y_{t}-s_{t-m}\right)+(1-\alpha)\left(l_{t-1}+b_{t-1}\right) \\
b_{t}=\beta\left(l_{t}-l_{t-1}\right)+(1-\beta) b_{t-1} \\
s_{t}=\gamma\left(y_{t}-l_{t-1}-b_{t-1}\right)+(1-\gamma) s_{t-m}
\end{gathered}
$$

\footnotetext{
${ }^{7}$ Para simplificar a notação nos modelos sazonalidade, consideraremos:
}

$$
h_{m}^{+}=[(h-1) \bmod m]+1
$$


- $\quad \mathrm{A}_{\mathrm{am}} \mathrm{A}$ (Tendência aditiva amortecida e sazonalidade aditiva)

$$
\begin{gathered}
\hat{y}_{t+h \mid t}=l_{t}+\varphi_{h} b_{t}+s_{t-m+h_{m}^{+}} \\
l_{t}=\alpha\left(y_{t}-s_{t-m}\right)+(1-\alpha)\left(l_{t-1}+\varphi b_{t-1}\right) \\
b_{t}=\beta\left(l_{t}-l_{t-1}\right)+(1-\beta) \varphi b_{t-1} \\
s_{t}=\gamma\left(y_{t}-l_{t}-\varphi b_{t}\right)+(1-\gamma) s_{t-m}
\end{gathered}
$$

- MA (Tendência multiplicativa e sazonalidade aditiva)

$$
\begin{gathered}
\hat{y}_{t+h \mid t}=l_{t} b_{t}{ }^{h}+s_{t-m+h_{m}^{+}} \\
l_{t}=\alpha\left(y_{t}-s_{t-m}\right)+(1-\alpha) l_{t-1} b_{t-1} \\
b_{t}=\beta\left(\frac{l_{t}}{l_{t-1}}\right)+(1-\beta) b_{t-1} \\
s_{t}=\gamma\left(y_{t}-l_{t-1} b_{t-1}\right)+(1-\gamma) s_{t-m}
\end{gathered}
$$

- $\mathrm{M}_{\mathrm{am}} \mathrm{A}$ (Tendência multiplicativa amortecida e sazonalidade aditiva)

$$
\begin{gathered}
\hat{y}_{t+h \mid t}=l_{t} b_{t}^{\varphi_{h}}+s_{t-m+h_{m}^{+}} \\
l_{t}=\alpha\left(y_{t}-s_{t-m}\right)+(1-\alpha)\left(l_{t-1} b_{t-1}{ }^{\varphi}\right) \\
b_{t}=\beta\left(\frac{l_{t}}{l_{t-1}}\right)+(1-\beta) b_{t-1}{ }^{\varphi} \\
s_{t}=\gamma\left(y_{t}-l_{t} b_{t-1}^{\varphi}\right)+(1-\gamma) s_{t-m}
\end{gathered}
$$

- $\mathrm{NM}$ (Sem tendência e sazonalidade multiplicativa)

$$
\begin{gathered}
\hat{y}_{t+h \mid t}=l_{t} s_{t-m+h_{m}^{+}} \\
l_{t}=\alpha\left(\frac{y_{t}}{s_{t-m}}\right)+(1-\alpha)\left(l_{t-1}\right) \\
s_{t}=\gamma\left(\frac{y_{t}}{l_{t-1}}\right)+(1-\gamma) s_{t-m}
\end{gathered}
$$

- AM (Tendência aditiva e sazonalidade multiplicativa)

$$
\begin{gathered}
\hat{y}_{t+h \mid t}=\left(l_{t}+h b_{t}\right) s_{t-m+h_{m}^{+}} \\
l_{t}=\alpha\left(\frac{y_{t}}{s_{t-m}}\right)+(1-\alpha)\left(l_{t-1}+b_{t-1}\right) \\
b_{t}=\beta\left(l_{t}-l_{t-1}\right)+(1-\beta) b_{t-1} \\
s_{t}=\gamma\left(\frac{y_{t}}{l_{t-1}+b_{t-1}}\right)+(1-\gamma) s_{t-m}
\end{gathered}
$$


- $\mathrm{A}_{\mathrm{am}} \mathrm{M}$ (Tendência aditiva amortecida e sazonalidade multiplicativa)

$$
\begin{gathered}
\hat{y}_{t+h \mid t}=\left(l_{t}+\varphi_{h} b_{t}\right) s_{t-m+h_{m}^{+}} \\
l_{t}=\alpha\left(\frac{y_{t}}{s_{t-m}}\right)+(1-\alpha)\left(l_{t-1}+\varphi b_{t-1}\right) \\
b_{t}=\beta\left(l_{t}-l_{t-1}\right)+(1-\beta) \varphi b_{t-1} \\
s_{t}=\gamma\left(\frac{y_{t}}{l_{t-1}+\varphi b_{t-1}}\right)+(1-\gamma) s_{t-m}
\end{gathered}
$$

- MM (Tendência multiplicativa e sazonalidade multiplicativa)

$$
\begin{gathered}
\hat{y}_{t+h \mid t}=\left(l_{t} b_{t}{ }^{h}\right) s_{t-m+h_{m}^{+}} \\
l_{t}=\alpha\left(\frac{y_{t}}{s_{t-p}}\right)+(1-\alpha) l_{t-1} b_{t-1} \\
b_{t}=\beta\left(\frac{l_{t}}{l_{t-1}}\right)+(1-\beta) b_{t-1} \\
s_{t}=\gamma\left(\frac{y_{t}}{l_{t-1} b_{t-1}}\right)+(1-\gamma) s_{t-m}
\end{gathered}
$$

- $\mathrm{M}_{\mathrm{am}} \mathrm{M}$ (Tendência multiplicativa amortecida e sazonalidade multiplicativa)

$$
\begin{gathered}
\hat{y}_{t+h \mid t}=\left(l_{t} b_{t}^{\varphi_{h}}\right) s_{t-m+h_{m}^{+}} \\
l_{t}=\alpha\left(\frac{y_{t}}{s_{t-m}}\right)+(1-\alpha)\left(l_{t-1} b_{t-1}^{\varphi}\right) \\
b_{t}=\beta\left(\frac{l_{t}}{l_{t-1}}\right)+(1-\beta) b_{t-1} \varphi \\
s_{t}=\gamma\left(\frac{y_{t}}{l_{t-1} b_{t-1}^{\varphi}}\right)+(1-\gamma) s_{t-m}
\end{gathered}
$$

Com relação aos procedimentos de estimação dos parâmetros e dos hiperparâmetros dos modelos desenvolvidos, maiores detalhes podem ser encontrados em (Montgomery, Johnson e Gardiner, 1990) e (Souza e Oliveira, 2015).

\subsubsection{O método de amortecimento exponencial de múltiplos ciclos}

Os modelos descritos acima podem ser empregados para uma ampla variedade de tipos de séries temporais, porém, eles não deixam de ter limitações que motivam novos desenvolvimentos. Uma destas limitações é a incapacidade de 
lidar com sazonalidades complexas, como séries que possuem mais de um padrão sazonal. A figura a seguir ilustra um caso desses, onde a série de dados poderia ser decomposta em dois padrões de sazonalidade com períodos diferentes.

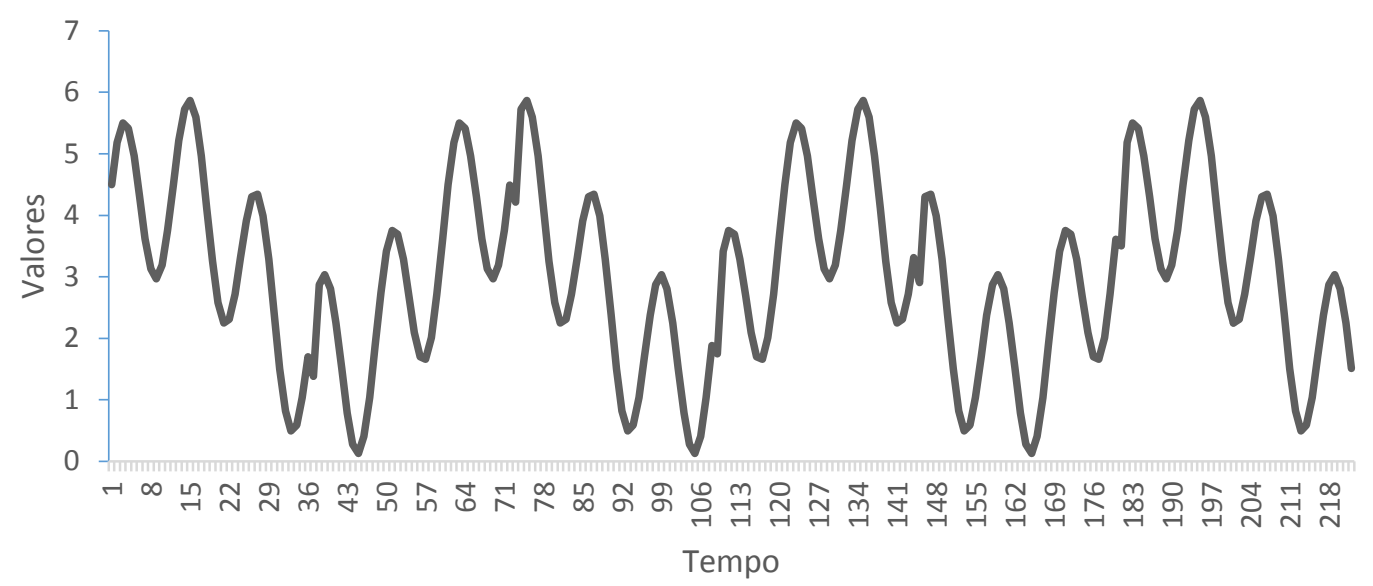

Figura 7 - Exemplo de série temporal com dois ciclos

Para dar conta desse tipo de comportamento, foi desenvolvido em (Taylor, 2003b) uma extensão do método de Holt-Winters multiplicativo ${ }^{8}$ para lidar com dois ciclos sazonais, um diário e um semanal, nos dados de demanda de energia elétrica na Inglaterra. A partir daí surgiram vários desdobramentos desse trabalho, como em (Miranda, 2007), que usou o modelo proposto por Taylor para os dados de demanda de energia elétrica no Brasil, incorporando ainda algoritmos genéticos para a otimização dos hiperparâmetros e a consideração de fatores exógenos. Posteriormente, ainda temos (Taylor, 2010a) que realiza adaptações do seu trabalho de 2003 nos método de estimação dos fatores sazonais diários e (Taylor, 2010b) na extensão de um modelo com três ciclos sazonais. Ainda em (Gould $e t$ al., 2008), é estabelecida para os modelos de amortecimento exponencial de múltiplos ciclos uma formulação via espaços de estados.

A seguir temos a formulação do modelo de dois ciclos sazonais, com tendência aditiva e sazonalidade multiplicativa, expressos nas equações 72 a 76.

\footnotetext{
${ }^{8} \mathrm{Na}$ classificação estabelecida anteriormente, esse seria equivalente a um modelo do tipo AM, contendo dois parâmetros de sazonalidade
} 


$$
\begin{gathered}
\hat{y}_{t+h \mid t}=\left(l_{t}+h b_{t}\right) s_{t-m_{1}+h_{m_{1}}^{+}}^{(1)} s_{t-m_{2}+h_{m_{2}}^{+}}^{(2)} \\
l_{t}=\alpha\left(\frac{y_{t}}{s_{t-m_{1}}^{(1)} s_{t-m_{2}}^{(2)}}\right)+(1-\alpha)\left(l_{t-1}+b_{t-1}\right) \\
b_{t}=\beta\left(l_{t}-l_{t-1}\right)+(1-\beta) b_{t-1} \\
s_{t}^{(1)}=\gamma_{1}\left(\frac{y_{t}}{\left(l_{t-1}+b_{t-1}\right) s_{t-m_{2}}^{(2)}}\right)+\left(1-\gamma_{1}\right) s_{t-m_{1}}^{(1)} \\
s_{t}^{(2)}=\gamma_{2}\left(\frac{y_{t}}{\left(l_{t-1}+b_{t-1}\right) s_{t-m_{1}}^{(1)}}\right)+\left(1-\gamma_{2}\right) s_{t-m_{2}}^{(2)}
\end{gathered}
$$

Onde $s_{t}^{(1)}$ e $s_{t}^{(2)}$ são os parâmetros do primeiro e segundo ciclo respectivamente, no instante $t, \gamma_{1}$ e $\gamma_{2}$ são os hiperparâmetros do primeiro e segundo ciclo respectivamente.

Como observa (Miranda, 2007), para o modelo desenvolvido anteriormente nas equações 72 a 76, é recomendável manter a restrição existente no método Holt-Winters multiplicativo padrão, que diz que a soma dos fatores sazonais deve ser igual ao comprimento do ciclo. Por isto, é necessário normalizar os fatores a cada atualização, de forma que as equações 77 e 78 sejam válidas.

$$
\begin{gathered}
\sum_{i=1}^{m_{1}} s_{i}^{(1)}=m_{1} \\
\sum_{i=1}^{m_{2}} s_{i}^{(1)}=m_{2}
\end{gathered}
$$

Com relação aos procedimentos de estimação dos parâmetros e dos hiperparâmetros do modelo desenvolvido na equação 72 a 76, maiores detalhes podem ser encontrados em (Souza e Oliveira, 2015) e (Taylor, 2003b).

\subsection{A decomposição de séries temporais pelo método TBATS}

O TBATS (Trigonometric, Box-Cox transformation, ARMA errors, Trend and Seasonal components) é um método de previsão e decomposição de séries temporais proposto em (De Livera, Hyndman e Snyder, 2011), para lidar com dados que apresentam padrões sazonais complexos. Ele se apresenta como uma 
extensão do modelo BATS, explorado em trabalhos como (Proietti, 2000) e (Harvey, 1990).

O método é formulado de maneira muito similar aos de amortecimento exponencial no contexto de espaço de estados em (Hyndman et al., 2008), mas incorpora uma transformação do tipo Box-Cox para lidar com não linearidades e heterocedasticidade (equação 77), um filtro do tipo ARMA para os resíduos (equação 82), além dos padrões de sazonalidade serem tratados a partir de funções trigonométricas como séries de Fourier (equações 83 a 85).

Aqui o modelo será explorado no contexto da decomposição e filtragem de séries temporais, como o método de médias móveis, a decomposição STL, o X-12 ARIMA (Hyndman e Athanasopoulos, 2014) e a análise singular espectral (Hassani, 2007). As principais vantagens do TBATS apontadas por (De Livera, Hyndman e Snyder, 2011) sobre as outras formulações são que os parâmetros podem ser calculados por método de máxima verossimilhança, além da utilização de critérios de informação para avaliação do modelo e a capacidade de lidar com padrões complexos de sazonalidade, onde existem múltiplos ciclos e o tamanho dos ciclos não é um número inteiro. A seguir é apresentada a formulação do modelo.

$$
\begin{aligned}
& y_{t}^{(\omega)}= \begin{cases}\frac{y_{t}^{(\omega)}-1}{\omega} & \omega \neq 0 \\
\log y_{t} & \omega=0\end{cases} \\
& y_{t}^{(\omega)}=l_{t-1}+\varphi b_{t-1}+\sum_{i=1}^{T} s_{t-m_{i}}^{(i)}+d_{t} \\
& l_{t}=l_{t-1}+\varphi b_{t-1}+\alpha d_{t} \\
& b_{t}=(1-\varphi) b+\varphi b_{t-1}+\beta d_{t} \\
& s_{t}^{(i)}=s_{t-m_{i}}^{(i)}+\gamma_{i} d_{t} \\
& d_{t}=\sum_{i=1}^{p} \phi_{i} d_{t-i}+\sum_{i=1}^{q} \theta_{i} \varepsilon_{t-i}+\varepsilon_{t} \\
& s_{t}^{(i)}=\sum_{j=1}^{k_{i}} s_{j, t}^{(i)} \\
& s_{j, t}^{(i)}=s_{j, t-1}^{(i)} \cos \lambda_{j}^{(i)}+s_{j, t}^{*(i)} \sin \lambda_{j}^{(i)}+\gamma_{1}^{(i)} d_{t} \\
& s_{j, t}^{*(i)}=-s_{j, t-1} \sin \lambda_{j}^{(i)}+s_{j, t}^{*(i)} \cos \lambda_{j}^{(i)}+\gamma_{2}^{(i)} d_{t}
\end{aligned}
$$


A partir da notação utilizada, $d_{t}$ é um processo $\operatorname{ARMA}(p, q), \omega$ é o parâmetro da transformação Box-Cox, $b$ é a média dos parâmetros de tendência anteriores, $\phi$ e $\theta$ são os parâmetros da parte autoregressiva e de médias móveis do modelo ARMA respectivamente, $T$ é a quantidade de padrões sazonais, $k_{i}$ é o número de harmônicas necessárias para a i-ésima componente sazonal $s_{t}^{(i)}$, $\lambda_{j}^{(i)}=2 \pi j / m_{i}, s_{j, t}^{*(i)}$ é uma variável auxiliar para o cálculo das componentes sazonais e $\varepsilon_{t}$ é um ruído branco, ou seja, um processo estocástico com distribuição normal, média zero e variância constante.

Dessa forma, a ordem do modelo pode ser representada pela notação TBATS $\left(\omega, \varphi, p, q, m_{1}, m_{2}, \ldots, m_{T}\right)$. Logo, um modelo com sazonalidade mensal pode ser descrito como TBATS $(1,1,0,0,12)$ e um modelo com dois ciclos, transformação Box-Cox e filtro autoregressivo de ordem 1 para os resíduos pode ser descrito como TBATS $\left(\omega, 1,1,0, m_{1}, m_{2}\right)$. O modelo pode ser desenvolvido em uma linguagem computacional como o $R^{9}$ e os detalhes do procedimento de estimação dos parâmetros podem ser encontrados em (De Livera, Hyndman e Snyder, 2011). Segue abaixo um exemplo de decomposição de uma série temporal de ligações em um call center com frequência de aquisição de 5 minutos, onde existe um ciclo diário e um ciclo semanal.

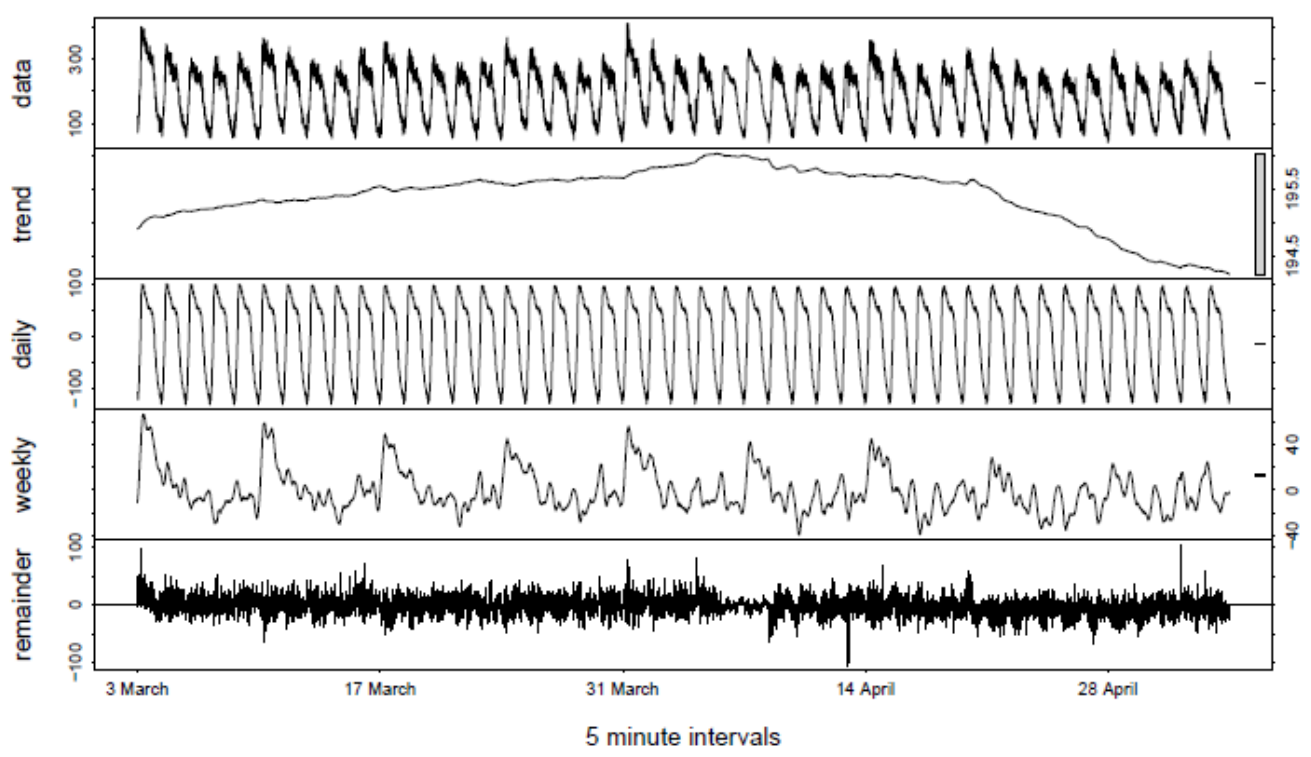

Figura 8 - Decomposição com TBATS

Fonte: (De Livera, Hyndman e Snyder, 2011)

\footnotetext{
${ }^{9}$ O modelo TBATS se encontra detalhado e desenvolvido no pacote forecast.
} 


\section{Energia Eólica}

\subsection{Histórico da Energia Eólica}

Retirar energia do vento não é uma idéia contemporânea, mas já existe a séculos na história da humanidade. Existem relatos que na Pérsia do século I d.C. mecanismos para a moagem de cereais utilizavam o vento como fonte de energia, através de um sistema de pás que giram um eixo vertical. Na Europa na época da idade média esta forma de energia também já era conhecida, com os moinhos de vento com pás girando através de um eixo vertical, com engrenagens para a rotação no eixo horizontal, que servia para a moagem de grãos e bombeamento de água, cuja imagem é amplamente difundida no imaginário popular.

Para a geração de eletricidade, o primeiro modelo surgiu nos Estados Unidos em 1888, quando o engenheiro Charles Brush construiu a primeira turbina para geração eletricidade em larga escala, com um sistema de pás de 17 metros de diâmetro tendo potência de $12 \mathrm{~kW}$. Após isso, o sistema começou a se difundir no interior dos Estados Unidos, principalmente para a geração de eletricidade em lugares isolados. Estes modelos se assemelham bastante com os utilizados hoje em dia, possuindo uma torre de sustentação e pás que giram em um eixo vertical que transmite a rotação para um gerador elétrico, conforme é mostrado abaixo na figura 9. 


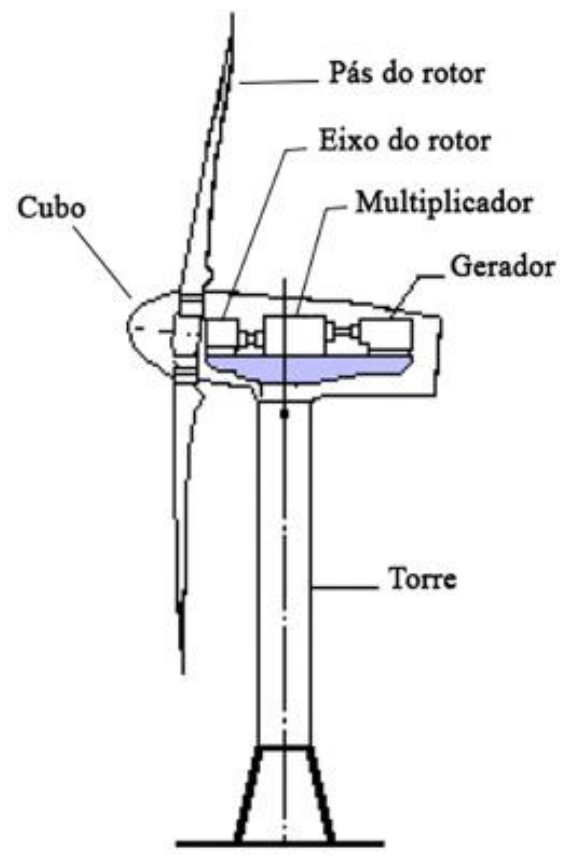

Figura 9 - Modelo de aerogerador

Fonte: (Picolo, Rühler e Rampinelli, 2014)

Mas devido ao avanço da indústria do petróleo e a competitividade dos preços de outras formas de energia, durante boa parte do século XX a energia eólica não avançou em larga escala. Porém, em 1973, com a crise do petróleo levando ao aumento brusco do preço dos combustíveis fósseis no mercado internacional, os países desenvolvidos começaram a adotar estratégias de diversificação de suas matrizes energéticas (e elétricas consequentemente), o que levou a um renascimento dos investimentos em pesquisa e desenvolvimento no setor de energia eólica, sendo liderados pelos Estados Unidos.

Abaixo é possível visualizar a evolução dos aerogeradores após 1973, onde o crescimento do raio das pás provoca um aumento da potência, (fato que é descrito no item 3.4) 


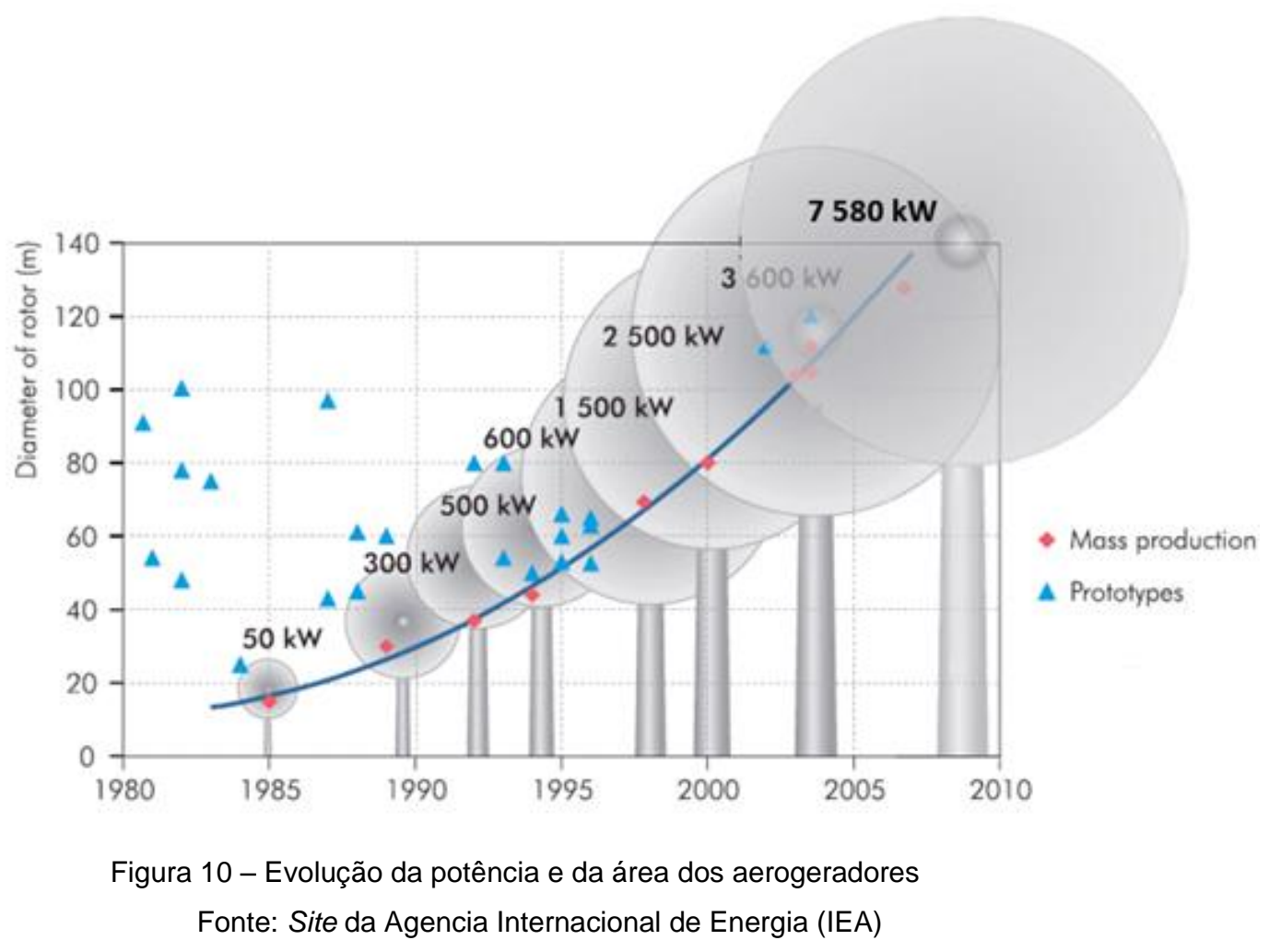

\subsection{A Energia Eólica no Mundo e no Brasil}

A energia eólica é uma fonte de energia que têm como principais atrativos as características de ser renovável e de baixo impacto ambiental, em um cenário onde a matriz elétrica mundial é extremamente dependente de fontes não renováveis e de alto impacto ambiental, como os combustíveis fosseis. Tais atrativos fizeram que nos últimos anos a capacidade instalada mundial de geração de energia eólica sofresse um grande aumento, e que levam as projeções a continuarem com essa perspectiva de crescimento, conforme aponta a figura 11. 
Capacidade Total Instalada 1997 - 2020 (MW)

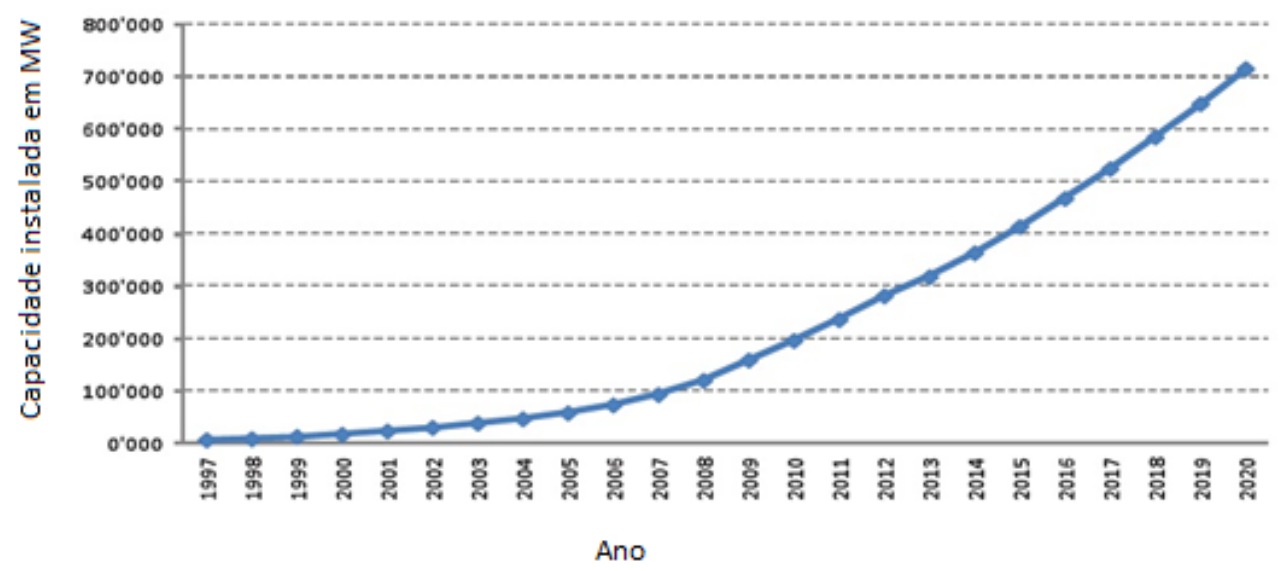

Figura 11 - Projeção da capacidade total instalada de geração de energia eólica no mundo até 2020

Fonte: Global Wind Energy Council (GWEC)

Esse crescimento é impulsionado principalmente pela China e pelos

Estados Unidos, como mostra a figura 12.

\begin{tabular}{|c|c|c|c|c|c|c|c|c|}
\hline Position & Country & $\begin{array}{c}\text { Total Capacity } \\
\text { by June } 2014 \\
{[\mathrm{MW}]}\end{array}$ & $\begin{array}{c}\text { Added } \\
\text { Capacity H1 } \\
2014 \\
{[\mathrm{MW}]}\end{array}$ & $\begin{array}{l}\text { Total Capacity } \\
\text { end } 2013 \\
{[\mathrm{MW}]}\end{array}$ & $\begin{array}{c}\text { Added } \\
\text { Capacity } \\
\text { H1 } 2013 \\
{[\mathrm{MW}]}\end{array}$ & $\begin{array}{l}\text { Total Capacity } \\
\text { end } 2012 \\
\text { [MW] }\end{array}$ & $\begin{array}{c}\text { Added } \\
\text { Capacity } \\
\text { H1 } 2012 \\
{[\mathrm{MW}]}\end{array}$ & $\begin{array}{c}\text { Total Capacity } \\
\text { end } 2011 \\
\text { [MW] }\end{array}$ \\
\hline 1 & China & $98^{\prime} 588$ & 7'175 & $91^{\prime} 413$ & 5'503 & 75'324 & $5^{\prime} 410$ & 62'364 \\
\hline 2 & USA & $61^{\prime} 946$ & 835 & $61^{\prime} 108$ & 1,6 & $59 ' 882$ & $2^{\prime} 883$ & 46'919 \\
\hline 3 & Germany & $36^{\prime} 488$ & $1^{\prime} 830$ & $34^{\prime} 658$ & $1^{\prime} 143$ & 31'315 & 941 & $29^{\prime} 075$ \\
\hline 4 & Spain & $22^{\prime} 970$ & 0,1 & $22^{\prime} 959$ & 122 & $22 ' 796$ & 414 & $21^{\prime} 673$ \\
\hline 5 & India* & $21^{\prime} 262$ & $1^{\prime} 112$ & $20^{\prime} 150$ & $1^{\prime} 243$ & $18^{\prime} 321$ & $1^{\prime} 471$ & $15^{\prime} 880$ \\
\hline 6 & United Kingdom & $11^{\prime} 180$ & 649 & $10^{\prime} 531$ & 1'331 & $8^{\prime} 445$ & 822 & $6^{\prime} 018$ \\
\hline 7 & France & $8^{\prime} 592$ & 338 & $8 ' 254$ & 198 & 7'499 & 320 & 6'877 \\
\hline 8 & Italy & 8'586 & 30 & 8'551 & 273 & $8^{\prime} 144$ & 650 & $6^{\prime} 640$ \\
\hline 9 & Canada & $8^{\prime} 526$ & 723 & $7^{\prime} 698$ & 377 & 6'201 & 246 & $5^{\prime} 265$ \\
\hline 10 & Denmark & 4'855 & 83 & 4'772 & 416 & 4'162 & 56 & $3^{\prime} 927$ \\
\hline 11 & Portugal & $4^{\prime} 829$ & 105 & $4^{\prime} 724$ & 22 & $4^{\prime} 525$ & 19 & $4^{\prime} 379$ \\
\hline 12 & Sweden & $4^{\prime} 824$ & 354 & $4^{\prime} 470$ & 526 & $3^{\prime} 745$ & - & 2'798 \\
\hline 13 & Brazil & $4^{\prime} 700$ & $1^{\prime} 301$ & 3'399 & 281 & $2^{\prime} 507$ & 118 & $1^{\prime} 429$ \\
\hline 14 & Australia & $3^{\prime} 748$ & 699 & $3^{\prime} 049$ & 475 & $2^{\prime} 584$ & - & $2^{\prime} 226$ \\
\hline \multirow[t]{3}{*}{15} & Poland & $3^{\prime} 727$ & 337 & 3'390 & 310 & $2^{\prime} 497$ & - & $1^{\prime} 616$ \\
\hline & Rest of the World & $31^{\prime} 506$ & $2^{\prime} 042$ & $29^{\prime} 451$ & $1^{\prime} 761$ & $24^{\prime} 660$ & $3^{\prime} 026$ & $16^{\prime} 493$ \\
\hline & Total & $336^{\prime} 327$ & $17^{\prime} 613$ & $318^{\prime} 488$ & $13^{\prime} 978$ & $282 ' 607$ & $16^{\prime} 376$ & 233 '579 \\
\hline
\end{tabular}

Figura 12 - Ranking dos países segundo a capacidade instalada de geração de energia eólica Fonte: GWEC

Se concentrando no caso brasileiro, segundo dados da Empresa de Pesquisa Energética (EPE), a fonte de energia que mais cresce no país é a eólica, subindo de 25 MW instalados em 2005 para 5610 MW em outubro de 2014. Esse aumento se deu principalmente pelo interesse do governo federal na diversificação da Matriz Elétrica Nacional, depois da crise energética de 2001, culminando no Programa de Incentivo as Fontes Alternativas de Energia (PROINFA), que 
aumentou a atratividade econômica do setor. Com esse aumento, a previsão é de que em 2016, a energia eólica seja responsável por 5,5\% da matriz elétrica do país.

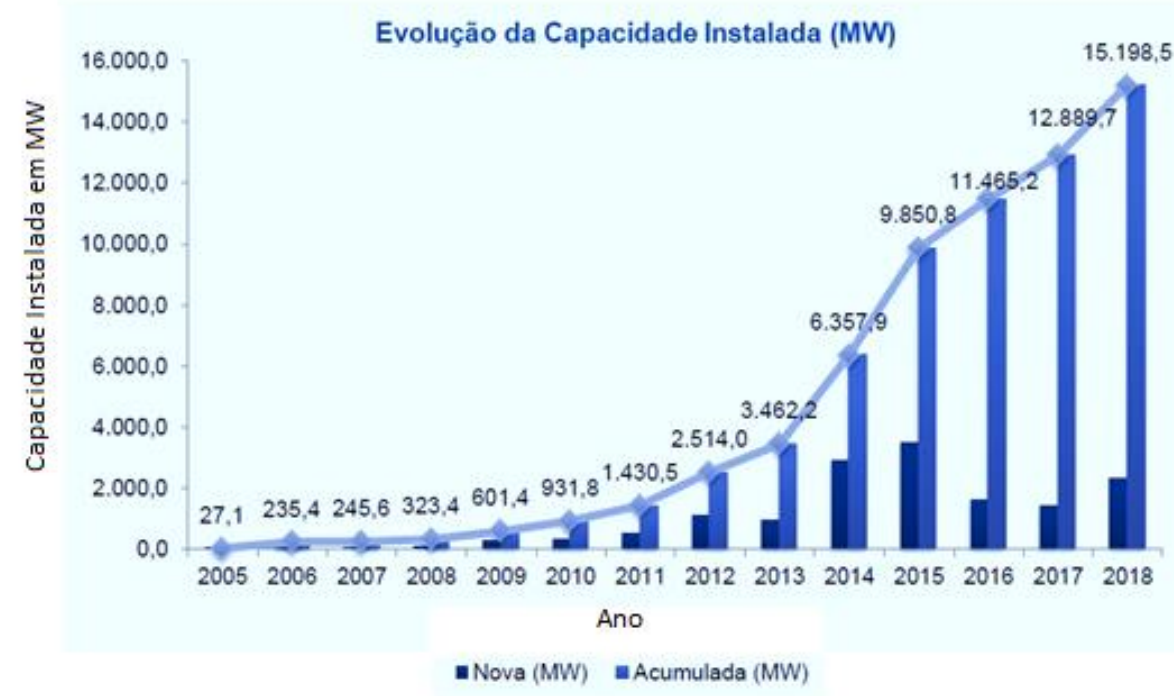

Figura 13 - Projeção da capacidade total instalada de geração de energia eólica do Brasil até 2018 Fonte: ABEEÓLICA

Se pode observar na figura acima a projeção da capacidade instalada de energia eólica na matriz elétrica nacional, que deve alcançar 9850,8 MW no final de 2015 , chegando possivelmente a $7^{\mathrm{a}}$ posição do ranking mundial de produção de energia eólica.

Contextualizando geograficamente a produção nacional de energia eólica, o gráfico abaixo mostra a distribuição da potencia instalada pelos estados no país. Desta forma, fica evidenciada a relação da figura 16 que contém a distribuição das velocidades de vento médias em território nacional com as regiões que são responsáveis pela maior produção de energia eólica, (sul e nordeste). 


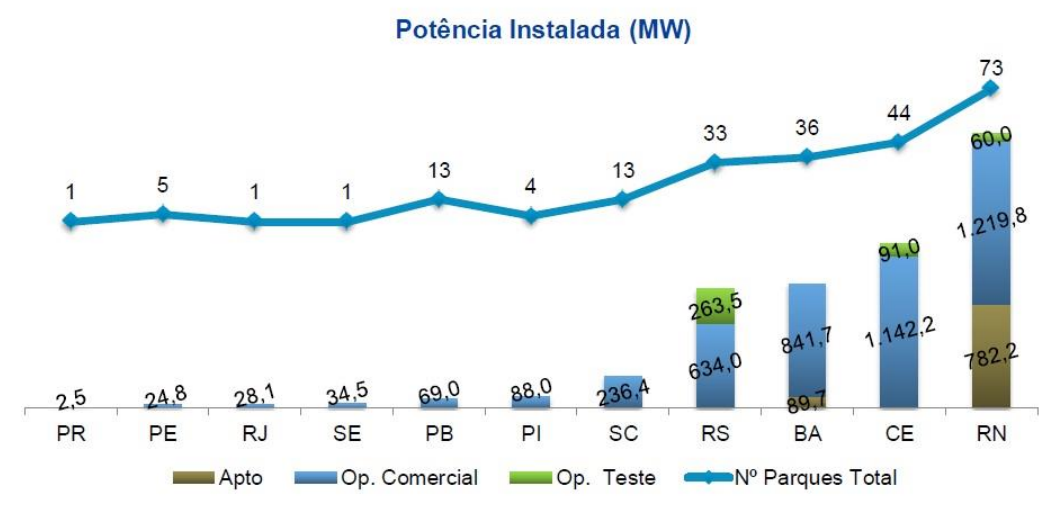

Figura 14 - Capacidade instalada de geração de energia eólica por estado no Brasil em 2014 Fonte: ABEEÓLICA

Ainda analisando a distribuição da produção de energia eólica pelo país, os parques que estão sendo construídos continuam se alocando nas regiões nordeste e sul, deixando claro que estas regiões continuarão sendo as grandes produtoras de energia eólica nos próximos anos, como mostra o gráfico abaixo.

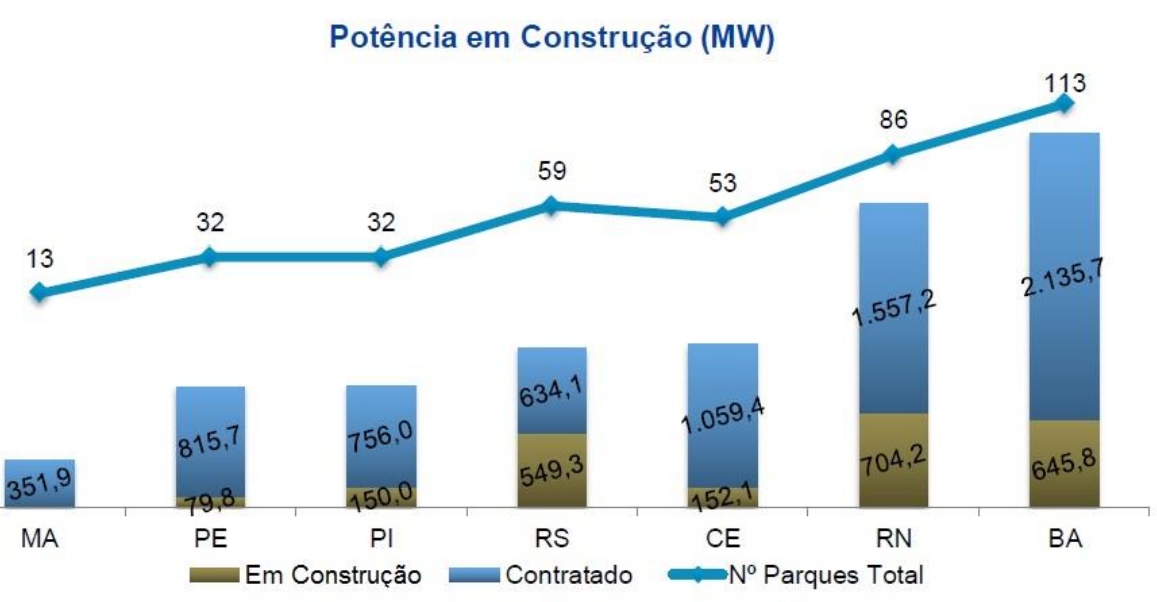

Figura 15 - Capacidade em construção de geração de energia eólica por estado no Brasil em 2014

Fonte: ABEEÓLICA

Esse fato pode ser melhor compreendido quando observamos a figura 16, que contém a distribuição da velocidade média anual do vento ao longo do território nacional, onde é possível identificar os maiores potencias eólicos do país, dando destaque ao estado da Bahia, do Rio Grande do Norte e do Rio Grande do Sul. 


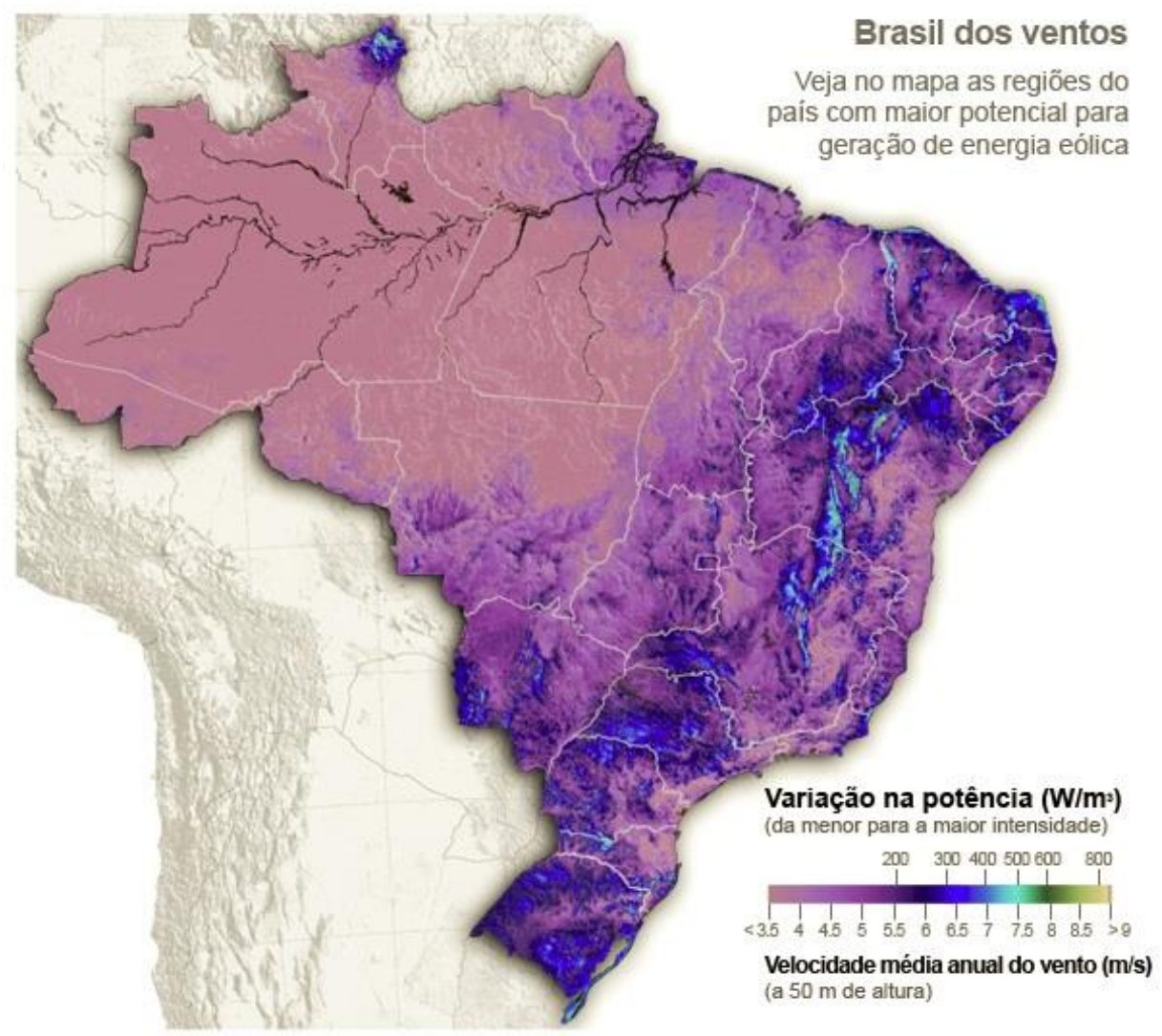

Figura 16 - Mapa eólico do Brasil

Fonte: Atlas eólico do Brasil

\subsubsection{Panorama do Setor Elétrico Nacional e a Energia Eólica}

Observando a distribuição da matriz elétrica brasileira, fica evidente a forte predominância da energia hidráulica, seguido das fontes termoelétricas. Com isso, fica claro uma das mais marcantes características da Matriz Elétrica Nacional: a forte dependência dos regimes hidrológicos.

\section{Matriz Elétrica Brasileira}

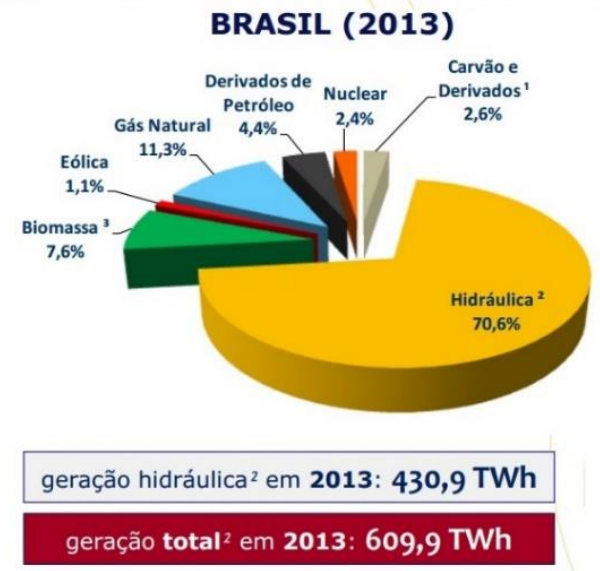

Figura 17 - Matriz elétrica do Brasil por tipo de fonte Fonte: EPE 
Combinando as informações da matriz elétrica nacional no atual momento e das projeções feitas para o crescimento da energia eólica no país, é obtida a expectativa de participação percentual da energia eólica na matriz elétrica nos próximos anos, mostrando um aumento de 1,5\% em 2012 para 9,5\% em 2022.
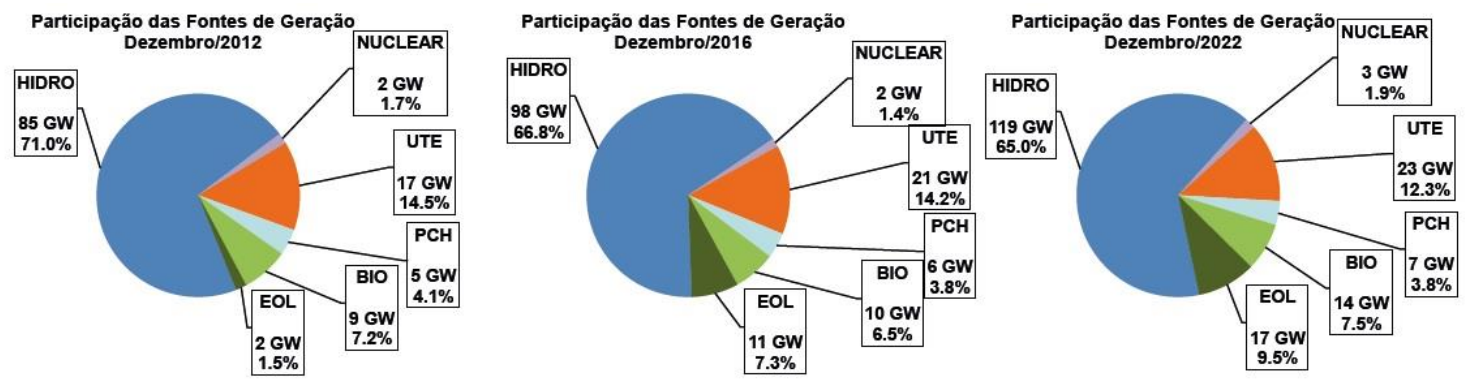

Figura 18 - Projeção da matriz elétrica brasileira por fonte até 2020

Fonte: EPE

O gráfico abaixo representa durante o período de janeiro de 2000 a outubro de 2008 o percentual da produção física eólica quando comparada com a capacidade máxima de produção, e o percentual de energia armazenada nas hidroelétricas quando comparada com a capacidade máxima de armazenamento. Como a produção de energia eólica depende do regime de ventos, e o armazenamento de água para produção de hidroeletricidade depende do regime hidrológico, ambas as produções apresentam caráter sazonal com período de 1 ano.

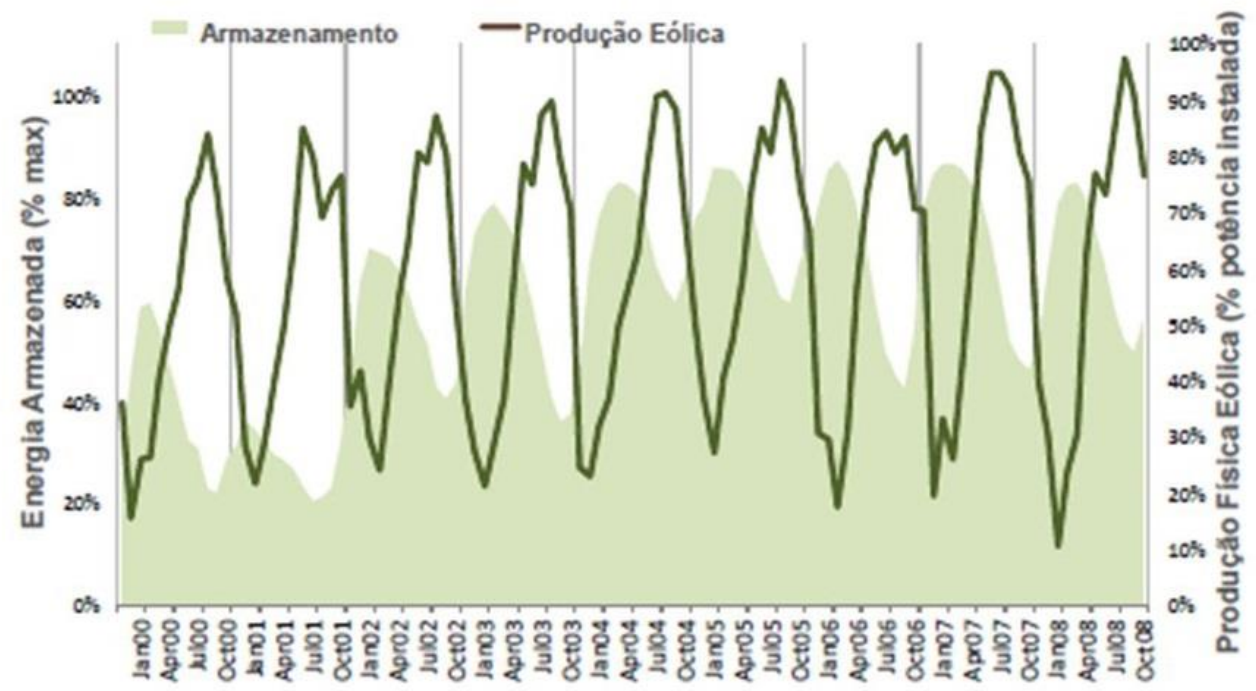

Figura 19 - Produção de energia eólica e energia hidroelétrica acumulada Fonte: BNDES

Mas é interessante observar que as produções são complementares, pois quando temos o mínimo de chuva, a velocidade de vento média é máxima (meses 
secos, de abril a setembro) e quando temos o máximo de chuvas, há o mínimo de velocidade de vento média (meses úmidos, de outubro a março). Por esse motivo, o aumento de produção de energia eólica se torna estratégico a médio e longo prazo para a diversificação da matriz elétrica nacional, e tem impacto direto no planejamento do sistema integrado nacional, e como a demanda de energia será suprida.

Para atender a demanda de energia elétrica, o Operador Nacional do Sistema (ONS) se depara com um processo de tomada de decisão onde deve escolher quais estações (hidroelétricas e térmicas) serão acionadas para que se gere a energia requerida ao longo do tempo, com o mínimo de custo possível.

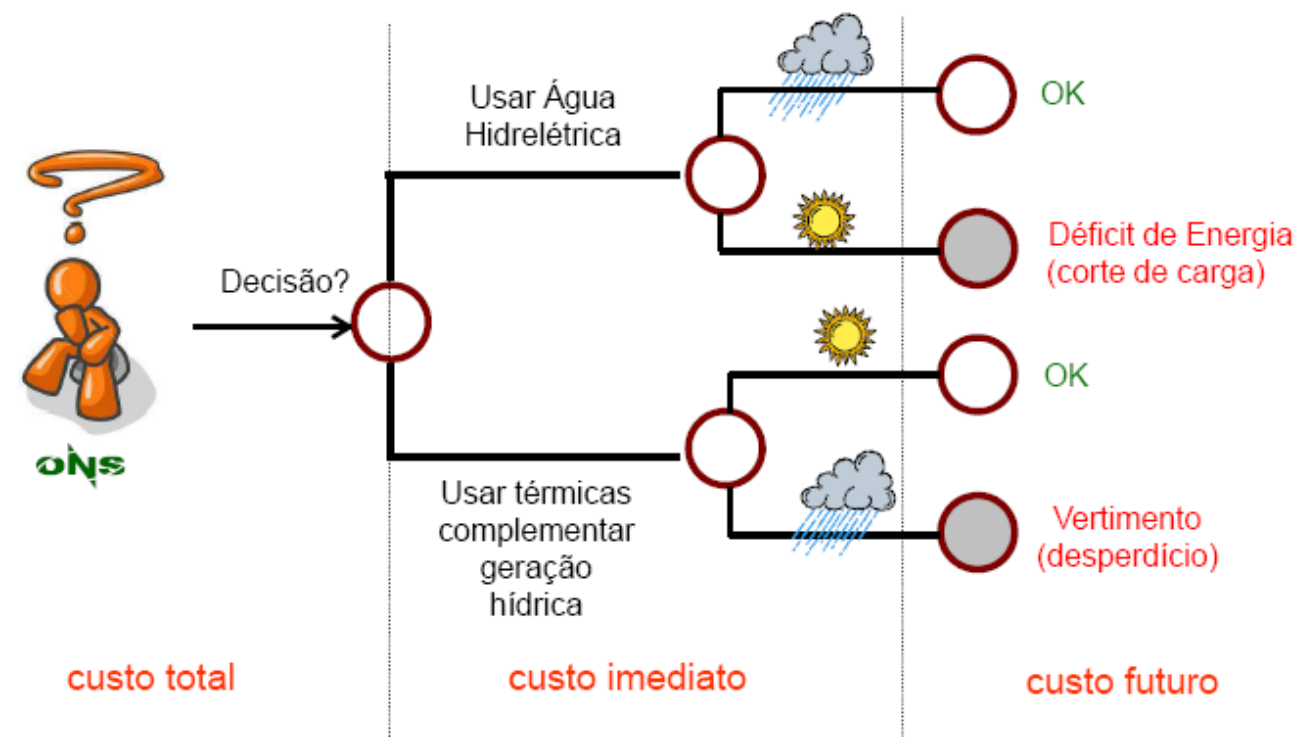

Figura 20 - Processo de decisão do despacho hidrotérmico do ONS

Fonte: Projeto MDDH PUC-Rio

Inicialmente, as alternativas possíveis são utilizar a energia armazenada ou na forma de água nas hidroelétricas, ou na forma de combustíveis fósseis e biomassa nas termoelétricas. Supondo hipoteticamente que foi utilizado água nos reservatórios, mas futuramente ocorre um período de seca, o preço da energia sofrerá um aumento, podendo até a chegar a ocorrer cortes de energia (como na crise energética sofrida em 2001 pelo país) devido a não otimalidade da decisão. Porém se o período subsequente tiver bastante chuva, os reservatórios futuramente seguirão a um nível aceitável, sendo assim uma decisão ótima. Por outro lado, quando as termoelétricas são acionadas, mas futuramente ocorre um período chuvoso, o nível dos reservatórios pode subir muito, levando a necessidade de se verter água e a um consequente desperdício de energia. Porém se ocorre 
posteriormente um período seco, os reservatórios se mantém em níveis aceitáveis e a decisão foi ótima. Esse problema é conhecido como a otimização do despacho hidrotérmico, e envolve uma modelagem matemática computacional complexa, que é operacionalizada pelo ONS. Mais detalhes sobre o planejamento dos sistemas hidrotérmicos no Brasil podem ser encontrados em (Souza et al., 2014).

Nesse contexto, a previsão da produção de energia eólica se torna fundamental, pois como ela é produzida continuamente, o conhecimento de seu comportamento a curto, médio e longo prazo é fundamental para o planejamento do sistema elétrico nacional.

\subsection{Fundamentos de Energia Eólica}

A geração de energia eólica pode ser caracterizada como o processo de transformação de energia cinética contida no deslocamento de massas de ar em energia elétrica ou mecânica através de um aerogerador (Burton et al., 2001).

Com isso, é importante determinar a relação entre a potência elétrica gerada e as variáveis que a determinam, tendo como variável principal a velocidade do vento. Segundo (Custódio, 2009), a equação 79 expressa essa relação, e descreve a curva de potência de um aerogerador, também representada abaixo na figura 20 .

$$
P(v)=\left\{\begin{array}{cc}
0 & v<v_{p} \\
0,5 C_{p} \eta_{m} \eta_{g} \rho A v^{3} & v_{p} \leq v<v_{n} \\
0,5 C_{p} \eta_{m} \eta_{g} \rho A v_{n}^{3} & v_{n} \leq v<v_{c} \\
0 & v>v_{c}
\end{array}\right.
$$

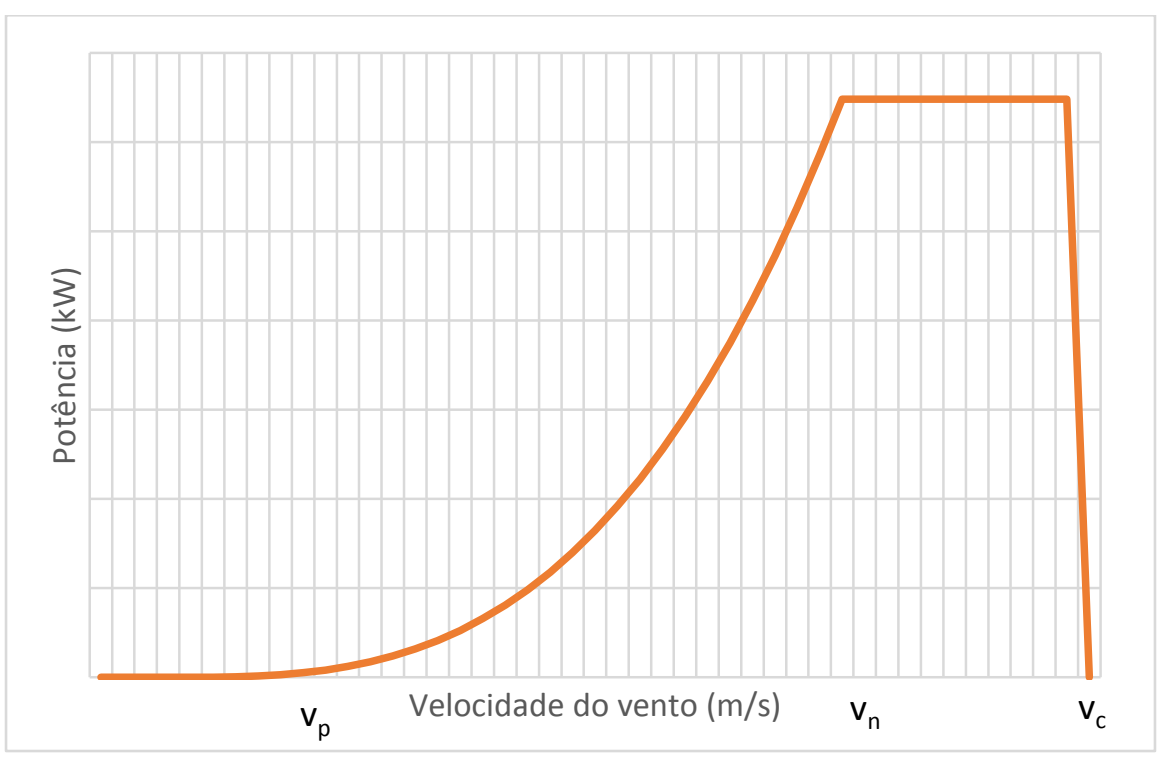

Figura 21 - Curva de Potência 
Onde $v_{p}$ é denominada velocidade de partida, pois abaixo dela a intensidade do vento não é suficiente para a geração de energia, e com valores de velocidade entre $v_{p}$ e $v_{n}$ a potência é obtida pela segunda linha da equação 79 . A partir de $v_{n}$ a potência atinge o seu valor máximo, que só é interrompido quando a velocidade ultrapassa $v_{c}$, que é a velocidade de corte, onde através de um mecanismo de segurança do aerogerador a turbina é desligada para segurança do equipamento. Os outros parâmetros que determinam a potência gerada são o rendimento do aerogerador $\eta_{g}$, o rendimento mecânico da caixa de transmissão $\eta_{m}$, o coeficiente de potência $C_{p}$ e a densidade do ar $\rho$ (Pessanha, De Santana e Siller, 2014). O conjunto de parâmetros de velocidade $v_{p}, v_{n}$ e $v_{c}$, os coeficientes $\eta_{g}$ e $\eta_{m}$ e a área das pás $A$ são determinados devido a características técnicas do modelo do aerogerador em questão. O coeficiente de potência varia de acordo com a velocidade do vento, fazendo a curva de potência se estabilizar entre $v_{n} \mathrm{e}$ $v_{c}$ e também é um parâmero técnico como os anteriores. A densidade do ar $\rho$ é geralmente assumida como $1,225 \mathrm{~kg} / \mathrm{m}^{3}$.

Com isso, para se determinar a potência de saída, a velocidade do vento é a variável mais crítica, pois depende de condições anemométricas externas, e tem a necessidade de ser modelada estatisticamente para se entender o seu padrão de variação. De acordo com (Harris e Cook, 2014) e (Seguro e Lambert, 2000), uma alternativa para se modelar a frequência da velocidade de vento é a distribuição de Weibull, que pode ser descrita como:

$$
P\left(v<v_{i}<v+d v\right)=P(v>0)\left(\frac{k}{c}\right)\left(\frac{v_{i}}{c}\right)^{k-1} \exp \left[-\left(\frac{v_{i}}{c}\right)^{k}\right] d v
$$

Onde $c$ é o parâmetro de escala da distribuição de Weibull, dado em unidades de velocidade de vento $(\mathrm{m} / \mathrm{s}), k$ é o parâmetro adimensional de forma da distribuição, $v$ é a variavel aleatória de velocidade de vento e $v_{i}$ é um valor específico de $v$.

A partir da distribuição acima, se pode obter a função de distribuição acumulada:

$$
P\left(v<v_{i}\right)=P(v \geq 0)\left\{1-\exp \left[-\left(\frac{v_{i}}{c}\right)^{k}\right]\right\}
$$


Também se pode chegar à relação da média de $v$ com os dois parâmetros $C$ e $k$ através da expressão seguinte:

$$
\bar{v}=c \Gamma\left(1+\frac{1}{k}\right)
$$

\subsection{Modelos de previsão aplicados a energia eólica}

Devido à importância da integração da energia eólica para o setor elétrico, e o desafio teórico que se constitui, realizar previsões com o maior grau de precisão das séries temporais de velocidade de vento e de energia se torna um tema amplamente estudado na literatura.

No entanto, os modelos de previsão para o problema em questão surgem de várias abordagens possíveis. Seguindo a classificação proposta por (Lei et al., 2009), podemos dividir os modelos de previsão de acordo com duas características: horizonte de previsão e natureza do modelo.

De acordo com (Wang, Guo e Huang, 2011), o horizonte de previsão pode ser classificado em três tipos, sendo eles curto, médio e longo prazo, e está diretamente relacionado com o objetivo que se tem com a previsão, conforme pode ser visto na tabela 2 que está abaixo.

\begin{tabular}{|c|c|c|}
\hline Tipo de previsão & Amplitude & Aplicações \\
\hline Curto prazo & 8 horas à frente & $\begin{array}{c}\text { Operações em tempo real na rede } \\
\text { elétrica }\end{array}$ \\
\hline Médio prazo & 1 dia à frente & $\begin{array}{l}\text { Planejamento econômico do } \\
\text { despacho de energia } \\
\text { Segurança operacional no } \\
\text { mercado de energia }\end{array}$ \\
\hline Longo prazo & Mais de 1 dia à frente & $\begin{array}{c}\text { Planejamento de manutenção } \\
\text { Gerenciamento operacional } \\
\text { Otimização do custo operacional }\end{array}$ \\
\hline
\end{tabular}

Já quanto à natureza podemos dividir os modelos em quatro grupos: os modelos físicos, os modelos de correlação espacial, os modelos estatísticos, os modelos de inteligência artificial e híbridos. 
Os modelos físicos se utilizam de parâmetros físicos da localidade em questão, como relevo do terreno, temperatura, pressão, umidade para construir modelos matemáticos de natureza determinística chamados de Previsões Numérico-Climatológicas (NWP) para obter a velocidade do vento, e então através das especificações técnicas e número de turbinas utilizadas, obter a energia gerada pelo parque eólico em questão. Os modelos de correlação espacial são bastante similares aos modelos físicos, mas consideram a correlação da velocidade do vento em várias localidades diferentes para se prever a velocidade do vento aonde se deseja.

Os modelos estatísticos levam em consideração o histórico de dados de velocidade do vento e/ou energia gerada para se prever os próximos valores, sendo os modelos dos mais variados tipos, como Box \& Jenkins, amortecimento exponencial, modelos estruturais, modelos bayesianos e análise espectral singular (SSA). Como exemplo temos os trabalhos de (Menezes, Souza e Pessanha, 2014) onde é aplicado um modelo PAR (p) e SSA para previsão de velocidade de vento e em (Pessanha, De Santana e Siller, 2014), onde a produção mensal de energia eólica é prevista utilizando um modelo SSA.

Os modelos de inteligência computacional e híbridos se utilizam de ferramentas como redes neurais, lógica fuzzy e algoritmos genéticos para realizar previsões de séries temporais, e ainda se combinar com modelos estatísticos para gerar previsões mais refinadas. Temos como exemplo o trabalho de (Barbounis et al., 2006), onde são utilizadas redes neurais para previsão de velocidade de vento e potência, (Capitão, 2010) em que a previsão de velocidade de vento é feita com técnicas de data mining, e (Pessanha, Da Silva e Souza, 2010), onde é elaborado um modelo neuro-fuzzy para previsão da velocidade de vento.

Diante dessa classificação, o modelo de previsão proposto no capítulo 5 se enquadra na categoria de previsão de médio prazo quanto ao horizonte e de modelo estatístico quanto à natureza. 


\section{Análise Exploratória dos Dados}

\subsection{Dados de velocidade do vento}

Conforme abordado anteriormente, a velocidade do vento é a medição determinante para que se tenha a potência da produção de energia eólica em um aerogerador. Os dados inicialmente obtidos de velocidade do vento estão em metros por segundo, medidos na estação anemométrica de São João do Cariri Paraíba, a 50 metros de altura, com frequência de aquisição de 10 minutos, de janeiro de 2006 a setembro de 2009, e foram convertidos para frequência horária através da média das 6 observações contidas em cada hora. Os dados estão disponíveis no site do Projeto SONDA (Sistema de Observação Nacional de Dados Anemométricos). A seguir é apresentado o histograma dos dados.

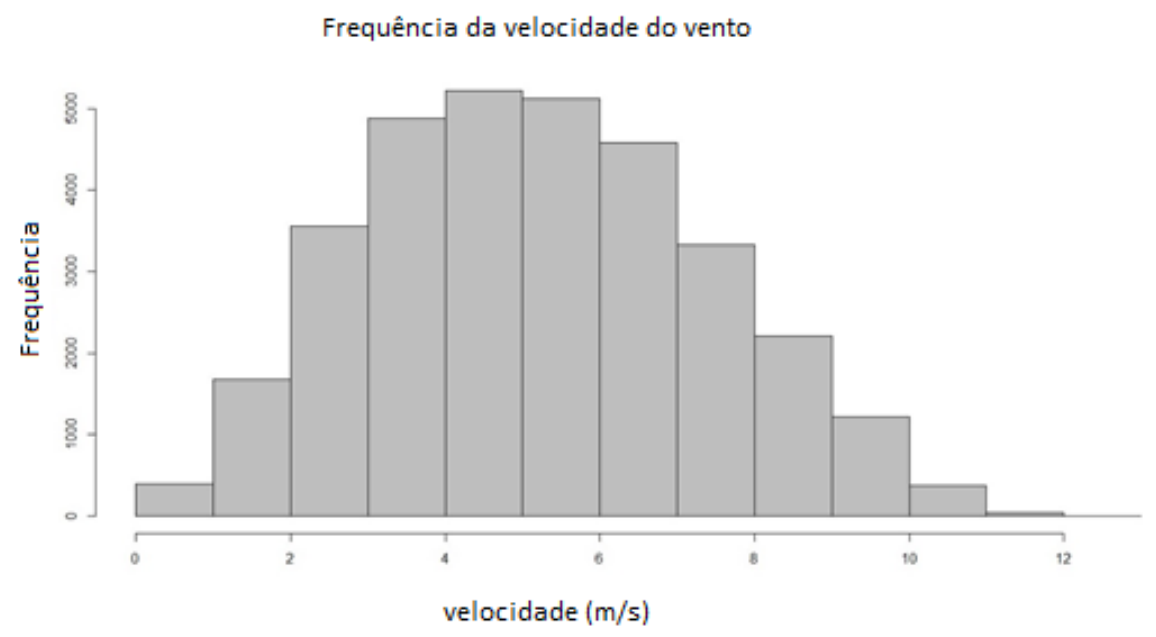

Figura 22 - Histograma dos dados 
Para entender o comportamento dos dados de velocidade de vento, uma das mais importantes características de se observar são os padrões de sazonalidade encontrados. No caso dos dados de energia eólica são tipicamente dois padrões: um referente ao ciclo diário, pois existem horários específicos dentro do dia em que devido à maior velocidade do vento, a produção de energia é maior, e o outro padrão é devido a sazonalidade mensal, pois em determinados meses devido a maior velocidade de vento, a produção também é maior. Estes padrões estão diretamente ligados a região geográfica em que as medições estão sendo realizadas. A existência dos padrões sazonais é explicitada quando são apresentados os gráficos abaixo, que mostram os dados agrupados tanto por horário quanto por meses.

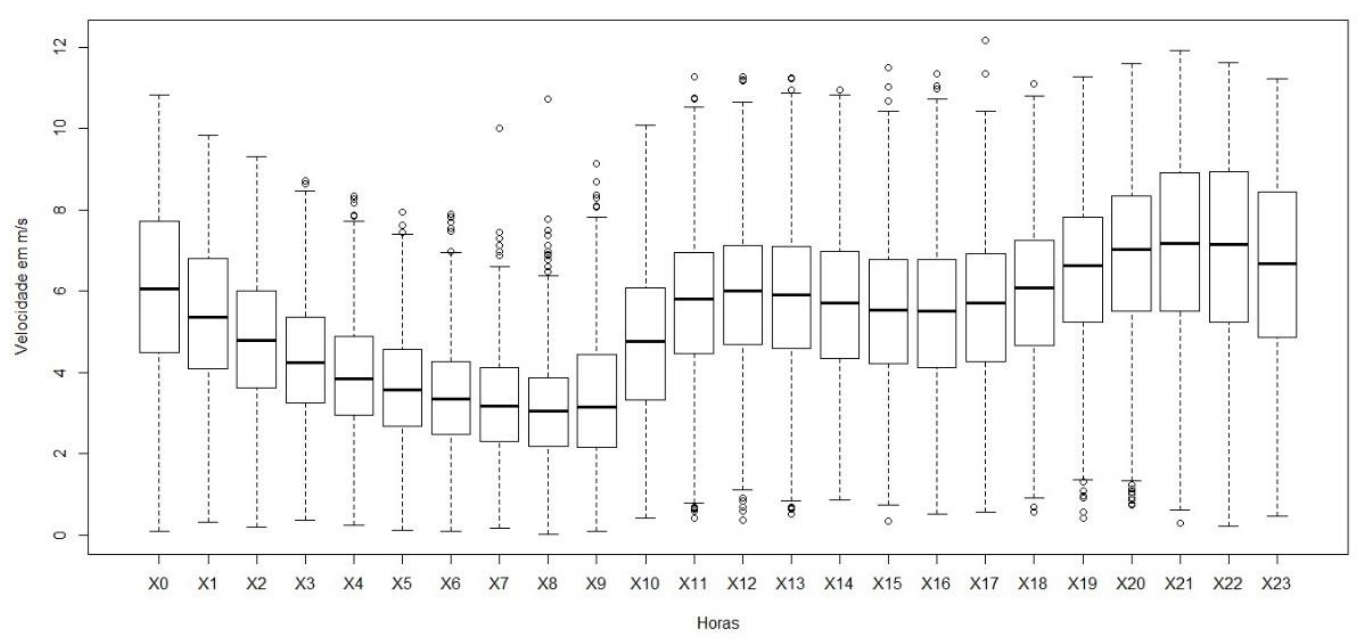

Figura 23 - Boxplot dos dados por hora

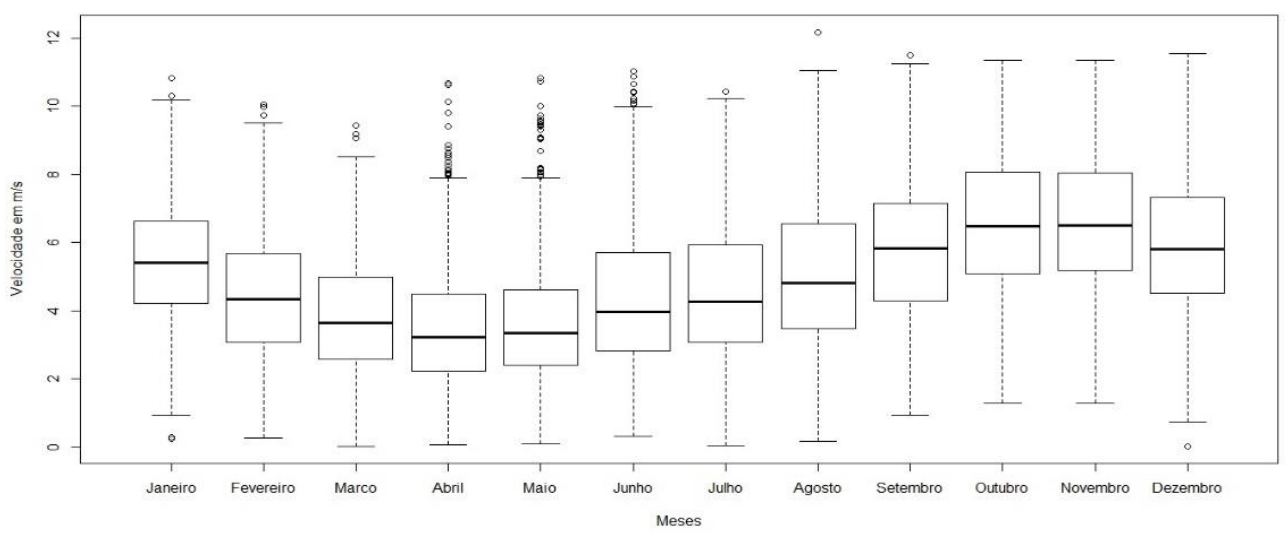

Figura 24 - Bloxplot dos dados por mês 
Para detalhar melhor a característica da sazonalidade mensal, abaixo são apresentadas as estatísticas descritivas estratificadas por mês e gerais. Vale destacar a variação das grandezas como média e mediana ao longo dos meses, corroborando a informação da figura 24. 


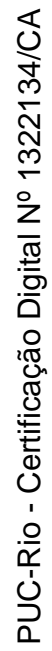

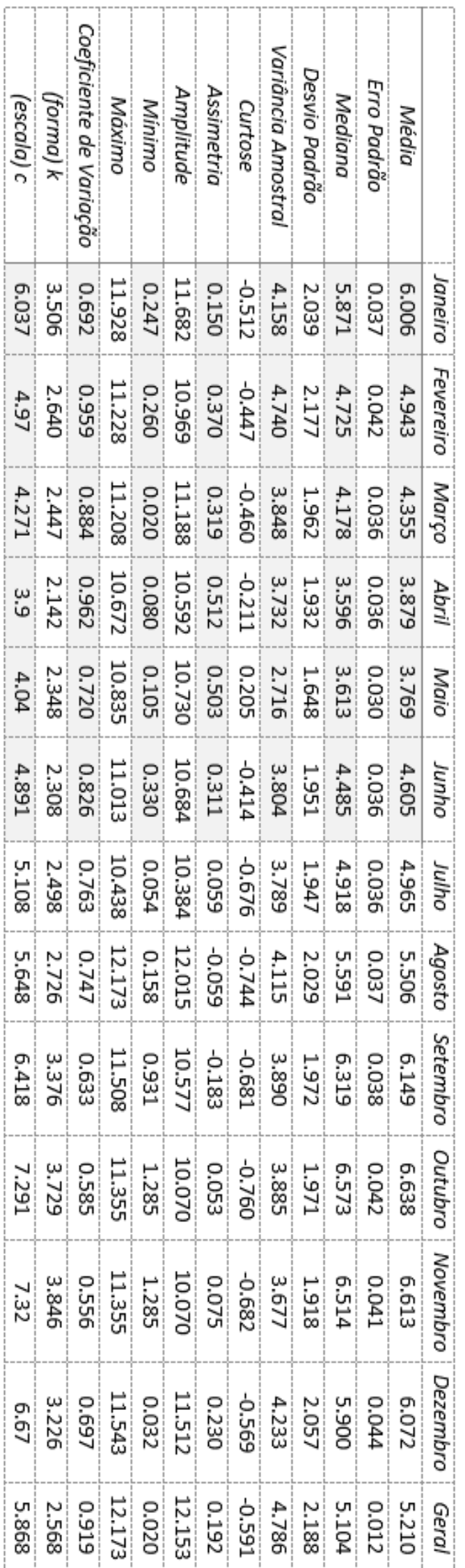

Tabela 3 - Estatísticas descritivas por mês 
Outro gráfico útil para entender o comportamento dos dados é o histograma e a distribuição de Weibull ajustada aos dados, com os parâmetros de forma (k) e escala (c), que estão na tabela 3. A seguir é apresentada a comparação entre o mês de maio (menor média) e outubro (maior média), onde é possível notar uma alteração não só na localização do centro da distribuição, como a mudança no formato.

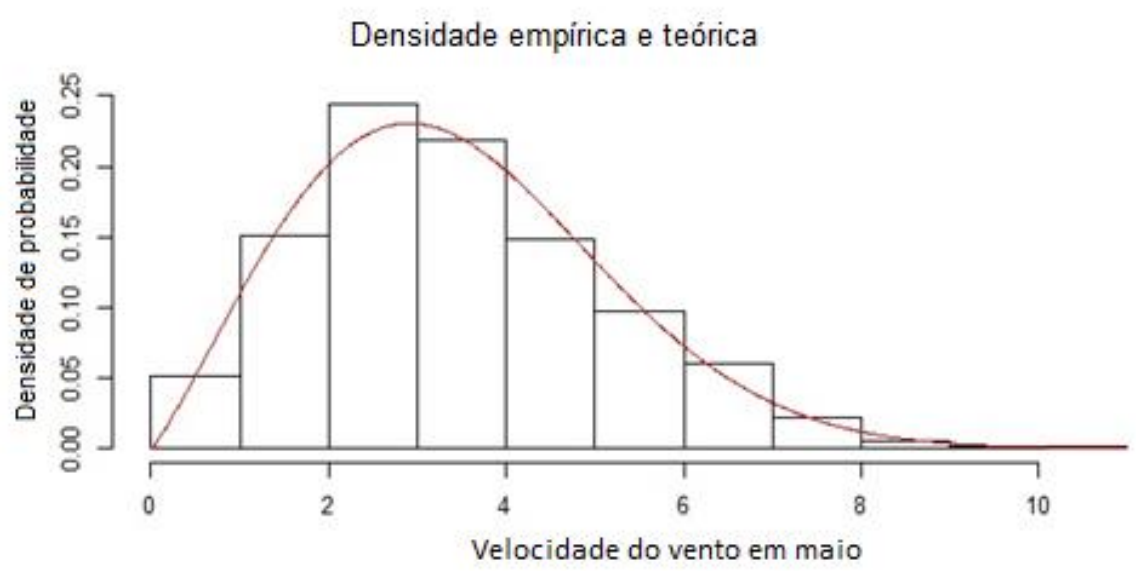

Densidade empírica e teórica
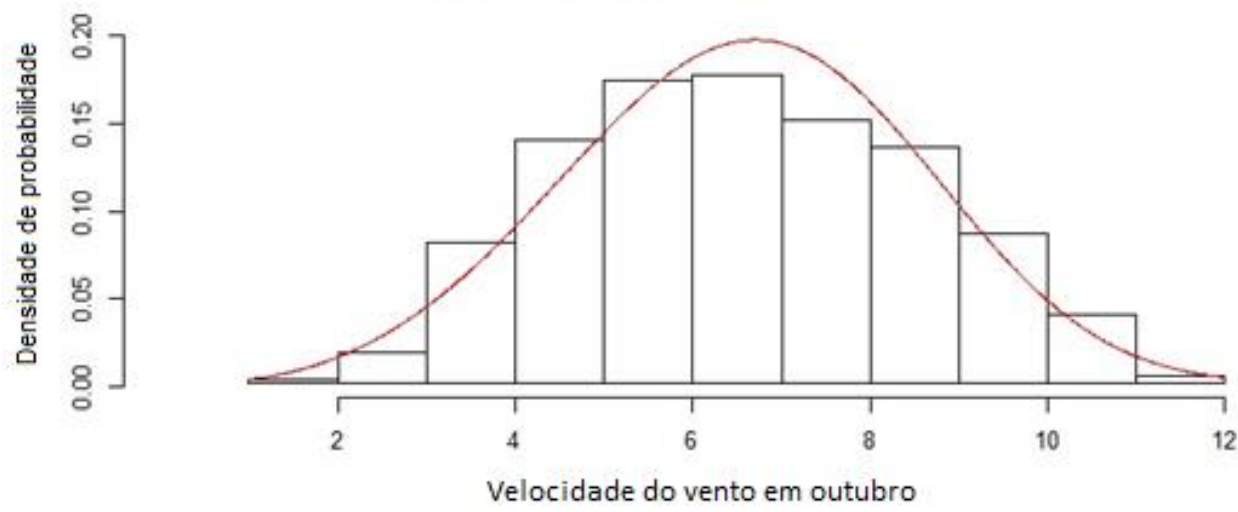

Figura 25 - Histograma e distribuição ajustada nos meses de maio e outubro

\subsection{Dados de potência}

Para realizar a conversão dos dados de velocidade do vento para potência gerada, foi adotado o seguinte procedimento.

A partir de um manual técnico de um aerogerador comercial de potência nominal de $2350 \mathrm{~kW}$ bastante utilizado no cenário nacional, uma curva de potência foi construída com as informações obtidas nas especificações técnicas do aerogerador, que se encontram na tabela 4. Após isso, foi utilizada a equação 83 e 
84 encontrada em (Custódio, 2009), para transformar os dados de velocidade, que estão na altura de $50 \mathrm{~m}\left(v_{50}\right)$ para a altura do centro da hélice do aerogerador de $108 \mathrm{~m}\left(v_{108}\right)$. Para isso, é necessário obter a média das velocidades a $50 \mathrm{~m}$ de altura $\left(\bar{v}_{50}\right)$ e a $25 \mathrm{~m}$ de altura $\left(\bar{v}_{25}\right)$.

$$
\begin{array}{r}
v_{108}=v_{50}\left(\frac{108}{50}\right)^{\alpha} \\
\alpha=\frac{\ln \left(\frac{\bar{v}_{50}}{\bar{v}_{25}}\right)}{\left(\bar{v}_{50}\right)}
\end{array}
$$

Para transformar os dados de velocidade em potência, foi realizada uma interpolação entre cada intervalo de velocidade na tabela 4 , de modo que para todos os valores reais de velocidade do vento na base dados, pode se obter valores de potência equivalentes se submetidos a esse aerogerador.

\begin{tabular}{cc}
\hline velocidade $(\mathrm{m} / \mathrm{s})$ & potência $(\mathrm{kW})$ \\
\hline $0-1$ & 0 \\
2 & 3 \\
3 & 25 \\
4 & 82 \\
5 & 174 \\
6 & 321 \\
7 & 532 \\
8 & 815 \\
9 & 1180 \\
10 & 1580 \\
11 & 1890 \\
12 & 2100 \\
13 & 2250 \\
14 & 2350 \\
$15-25$ & 2350 \\
\hline Tabela 4- Relação entre velocidade e potência
\end{tabular}

$\mathrm{Na}$ figura 26 é apresentado o gráfico resultante da interpolação dos valores da tabela. A interpolação foi implementada computacionalmente de maneira linear, chegando-se assim a uma curva composta de 14 segmentos de reta. 


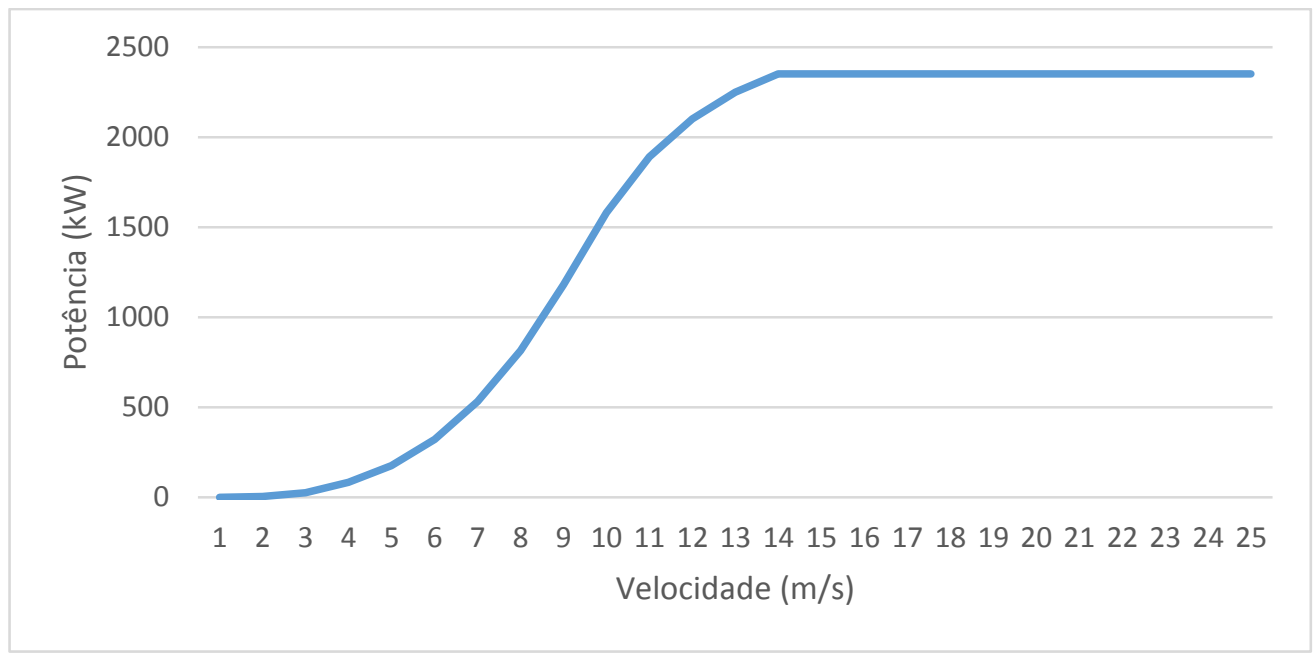

Figura 26 - Curva de potência do aerogerador utilizado

Com isso, uma análise importante que pode ser feita é através do gráfico de Pareto para a potência média horária de cada mês. Nela, podemos observar para cada mês, quais são os horários que concentram a maior produção de energia, e como esse conjunto de horários variam.

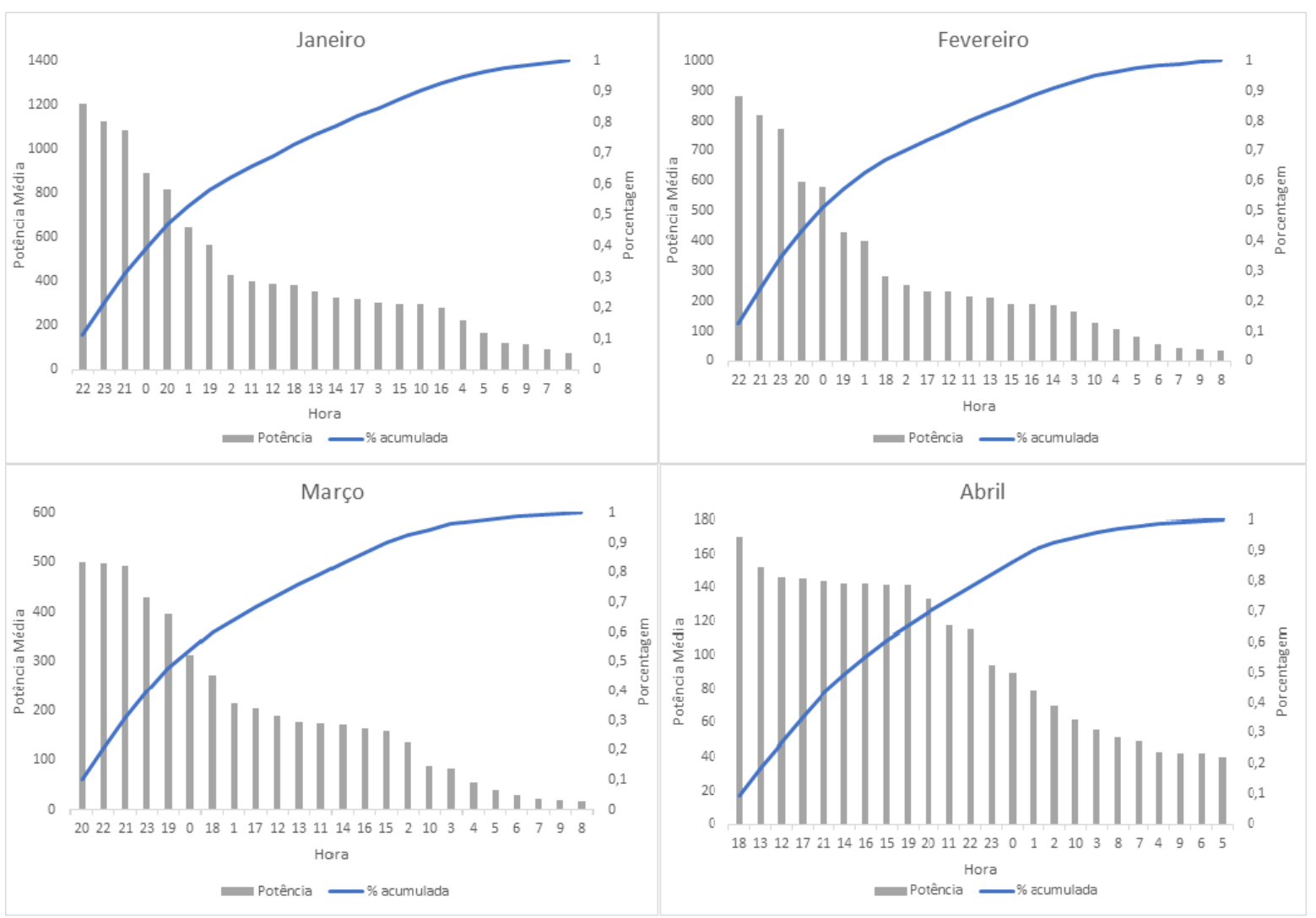

Figura 27 - Gráfico de pareto da produção média horária - janeiro a abril 


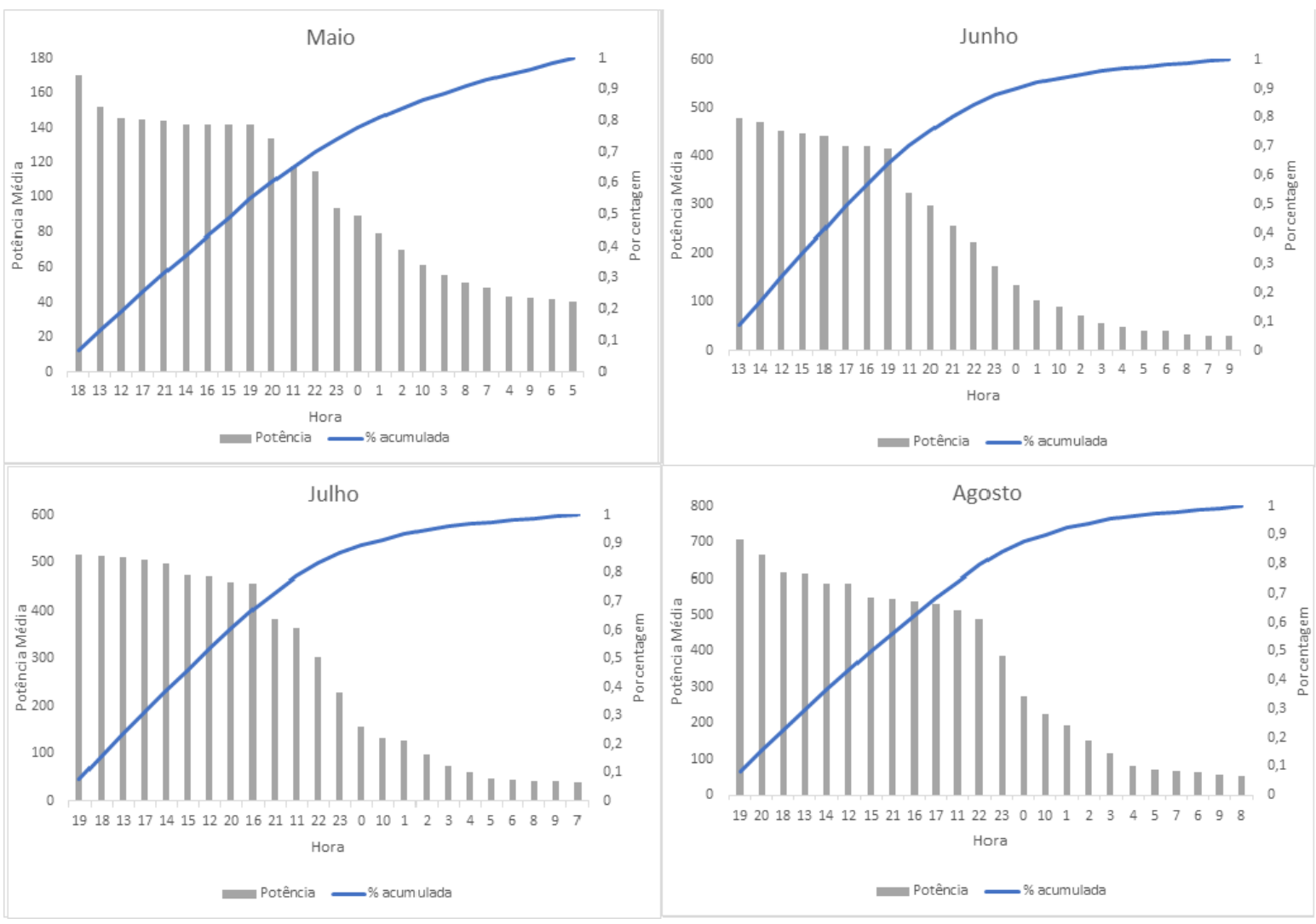

Figura 28 - Gráfico de pareto da produção média horária - maio a agosto
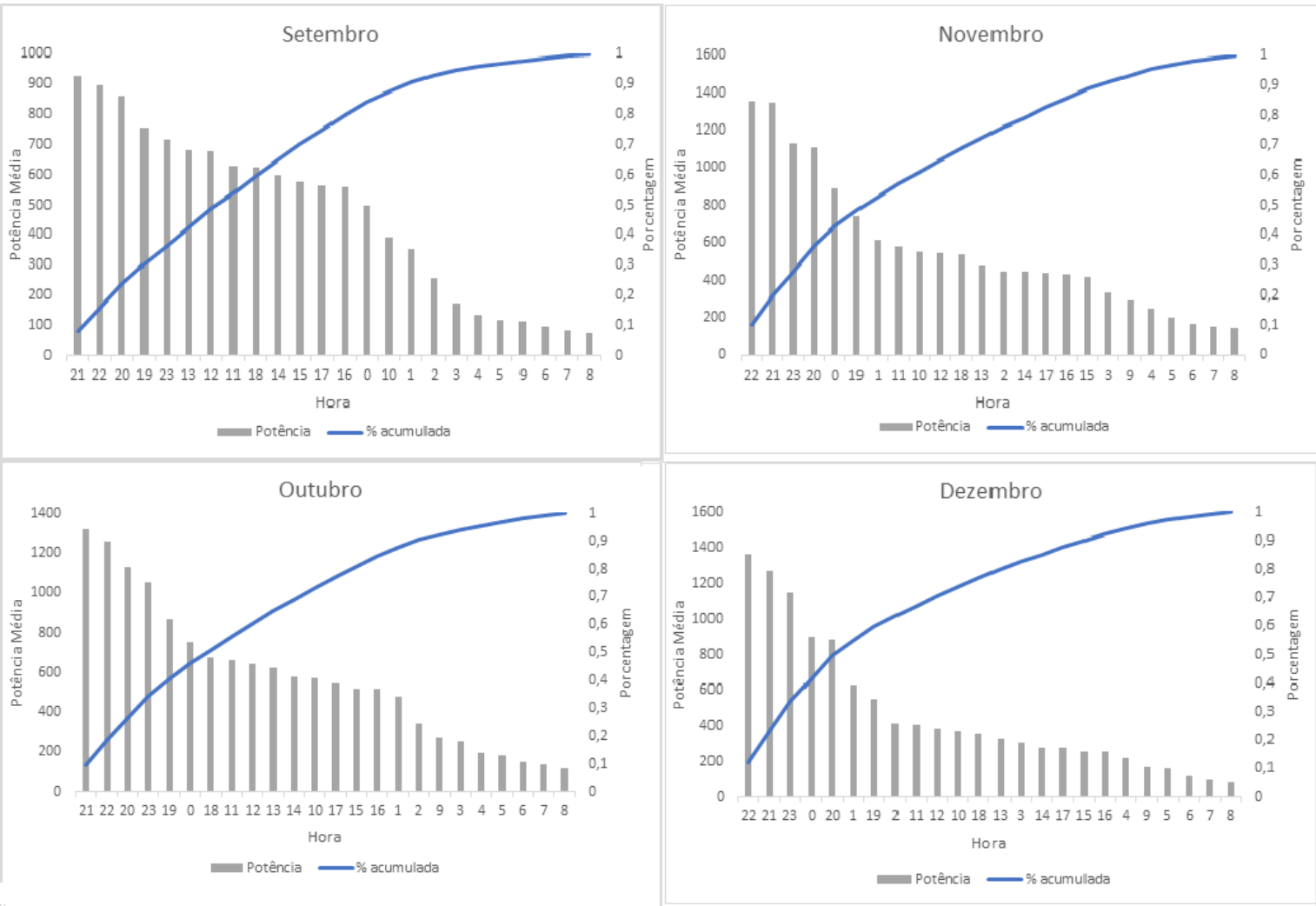

Figura 29 - Gráfico de pareto da produção média horária - setembro a dezembro 
Uma característica importante dos dados é apresentada no gráfico abaixo, onde é comparada a potência média percentual entre os meses de maior média (outubro) e menor média (maio). Assim, tem-se visualmente a diferença dos perfis de geração entre os meses com médias de produção mais discrepantes.

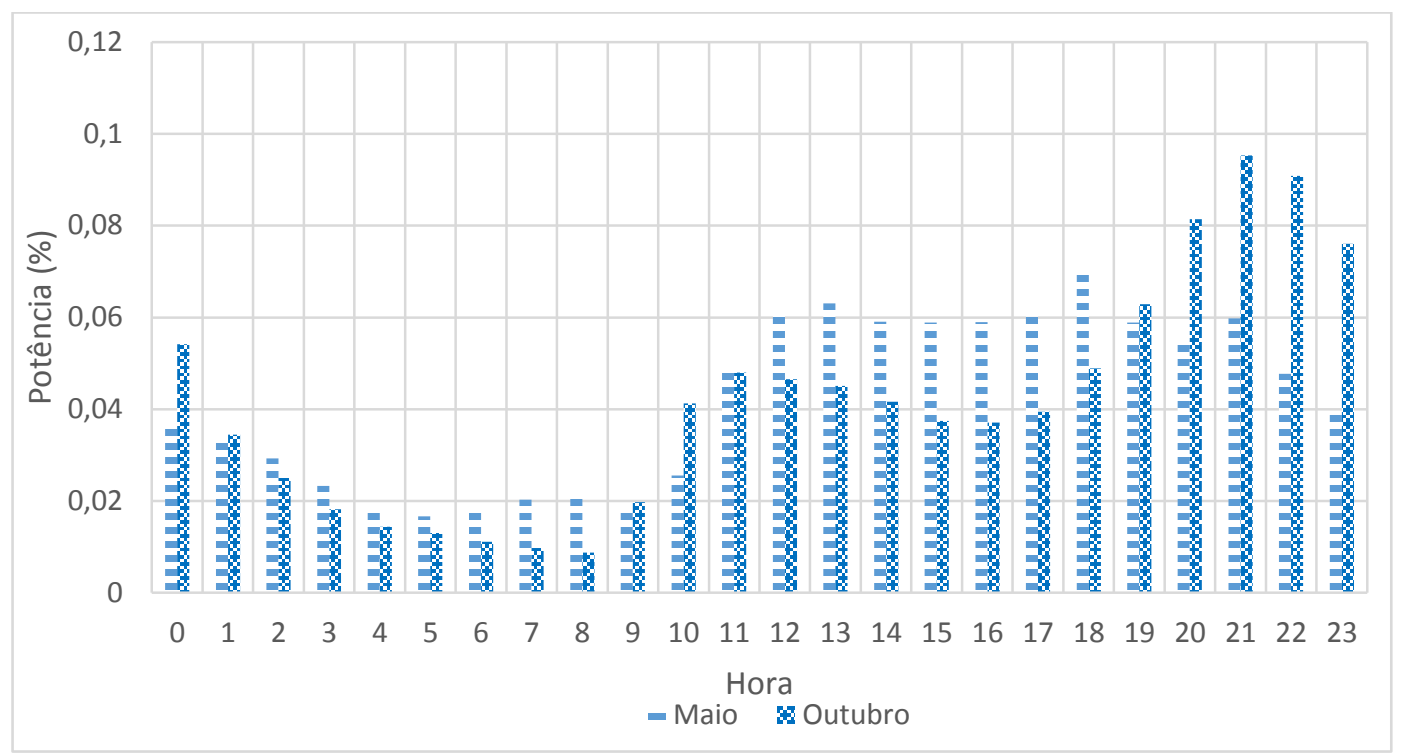

Figura 30 - Potência média horária percentual nos meses de maio e outubro

Tal informação pode ser observada no gráfico de radar, onde fica clara a maior produção de outubro concentrada em nos horários de $21 \mathrm{~h}$ e $22 \mathrm{~h}$, ao contrário da produção de maio, que se demonstra mais homogênea durante o dia.

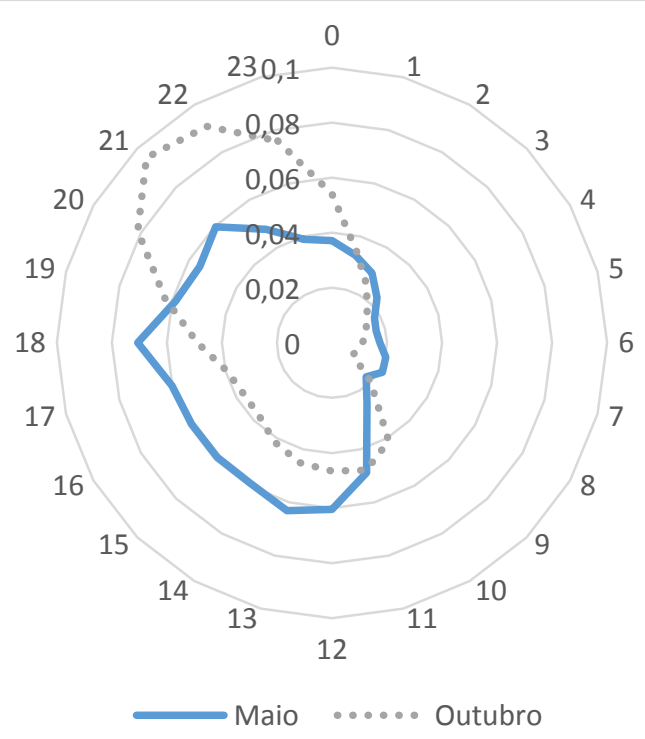

Figura 31 - Gráfico de radar da potência média horária percentual nos meses de maio e outubro

Uma característica importante dos dados que se destaca quando é realizada uma análise horária é a relação entre o coeficiente de variação e a média histórica. 
A figura 32 ilustra 24 pontos, cada um relativo aos dados de cada hora do dia, onde no eixo horizontal está a média e no eixo vertical o coeficiente de variação. É possível identificar uma relação linear entre a média e o coeficiente de variação, chegando a uma conclusão de que para um aumento da média temos uma diminuição da variabilidade.

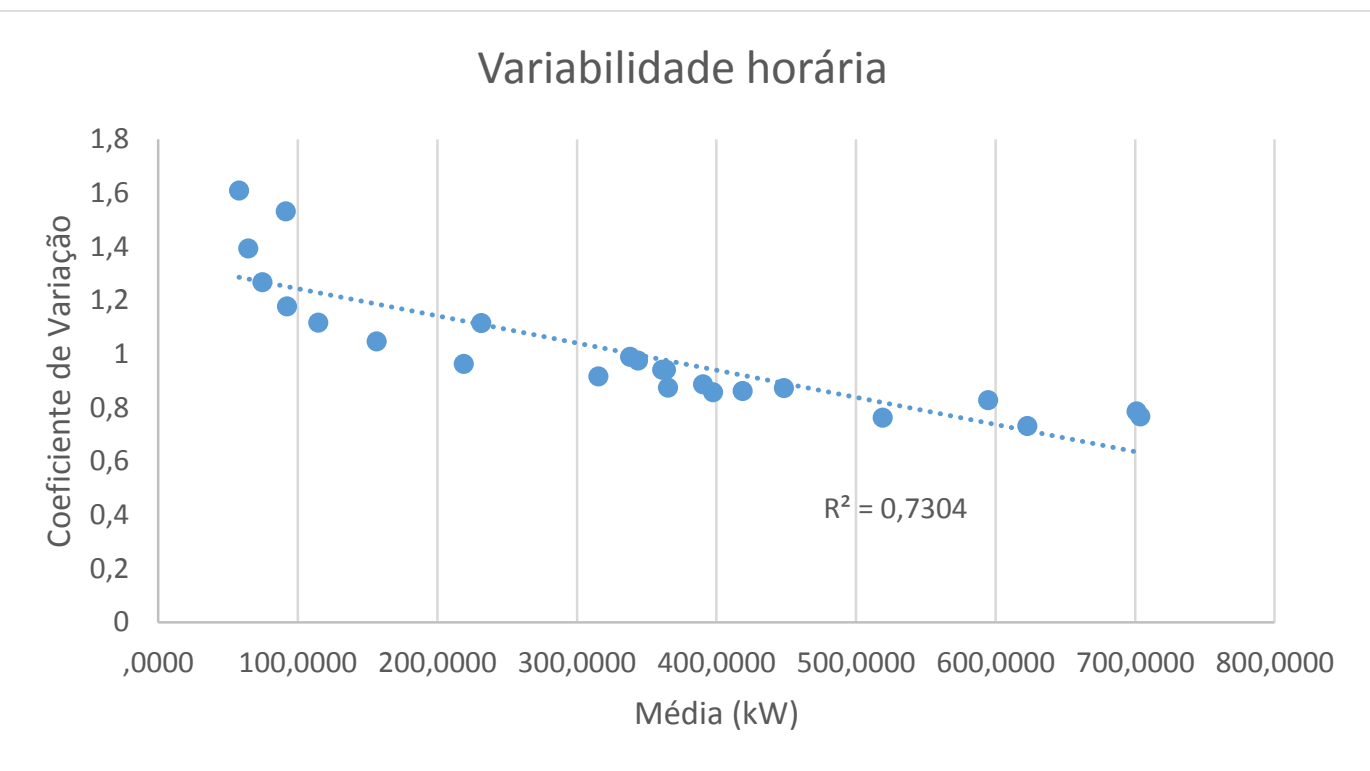

Figura 32 - Regressão linear entre o coeficiente de variação e a média da produção média horária

Essa característica se torna importante na construção dos modelos de previsão da série abordada, pois os horários em que a produção é mais baixa, como às 8 h (conforme a figura 33 aponta), o padrão de comportamento dos dados é bem mais irregular, enquanto no horário de maior produção média, (21h), fica bem mais claro um padrão sazonal.

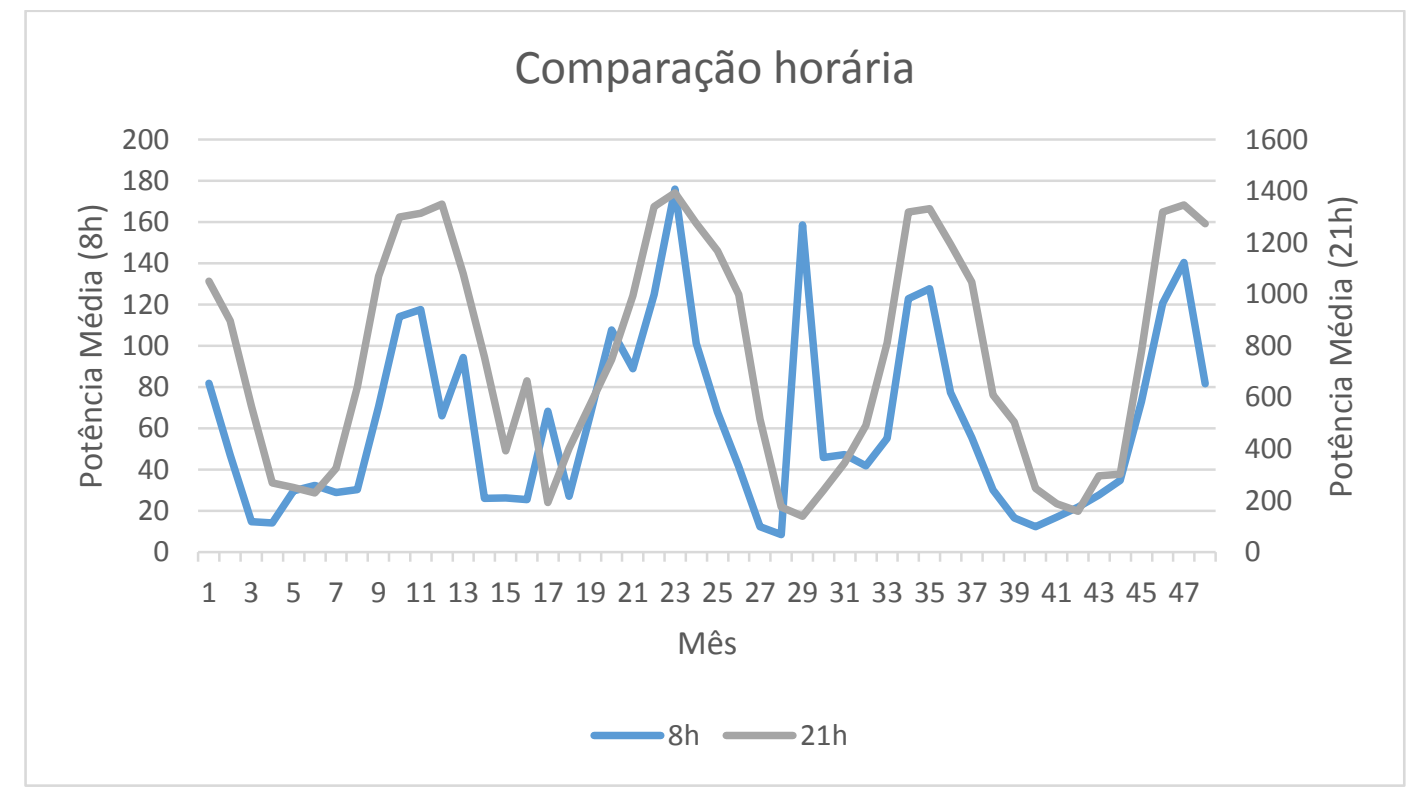

Figura 33 - Evolução da potência média mensal às 8h e às $21 \mathrm{~h}$. 
A seguir é apresentado um gráfico de superfície onde a potência média é expressa em função das horas do dia e dos meses do ano. Aqui pode-se visualizar a região de máxima produção $(1200 \mathrm{~kW}-1400 \mathrm{~kW}$, e da de mínima produção $(0 \mathrm{~kW}-200 \mathrm{~kW})$, e de como elas estão associadas a horários e meses específicos. Além disso, possivel observar a modificação da curva de geração horária ao longo dos meses, e da curva de geração mensal quando o horário de medição é modificado.

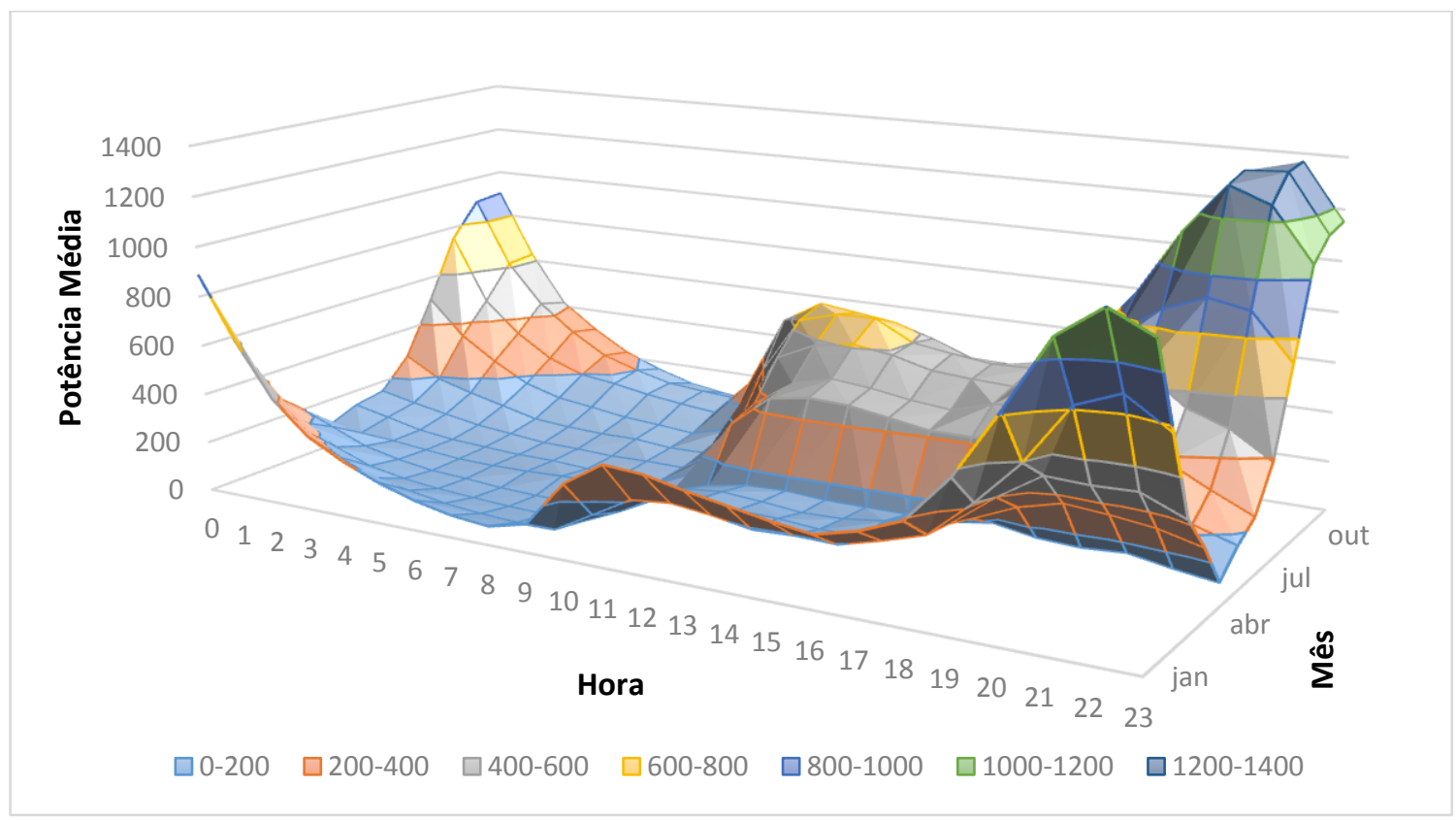

Figura 34 - Potência média de acordo com o horário e o mês

Observando essas características, foi adotada uma estratégia de agrupamento dos dados para facilitar a visualização dos padrões sazonais, que foi a de obter a média das observações horárias nos dias do mesmo mês. Por exemplo, no mês de outubro de 2007, são encontrados 31 dias, cada um com 24 observações, mas realizando essa transformação, foi obtido um dia "médio" representativo do mês de outubro de 2007, que contêm 24 observações. Essa estratégia foi adotada ao se observar que os padrões diários são bem similares dentro do mesmo mês. Dessa forma, o banco de dados agora conta com $24 \times 12 \times 4$ (1152) observações, que podem ser observadas na figura 35, que ilustra o ciclo diário e a sazonalidade mensal. 


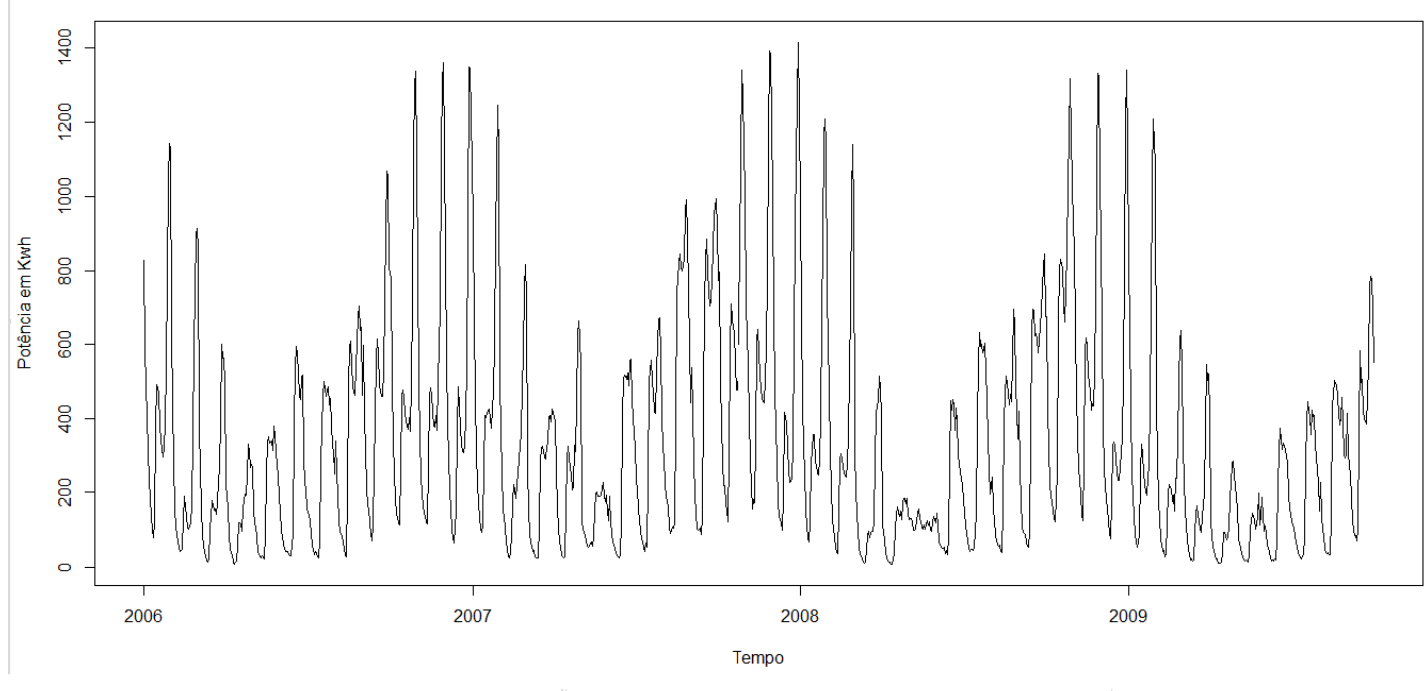

Figura 35 - Média horária por mês da potência

Diante da série apresentada depois da estratégia de agrupamento, um recurso que pode ser utilizado é a decomposição da série através do método TBATS, que permite uma decomposição da série com mais de uma componente de sazonalidade. Nela percebe-se a presença de um ciclo mais curto com período de 24 observações, que é o ciclo diário, e a presença de um ciclo mais longo, com período de 24x12 (288) observações, que é a sazonalidade mensal.

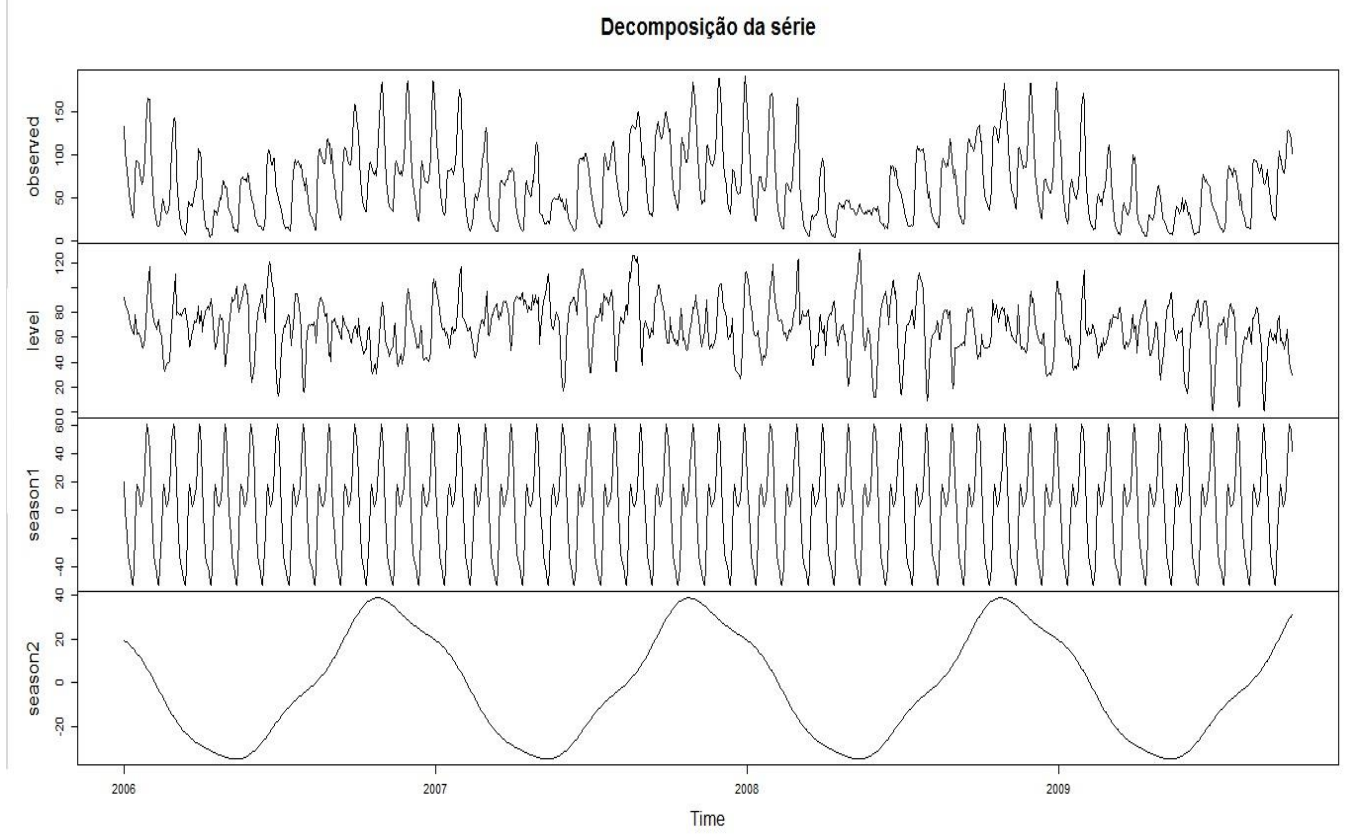

Figura 36 - Decomposição da série com duas componentes sazonais 


\section{Aplicação do Método de Previsão}

Este capítulo descreve o metodo de previsão que foi desenvolvido e utilizado no banco de dados de velocidade de vento descrito anteriormente, que se apresenta como um desdobramento da pesquisa efetuada em (Barros, Oliveira e Souza, 2015).

A abordagem dada aqui parte da idéia de decompor a série, gerar séries sintéticas combinando a decomposição e um modelo de simulação e realizar a previsão de cada uma das séries sintéticas, chegando a uma previsão que é a média das previsões das séries sintéticas. Esse tipo de abordagem é recente na literatura de séries temporais, e encontra resultados promissores, em trabalhos como (Bergmeir, Hyndman e Benitez, 2014), que utiliza o modelo STL $^{10}$ de decomposição com a técnica de moving blocks bootstrap para a geração de séries sintéticas e (Dantas e Oliveira, 2015), que modificam o trabalho anterior propondo a incorporação de um algoritmo de aprendizado de máquina para selecionar as séries sintéticas para previsão, e (Maçaira, Cyrino Oliveria e Souza, 2015), onde é utilizado o MSSA ${ }^{11}$ para a decomposição das séries temporais.

Foram utilizados três anos de dados 2006 a 2008 para treinamento do modelo e a primeira semana de 2009 para avaliação e calculo das métricas out-ofsample. No caso o modelo realizou previsões de 24 passos à frente, ou seja, como a série tem frequência horária, serão previsões de 1 dia à frente. Depois disso, as métricas de avaliação são calculadas e o modelo incorpora os 24 dados seguintes da série original e os primeiros 24 dados da série são eliminados, para que a o tamanho da série seja conservado. Por exemplo, na primeira previsão são utilizados 26280 dados (0hs de 1 de janeiro de 2006 a 23hs de 31 de dezembro de 2008) para realizar a previsão das 24 horas do dia 1 de janeiro de 2009. Após isso, são utilizados também 26280 dados (0hs de 2 de janeiro de 2006 a 23 hs de 1 de janeiro de 2009) para estimar um novo modelo e realizar a previsão das 24 horas do dia 2 de janeiro de 2009. A seguir será detalhado o método de previsão e a sua

\footnotetext{
${ }^{10}$ Seasonal and Trend decomposition using Loess

${ }^{11}$ Multichannel Singular Spectral Analysis
} 
aplicação na primeira previsão para o dia 1 de janeiro de 2009, onde será discutida a configuração ótima de alguns parâmetros do método proposto, para a posterior avaliação no restante dos dados.

A figura 37 exibe um fluxograma que detalha o método de previsão proposto.

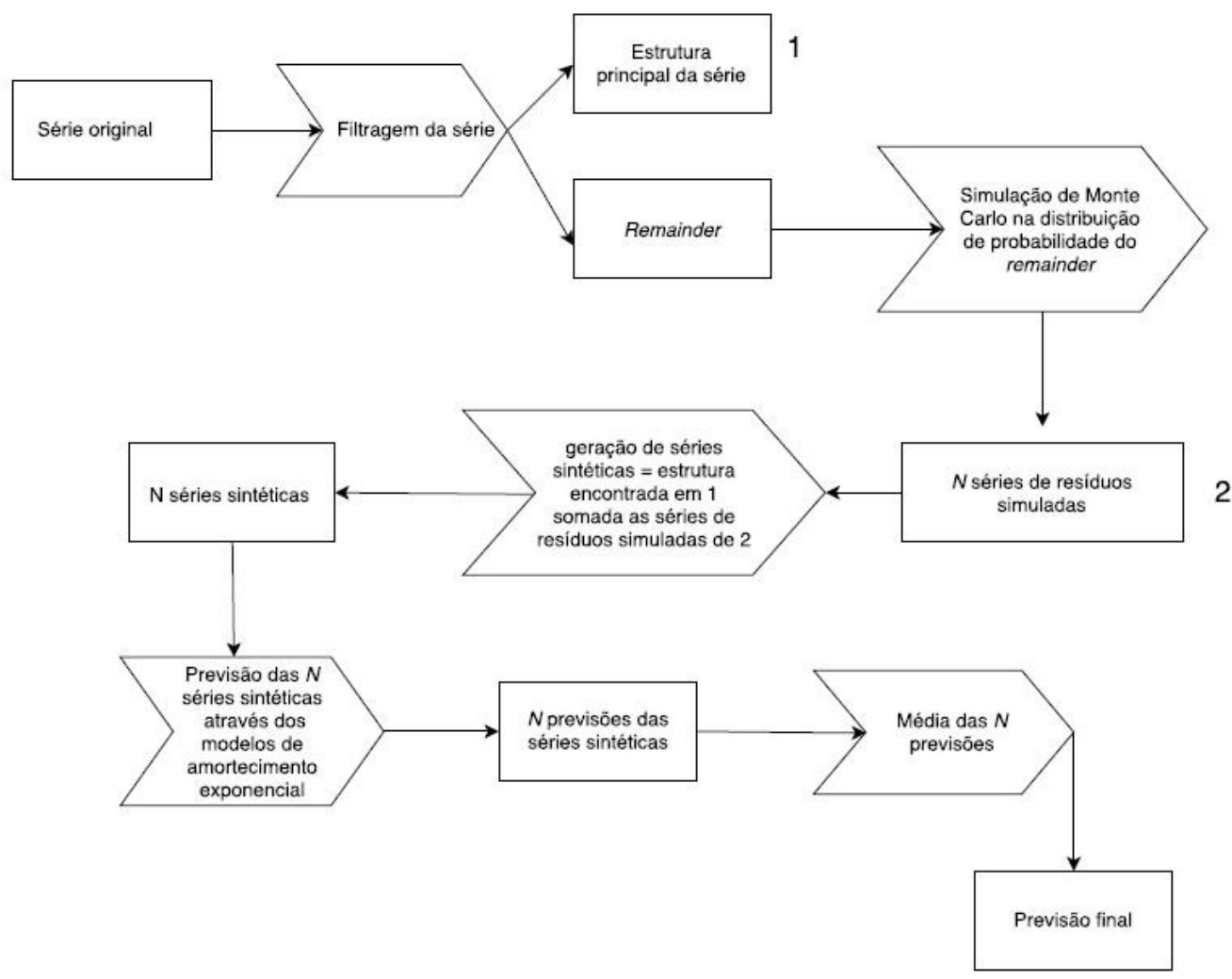

Figura 37 - Fluxograma do modelo de previsão

O primeiro passo é a partir da série de dados original realizar a filtragem da série através do algoritmo TBATS, onde são separados a estrutura principal da série e o seu resíduo. Como parâmetros para a decomposição foram escolhidos dois ciclos sazonais de comprimento 24 e 8760 (24x365), que representam respectivamente o ciclo diário e a sazonalidade mensal, em acordo com a análise exploratória do capítulo anterior.

No caso, a ordem do modelo TBATS encontrado foi a de $(1,1,2,0,24$, 8760), ou seja, não foi utilizado transformação Box-Cox e amortecimento de tendência, mas foi utilizado um filtro ARMA $(2,0)$, e dois ciclos sazonais de comprimento 24 e 8760 (24x365). A seguir temos o gráfico de decomposição da série e dos resíduos, respectivamente, nas figuras 38 e 39. 
Decomposition by TBATS model

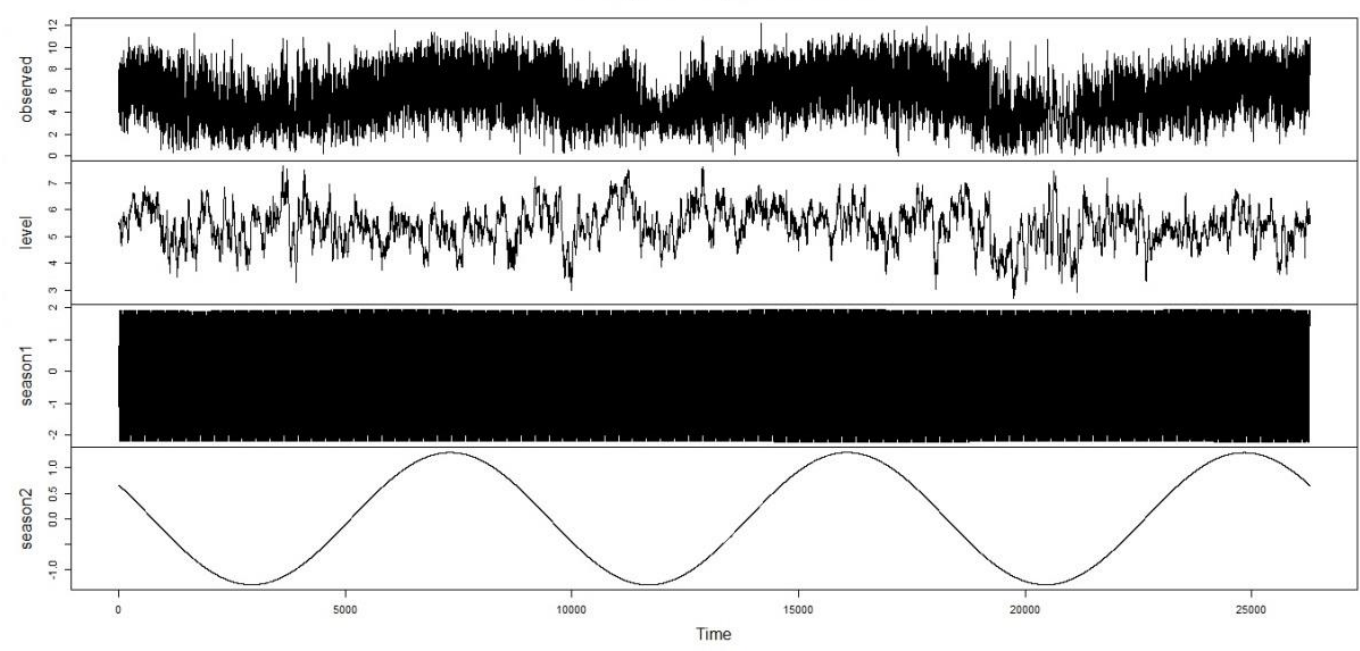

Figura 38 - Decomposição pelo TBATS

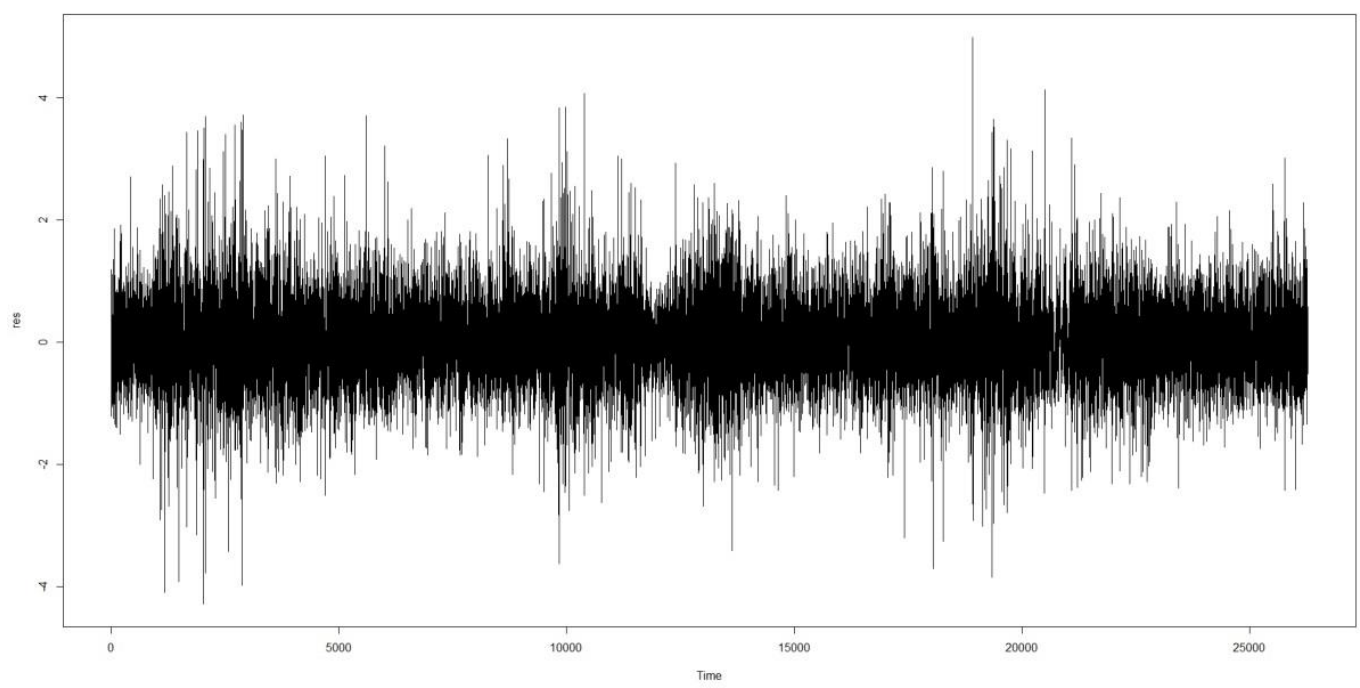

Figura 39 - Resíduo da decomposição

Para ter a confirmação de que o resíduo da decomposição não tem estrutura de autocorrelação, (fato necessário para a posterior utilização da simulação de Monte Carlo), foi realizado um teste de Ljung-Box, com nível de significância de $5 \%$, onde as hipóteses são:

$\mathrm{H}_{0}$ : Os resíduos são i.i.d.

$\mathrm{H}_{1}$ : Os resíduos não são i.i.d

Como o p-valor é maior que o nível de significância adotado, não há indícios para rejeitar a hipótese nula de que os resíduos não têm estrutura de autocorrelação, como pode se observar na figura 40 . 


\begin{tabular}{|ccc|}
\hline \multicolumn{3}{|c|}{ Teste de Ljung-Box } \\
\hline$\chi^{2}$ & g.l. & p-valor \\
\hline $\mathbf{0 . 2 8 2 1}$ & 2 & 0.8684 \\
\hline
\end{tabular}

Figura 40 - Teste de Ljung-Box nos resíduos

O passo seguinte é ajustar uma distribuição de probabilidade nos resíduos para que possa ser realizada a simulação de Monte Carlo. Com o histograma dos dados e o método qui-quadrado de aderência de distribuição de probabilidade através da função fitditrplus do $R$, foi gerada uma distribuição normal de média 0,000376 e desvio padrão 0,66279 . A seguir na figura 41 temos o histograma dos resíduos e a distribuição de probabilidade ajustada.

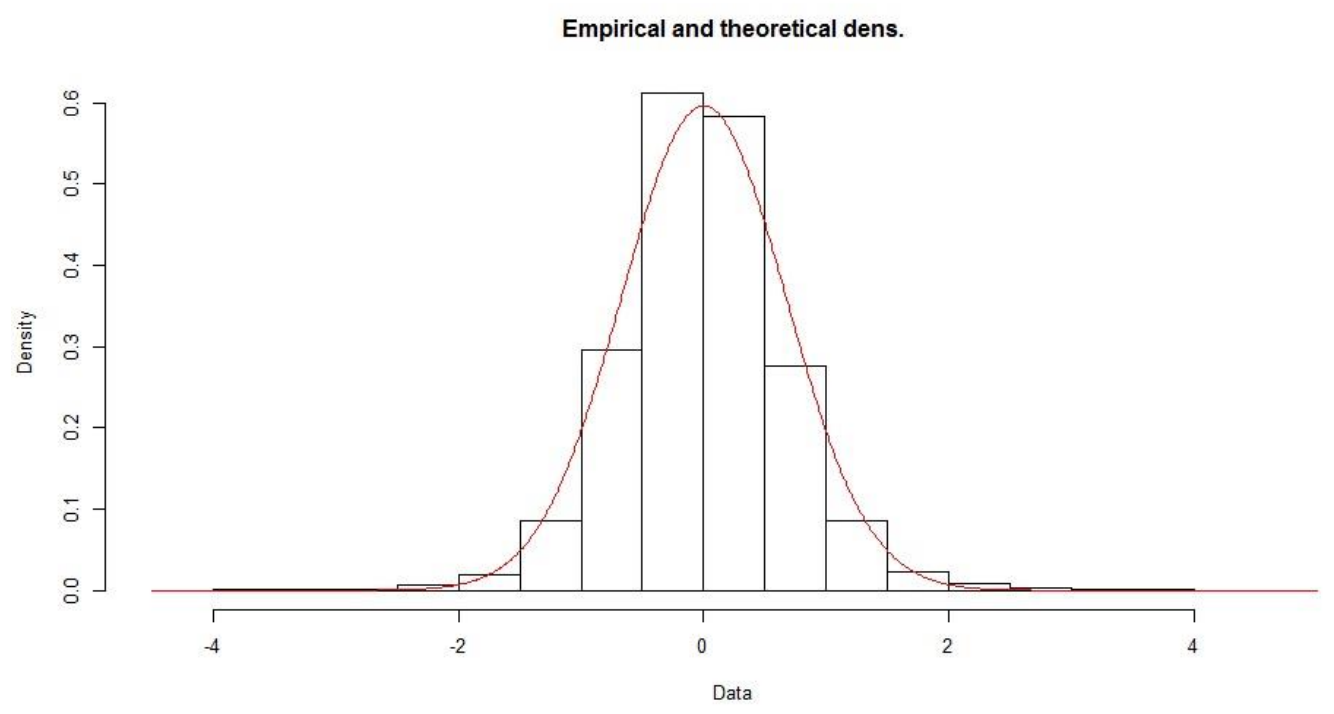

Figura 41 - Histograma e função de probabilidade

Com isso, uma quantidade qualquer de séries temporais de resíduos pode ser criada utilizando uma simulação de Monte Carlo na distribuição de probabilidade encontrada. Logo, prosseguindo com o fluxograma da figura 36, pode se criar uma quantidade qualquer desejada de séries sintéticas somando a estrutura principal da série encontrada pela decomposição TBATS com uma série de resíduos gerada pela simulação de Monte Carlo.

O passo seguinte é estimar e aplicar um método de amortecimento exponencial em cada uma das séries sintéticas e gerar assim uma quantidade $n$ de previsões 24 passos à frente. Assim, a previsão pontual da série será a média das $n$ previsões geradas. Para realizar as previsões, foi utilizado um modelo de múltiplos ciclos análogo ao proposto em (Taylor, 2003b), que trata simultaneamente o ciclo diário e a sazonalidade mensal. Abaixo na figura 42 é ilustrada a previsão final 
utilizando o modelo proposto com 30 séries sintéticas de velocidade de vento um modelo de múltiplos ciclos, onde os dados reais são representados pela linha verde, as previsões das séries sintéticas pelas linhas cinza e a previsão final pela linha preta.

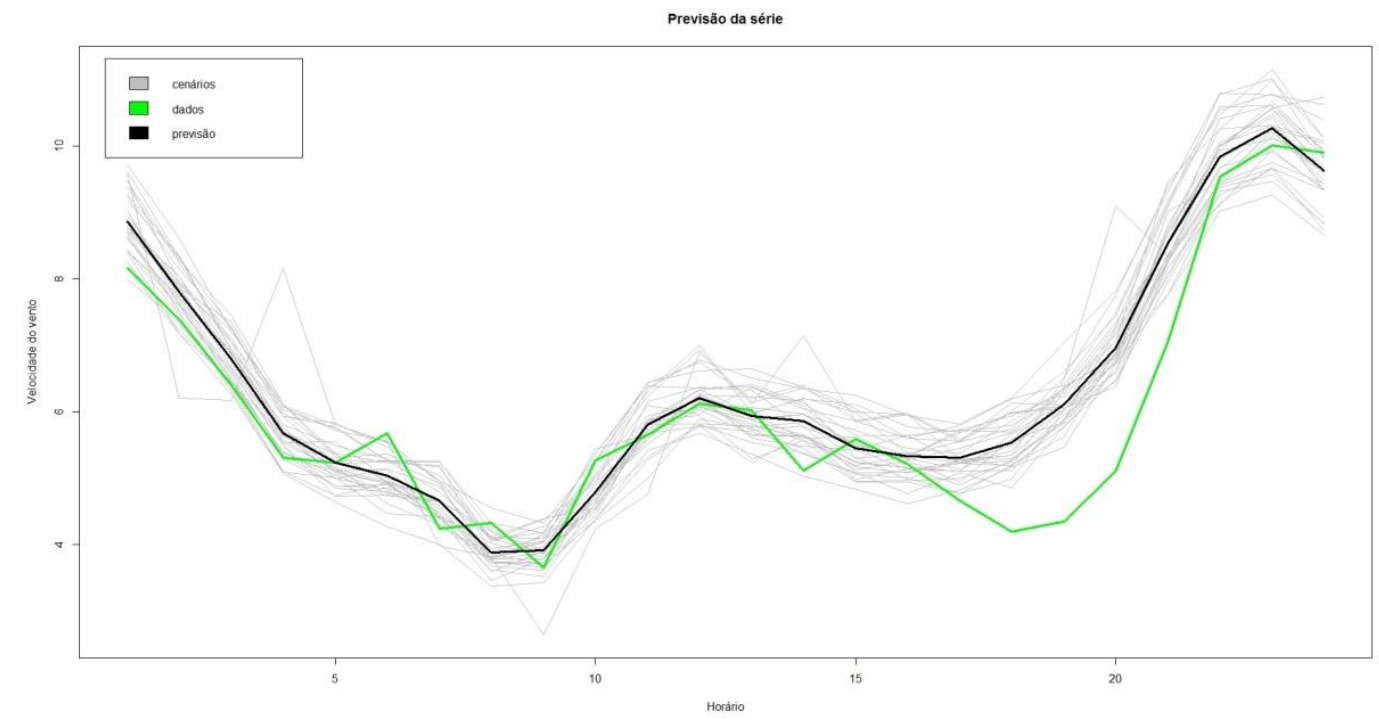

Figura 42 - Previsão com o método proposto

Contudo, durante a elaboração do fluxograma, foram levantadas duas questões que influenciariam na precisão do método. A primeira é se a média aritmética é uma medida de centralidade adequada para o cálculo da previsão final a partir das $n$ previsões das séries sintéticas.

Para verificar essa hipótese, foi construído um experimento em que o modelo de previsão proposto foi rodado 20 vezes, considerando o erro médio absoluto percentual (MAPE) tanto utilizando a média como a mediana. A mediana foi proposta por ser uma medida de centralidade robusta quando há presença de outliers na amostra.

Segundo (Souza e Oliveira, 2015), o MAPE pode ser definido como:

$$
M A P E=\frac{\sum_{i=1}^{N} \frac{|Y(t)-\hat{Y}(t)|}{Y(t)} \times 100}{N}
$$

Onde $Y(t)$ é o valor da série temporal no período $t, \widehat{Y}(t)$ é o valor da previsão para o período $t$ e $N$ é o total de observações.

A seguir é apresentada a tabela 5 com os valores do MAPE calculados. 


\begin{tabular}{|c|c|}
\hline Média (amostra 1) & Mediana (amostra 2) \\
\hline $10.44 \%$ & $10.04 \%$ \\
\hline $9.68 \%$ & $9.70 \%$ \\
\hline $10.35 \%$ & $9.82 \%$ \\
\hline $10.64 \%$ & $9.89 \%$ \\
\hline $9.67 \%$ & $9.64 \%$ \\
\hline $11.94 \%$ & $9.34 \%$ \\
\hline $13.30 \%$ & $9.50 \%$ \\
\hline $10.85 \%$ & $9.91 \%$ \\
\hline $9.95 \%$ & $9.75 \%$ \\
\hline $9.55 \%$ & $9.63 \%$ \\
\hline
\end{tabular}

Tabela 5 - Valores do MAPE para previsões utilizando média e mediana

Uma avaliação primária leva a conclusão de que a mediana leva a valores menores do MAPE quando comparadas a média aritmética. Porém, para ter uma conclusão mais confiável estatisticamente, foi construído um teste de hipótese para comparar a média do MAPE calculado a partir das duas medidas de centralidade propostas. Para testar as médias será empregado o teste $\mathrm{T}$ para amostras independentes; Porém, antes de testar a média, é preciso testar a variância das duas amostras ${ }^{12}$, para então decidir qual teste de médias é adequado, o com varâncias iguais ou com variâncias diferentes. Para isso foi utilizado um teste $\mathrm{F}$ para diferença de variância assumindo um nível de significância de 5\%, onde as hipóteses são:

$\mathrm{H}_{0}$ : As variâncias das duas amostras são iguais $\left(\sigma_{1}^{2}=\sigma_{2}^{2}\right)$

$\mathrm{H}_{1}$ : As variâncias das duas amostras são diferentes $\left(\sigma_{1}^{2} \neq \sigma_{2}^{2}\right)$

Como o p-valor é menor que o nível de significância adotado, há indícios para rejeitar a hipótese nula de que as variâncias das duas amostras são iguais. Abaixo na tabela 7 estão os dados completos do teste de hipótese.

\footnotetext{
${ }^{12}$ Aqui foi denominado amostra 1 o conjunto dos MAPEs calculados com a média aritmética e amostra 2 os calculados com a mediana
} 


\begin{tabular}{|c|c|c|}
\hline & Média (amostra 1) & Mediana (amostra 2) \\
\hline Média & 0.105464 & 0.097409 \\
\hline Variância & 0.000134 & 0.000004 \\
\hline Observações & 10 & 10 \\
\hline $\mathrm{gl}$ & 10 & 10 \\
\hline $\mathrm{F}$ & \multicolumn{2}{|c|}{0.000003} \\
\hline$P(F \leq f)$ bicaudal & \multicolumn{2}{|c|}{2.978237} \\
\hline F Critico bicaudal & \multicolumn{2}{|c|}{} \\
\hline
\end{tabular}

Tabela 6 - Teste de hipótese para diferença de variâncias

Com isso, para analisar se as médias das duas amostras são diferentes, foi aplicado um teste $\mathrm{T}$ assumindo variâncias diferentes e um nível de significância de 5\% com as seguintes hipóteses:

$\mathrm{H}_{0}$ : A média da amostra 1 é igual que a média da amostra $2\left(\mu_{1}=\mu_{2}\right)$

$\mathrm{H}_{1}$ : A média da amostra 1 é maior que a média da amostra $2\left(\mu_{1}>\mu_{2}\right)$

Como o p-valor é menor que o nível de significância adotado, rejeita-se a hipótese nula de que média da amostra 1 é igual que a média da amostra 2. Abaixo a tabela 7 contém o teste de hipótese para comparação de médias assumindo variâncias diferentes.

\begin{tabular}{|l|c|c|}
\hline & Média (amostra 1) & Mediana (amostra 2) \\
\hline Média & 0.105464 & 0.097409 \\
\hline Variância & 0.000134 & $4.25 \mathrm{E}-06$ \\
\hline Observações & 10 & 10 \\
\hline gl & \multicolumn{2}{|c|}{2.274917} \\
\hline estatística t & \multicolumn{2}{|c|}{0.021963} \\
\hline$P(T \leq t)$ unicaudal & 1.795885 \\
\hline t Crítico unicaudal & \multicolumn{2}{|c|}{} \\
\hline
\end{tabular}

Tabela 7 - Teste t para diferença de médias assumindo variâncias diferentes

Isso leva a conclusão que a previsão utilizando a mediana como medida de centralidade melhora os resultados do MAPE do método proposto. 
A segunda questão é se aumentando o número de séries sintéticas geradas ocorre um ganho de precisão do modelo. Para isso foi construído outro experimento onde o modelo de previsão proposto foi rodado 24 vezes, considerando o MAPE tanto utilizando 30 séries sintéticas como com 100 séries sintéticas, conforme exibe a tabela 8 .

\begin{tabular}{|l|l|}
\hline$N=30$ & $N=100$ \\
\hline $9.50 \%$ & $9.32 \%$ \\
\hline $9.30 \%$ & $9.53 \%$ \\
\hline $9.52 \%$ & $9.54 \%$ \\
\hline $9.85 \%$ & $9.70 \%$ \\
\hline $9.16 \%$ & $9.24 \%$ \\
\hline $10.33 \%$ & $9.46 \%$ \\
\hline $9.35 \%$ & $9.27 \%$ \\
\hline $10.00 \%$ & $9.48 \%$ \\
\hline $9.72 \%$ & $9.58 \%$ \\
\hline $9.18 \%$ & $9.59 \%$ \\
\hline $9.21 \%$ & $9.71 \%$ \\
\hline $9.40 \%$ & $9.24 \%$ \\
\hline
\end{tabular}

Tabela 8 - Valores do MAPE utilizando 30 e 100 séries sintéticas

Logo, foi feito um teste de hipótese para comparar a média do MAPE calculado a partir dos dois números de séries sintéticas. Porém, antes de testar a média, é preciso testar a variância das duas amostras, para então decidir qual teste de médias é adequado. Para isso foi utilizado um teste $\mathrm{F}$ para diferença de variância assumindo um nível de significância de 5\%, onde as hipóteses são:

$\mathrm{H}_{0}$ : As variâncias das duas amostras são iguais $\left(\sigma_{N 30}^{2}=\sigma_{N 100}^{2}\right)$

$\mathrm{H}_{1}$ : As variâncias das duas amostras são diferentes $\left(\sigma_{N 30}^{2} \neq \sigma_{N 30}^{2}\right)$

Como o p-valor é menor que o nível de significância adotado, há indícios para rejeitar a hipótese nula de que as variâncias das duas amostras são iguais. Abaixo na tabela 9 estão os dados completos do teste de hipótese 


\begin{tabular}{|c|c|c|}
\hline & $N=30$ & $N=100$ \\
\hline Média & 0.095433 & 0.094717 \\
\hline Variância & 0.000013 & 0.000003 \\
\hline Observações & 12 & 12 \\
\hline $\mathrm{g} 1$ & 11 & 11 \\
\hline $\mathrm{F}$ & \multicolumn{2}{|c|}{4.657395} \\
\hline$P(F \leq f)$ bicaudal & \multicolumn{2}{|c|}{0.008478} \\
\hline F Critico bicaudal & \multicolumn{2}{|c|}{2.81793} \\
\hline
\end{tabular}

Tabela 9 - Teste F para diferença de variâncias

Com isso, para comparar se as médias das duas amostras, foi aplicado um teste T assumindo variâncias diferentes e um nível de significância de 5\% com as seguintes hipóteses:

$\mathrm{H}_{0}$ : A média com $N=30$ é igual a média com $N=100\left(\mu_{N 30}=\mu_{N 100}\right)$

$\mathrm{H}_{1}$ : A média com $N=30$ é maior que a média com $N=100 \quad\left(\mu_{N 30}>\mu_{N 100}\right)$

Como o p-valor é maior que o nível de significância adotado, não há indícios para rejeitar a hipótese nula. Abaixo na tabela 10 se encontram os dados completos do teste de hipótese.

\begin{tabular}{|c|c|c|}
\hline & $N=30$ & $N=100$ \\
\hline Média & 0.095433 & 0.094717 \\
\hline Variância & 0.000013 & 0.000003 \\
\hline Observações & 12 & 12 \\
\hline$P(T \leq t)$ unicaudal & \multicolumn{2}{|c|}{0.617809} \\
\hline t Crítico unicaudal & \multicolumn{2}{|c|}{1.745884} \\
\hline
\end{tabular}

Tabela 10 - Teste T para diferença de médias assumindo variâncias diferentes

Isso leva a conclusão que a previsão utilizando um número maior de séries sintéticas não leva a uma melhora da precisão do método proposto.

Portanto, foi adotada uma configuração ótima do modelo, utilizando a mediana como medida de centralidade e gerando previsões a partir de 30 séries sintéticas.

Agora, é possível realizar uma comparação utilizando as variações de modelos de amortecimento exponencial, com os sete dias de teste, realizando 
previsões 24 passos à frente. $\mathrm{O}$ primeiro $(\mathrm{HW})$ é um modelo de sazonalidade multiplicativa, considerando apenas o ciclo diário de 24 observações, que por não considerar a sazonalidade mensal, só utiliza o último ano da base de dados para realizar a estimação dos parâmetros. O segundo (DSHW) é um modelo de múltiplos ciclos análogo ao proposto em (Taylor, 2003b), que trata simultaneamente o ciclo diário e a sazonalidade mensal. O terceiro (TBATS+HW) é um modelo utilizando a metodologia proposta na figura 36, com decomposição TBATS, simulação de Monte Carlo, mediana como medida de centralidade e 30 simulações, com o modelo de amortecimento exponencial com a mesma estrutura do primeiro (HW). O quarto (TBATS+DSHW) é similar ao terceiro, só que utiliza como modelo de amortecimento exponencial um com a mesma estrutura do segundo (DSHW). Abaixo na tabela 11 se encontram os resultados do MAPE de acordo com o modelo e dia de teste.

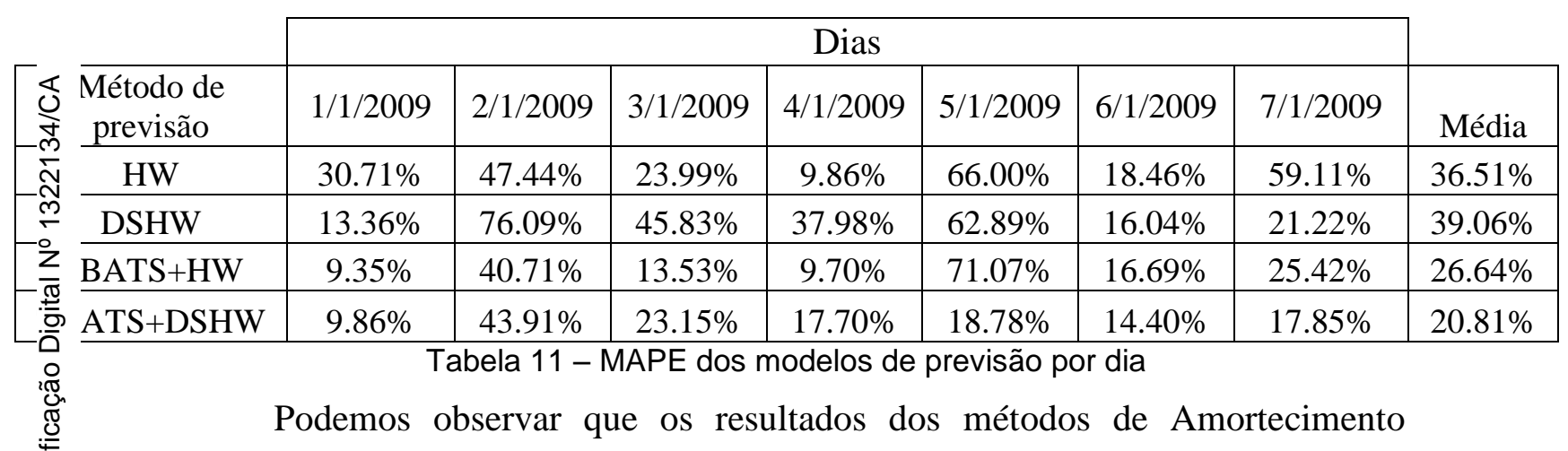

Exponencial que incorporam as técnicas de decomposição e simulação propostas apresentam resultados superiores aos modelos tradicionais utilizados para comparação. Os resultados podem ser explicitados também na forma de um gráfico de linhas, na figura 43, onde é possível notar a maior estabilidade do melhor método (TBATS+DSHW), que mesmo que não obtenha a melhor precisão em todos os dias, mantém na média um resultado melhor. 


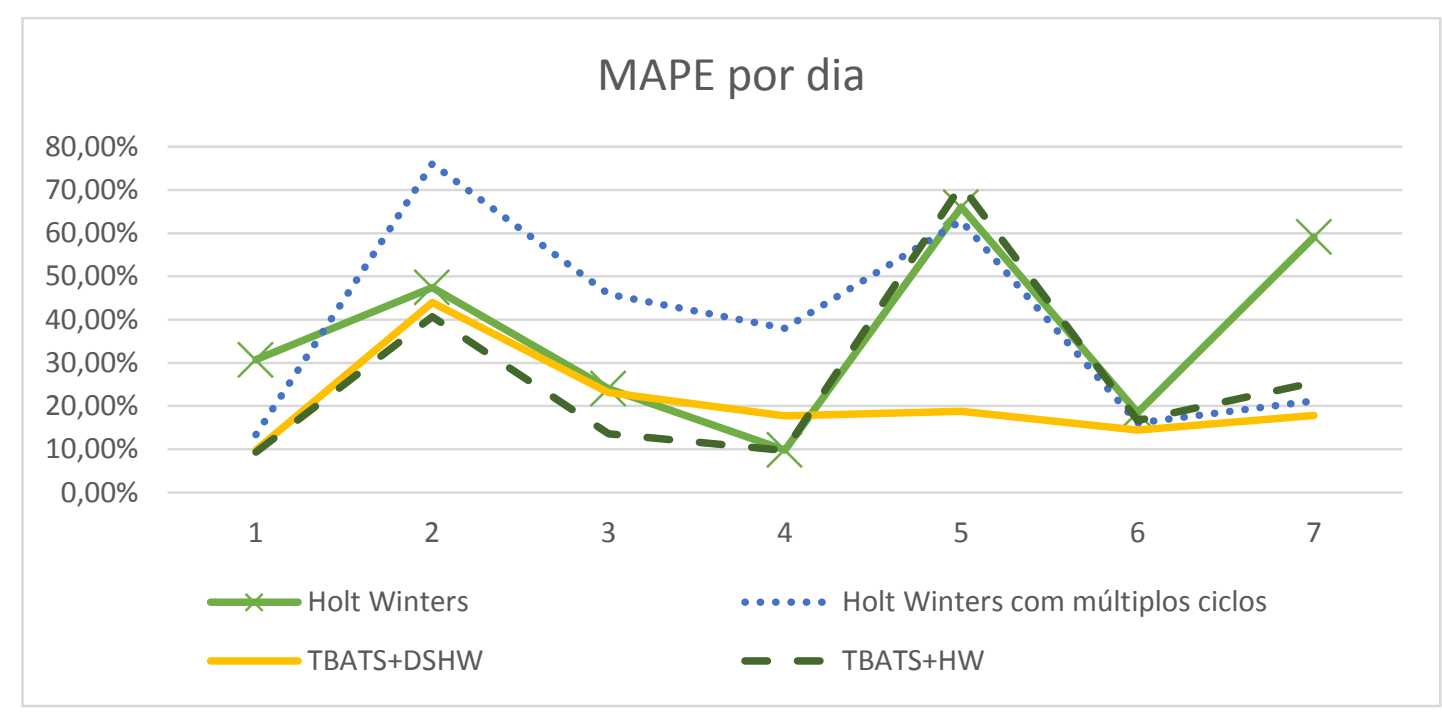

Figura 43 - Gráfico do MAPE por modelo de previsão

Porém, vale observar com mais atenção o dia 5, que com exceção do TBATS+DSHW, faz com que os métodos de previsão tenham taxas de erro bem altas (acima de 60\%). Podemos comparar os dados do dia 5 com os dados do dia 1 e com a média do mês de janeiro de 2009, conforme é apresentado na figura 44 abaixo.

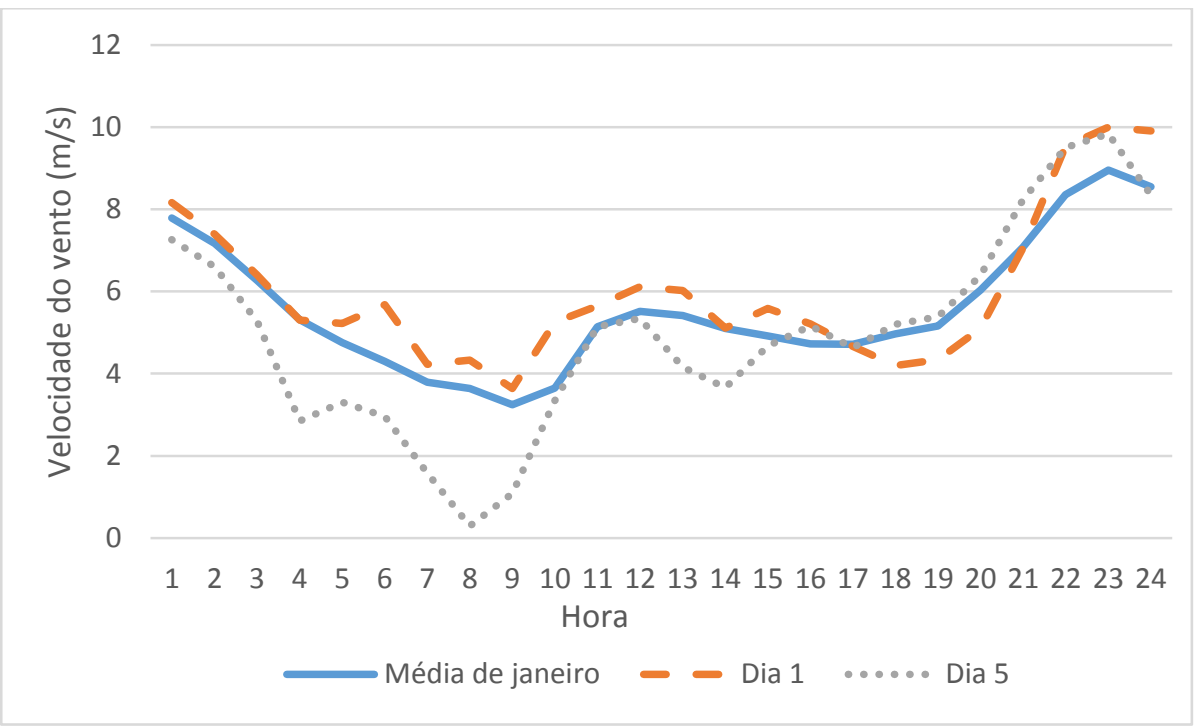

Figura 44 - Perfis de velocidade por dia

Logo, podemos notar que comparando com a média do mês, o dia 5 tem um comportamento atípico, o que justificaria os resultados dos modelos de previsão para esse dia. Isso também sugeriria uma maior robustez a dias que fogem ao padrão do modelo que incorpora as técnicas de decomposição, simulação e amortecimento exponencial de múltiplos ciclos (TBATS+DSHW). Também é possível observar que em dias que seguem um padrão muito parecido com a média do mês, como o dia 1 , os modelos de previsão que combinam as 
técnicas de amortecimento exponencial na abordagem proposta, obtêm um desempenho superior.

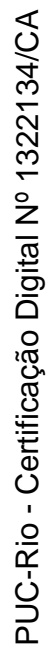




\section{Conclusão}

\subsection{Principais resultados}

Em função dos resultados obtidos nos capítulos 4 e 5, podemos apontar algumas conclusões importantes, como:

- A análise estatística dos dados de velocidade de vento mostra que a série de dados tem um padrão sazonal complexo, formado por um ciclo diário e uma sazonalidade mensal, o que exige então um modelo robusto para realizar a previsão.

- A análise dos dados de potência revela que de acordo com o mês o perfil horário da curva é alterado, levando a um deslocamento dos horários de maior produção, fato esse que é muito importante para o planejamento do sistema elétrico no que se refere ao despacho de energia.

- O método de previsão proposto se mostrou adequado e satisfatório quando comparado com modelos estabelecidos na literatura, como o Holt-Winters e o Holt-Winters com múltiplos ciclos, quando aplicado na série de velocidade de vento. Isso é um passo importante para a literatura dos modelos de amortecimento exponencial, pois corrobora a tese explorada em (Bergmeir, Hyndman e Benitez, 2014), de que novos modelos de amortecimento que incorporam diferentes técnicas estatísticas de decomposição e simulação são possibilidades de avanço no estado da arte nos modelos de amortecimento exponencial no que tange a precisão e robustez à outliers.

\subsection{Trabalhos futuros}

Como possibilidades de trabalhos futuros, temos algumas alternativas, que são: 
Testar o modelo que obteve o melhor resultado (TBATS+DSHW) em outras séries que tem padrão de sazonalidade complexo, para avaliar os resultados em diferentes cenários.

Como a ideia do método é decompor uma série temporal, encontrar sua estrutura principal, gerar séries sintéticas através de uma técnica de simulação no resíduo e depois aplicar um modelo de previsão nas séries sintéticas e chegar a uma previsão que seja uma combinação das previsões realizadas nas séries geradas, existe uma gama imensa de possibilidades de novas combinações, que são obtidas quando se muda uma dessas técnicas. A tabela a seguir apresenta uma sugestão de o que pode ser intercambiado para a geração de modelos alternativos.

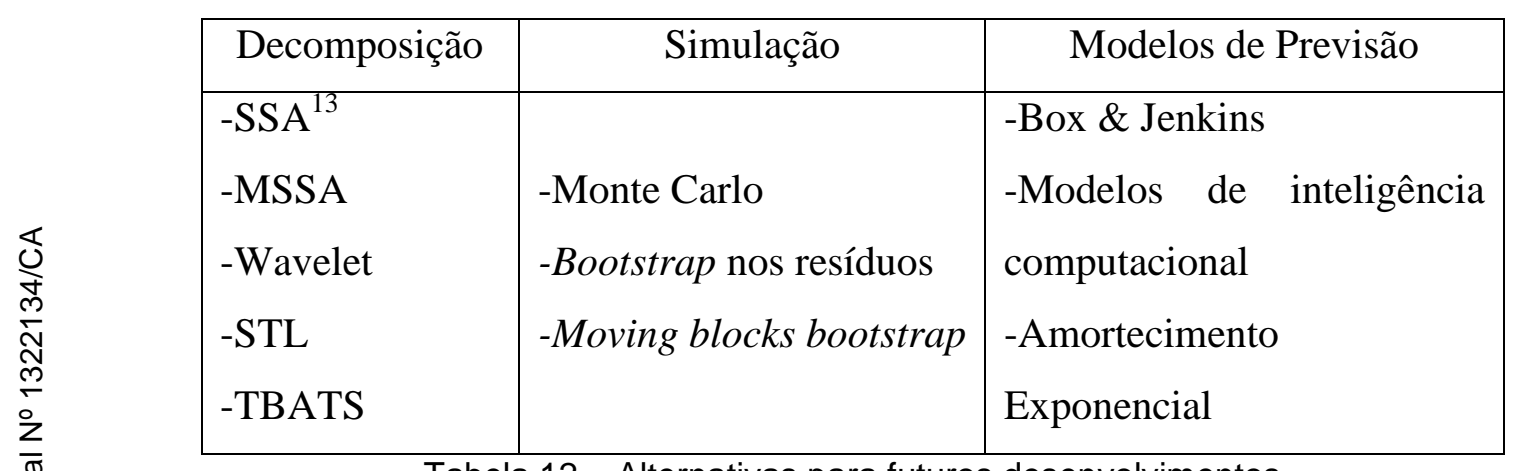

Tabela 12 - Alternativas para futuros desenvolvimentos

\footnotetext{
${ }^{13}$ Singular Spectral Analysis
} 


\section{Referências Bibliograficas}

BARBOUNIS, T. G. et al. Long-term wind speed and power forecasting using local recurrent neural network models. Energy Conversion, IEEE Transactions on, v. 21, n. 1, p. 273-284, 2006. ISSN 0885-8969.

BARROS, M. F. D.; OLIVEIRA, F. L. C.; SOUZA, R. C. Modelos de simulação de cenários de produção de energia eólica a partir do método de HoltWinters e suas variações. XLVII Simpósio Brasileiro de Pesquisa Operacional. OPERACIONAL, A. D. X. S. B. D. P. Porto de Galinhas 2015.

BEAUMONT, A. N. Data transforms with exponential smoothing methods of forecasting. International Journal of Forecasting, v. 30, n. 4, p. 918-927, 10// 2014. ISSN 0169-2070. Disponível em: < http://www.sciencedirect.com/science/article/pii/S0169207014000600 >. Acesso em: 2014/12//.

BERGMEIR, C.; HYNDMAN, R. J.; BENITEZ, J. M. Bagging Exponential Smoothing Methods using STL Decomposition and Box-Cox Transformation. Monash University, Department of Econometrics and Business Statistics. 2014

BILLAH, B. et al. Exponential smoothing model selection for forecasting. International Journal of Forecasting, v. 22, n. 2, p. 239-247, 4// 2006. ISSN Disponível em: http://www.sciencedirect.com/science/article/pii/S016920700500107X >. Acesso em: 2006/6//.

BROWN, R. G. Statistical forecasting for inventory control. New York: McGraw-Hill, 1959.

BURTON, T. et al. Wind energy handbook. John Wiley \& Sons, 2001. ISBN 0471489972.

CAPITÃO, M. A. Previsão de vento baseado em Técnicas de Data Mining. 2010.

CUSTÓDIO, R. Energia Eólica para Produção de Eletricidade: Eletrobrás 2009.

DANTAS, T. M.; OLIVEIRA, F. L. C. D. Forecasting the Air Transportation Demand: An application at Amsterdam Schiphol Airport using Bagged Holt Winters assisted by Compression-Based Dissimilarity measure. 35th International Symposium on Forecasting, 2015, Riverside - EUA. 
DE LIVERA, A. M.; HYNDMAN, R. J.; SNYDER, R. D. Forecasting time series with complex seasonal patterns using exponential smoothing. Journal of the American Statistical Association, v. 106, n. 496, p. 1513-1527, 2011. ISSN 0162-1459.

GARDNER, E. S. Exponential smoothing: The state of the art. Journal of Forecasting, v. 4, n. 1, p. 1-28, 1985. ISSN 1099-131X. Disponível em: < http://dx.doi.org/10.1002/for.3980040103 >.

GARDNER JR, E. S. Exponential smoothing: The state of the art-Part II. International Journal of Forecasting, v. 22, n. 4, p. 637-666, 10// 2006. ISSN 0169-2070.

Disponível em:

http://www.sciencedirect.com/science/article/pii/S0169207006000392 >. Acesso em: 2006/12//.

GOULD, P. G. et al. Forecasting time series with multiple seasonal patterns. European Journal of Operational Research, v. 191, n. 1, p. 207-222, 11/16/ 2008. ISSN 0377-2217. Disponível em: http://www.sciencedirect.com/science/article/pii/S0377221707008740 >.

HARRIS, R. I.; COOK, N. J. The parent wind speed distribution: Why Weibull? Journal of Wind Engineering and Industrial Aerodynamics, v. 131, n. 0, p. 72-87, 8// 2014. ISSN 0167-6105. Disponível em: < http://www.sciencedirect.com/science/article/pii/S0167610514001056 >.

HARVEY, A. C. Analysis and Generalisation of a Multivariate Exponential Smoothing Model. Management Science, v. 32, n. 3, p. 374-380, 1986. ISSN 00251909. Disponível em: < http://www.jstor.org/stable/2631421 >.

Forecasting, structural time series models and the Kalman filter. Cambridge university press, 1990. ISBN 0521405734.

HASSANI, H. Singular Spectrum Analysis: Methodology and Comparison. Journal of Data Science, v. 5, n. 2, p. 239-257, 2007-04-01 2007. Disponível em: < http://mpra.ub.uni-muenchen.de/4991/ >.

HOLT, C. C. Forecasting seasonals and trends by exponentially weighted moving averages. ONR Memorandum, v. 52, p. 297-307, 1957.

HYNDMAN, R. et al. Forecasting with exponential smoothing: the state space approach. Springer Science \& Business Media, 2008. ISBN 3540719180.

HYNDMAN, R. J.; ATHANASOPOULOS, G. Forecasting: principles and practice. OTexts, 2014. ISBN 0987507109.

HYNDMAN, R. J. et al. A state space framework for automatic forecasting using exponential smoothing methods. International Journal of Forecasting, v. 18, n. 3, p. 439-454, 7// 2002. ISSN 0169-2070. Disponível em: < 
http://www.sciencedirect.com/science/article/pii/S0169207001001108 >. Acesso em: 2002/9//.

LEI, M. et al. A review on the forecasting of wind speed and generated power. Renewable and Sustainable Energy Reviews, v. 13, n. 4, p. 915-920, 5// 2009. ISSN 1364-0321. Disponível em: http://www.sciencedirect.com/science/article/pii/S1364032108000282 >.

MAÇAIRA, P. M.; CYRINO OLIVERIA, F. L.; SOUZA, R. C. Forecasting natural inflow energy series with multi-channel singular spectrum analysis and bootstrap techniques. International Journal of Energy and Statistics, v. 3, n. 01, p. 1550005, 2015. ISSN 2335-6804.

MENEZES, M.; SOUZA, R.; PESSANHA, J. Combining singular spectrum analysis and PAR () structures to model wind speed time series. Journal of Systems Science and Complexity, v. 1, n. 27, p. 29-46, 2014. ISSN 1009-6124.

MIRANDA, C. V. C. D. Previsão de Dados de Alta Frequiência para Carga Elétrica Usando Holt-Winters com Dois Ciclos. 2007. (Dissertação de Mestrado). Departamento de Engenharia Elétrica, PUC-Rio

MONTGOMERY, D. C.; JOHNSON, L. A.; GARDINER, J. S. Forecasting and time series analysis. McGraw-Hill Companies, 1990. ISBN 0070428581.

MOONEY, C. Z. Monte carlo simulation. Sage Publications, 1997. ISBN 1506317901.

MOREIRA, P. J. F.; DE SANTANA, G. W. L.; SILLER, L. L. USANDO A ANÁLISE ESPECTRAL SINGULAR NA PREVISÃO DA PRODUÇÃO MENSAL DE UM PARQUE EÓLICO. Blucher Marine Engineering Proceedings, v. 1, n. 1, p. 201-212, 2014. ISSN 2358-5498.

ORD, J. K.; KOEHLER, A. B.; SNYDER, R. D. Estimation and Prediction for a Class of Dynamic Nonlinear Statistical Models. Journal of the American Statistical Association, v. 92, n. 440, p. 1621-1629, 1997. ISSN 01621459. Disponível em: < http://www.jstor.org/stable/2965433 >.

PEGELS, C. C. Exponential forecasting: some new variations. Management Science, v. 12, p. 311-315, 1969.

PESSANHA, J. F. M.; DA SILVA, I. V. G.; SOUZA, R. C. Previsão da Velocidade do Vento com Sistema de Inferência Neuro-fuzzy Adaptativo: Anais do $13^{\circ}$ Simpósio de Pesquisa Operacional e Logística da Marinha 2010.

PICOLO, A. P.; RÜHLER, A. J.; RAMPINELLI, G. A. Uma abordagem sobre a energia eólica como alternativa de ensino de tópicos de física clássica. Revista Brasileira de Ensino de Física, v. 36, p. 01-13, 2014. ISSN 1806-1117. Disponível em: < http://www.scielo.br/scielo.php?script=sci_arttext\&pid=S1806$\underline{11172014000400007 \& \mathrm{nrm}=\mathrm{iso}}>$. 
PROIETTI, T. Comparing seasonal components for structural time series models. International Journal of Forecasting, v. 16, n. 2, p. 247-260, 4// 2000. ISSN 0169-2070. Disponível em: < http://www.sciencedirect.com/science/article/pii/S0169207000000376 >. Acesso em: 2000/6//.

ROSS, S. M. A course in simulation. Prentice Hall PTR, 1990. ISBN 0024038911.

RUBinstein, R. Y.; KROESE, D. P. Simulation and the Monte Carlo method. John Wiley \& Sons, 2011. ISBN 1118210522.

SEGURO, J. V.; LAMBERT, T. W. Modern estimation of the parameters of the Weibull wind speed distribution for wind energy analysis. Journal of Wind Engineering and Industrial Aerodynamics, v. 85, n. 1, p. 75-84, 3// 2000. ISSN 0167-6105. Disponível em: http://www.sciencedirect.com/science/article/pii/S0167610599001221 >.

SOUZA, R. C. et al. Planejamento da Operação de Sistemas Hidrotérmicos no Brasil: Geração de Cenários e Otimização. Rio de Janeiro: PUC-Rio, 2014.

SOUZA, R. C.; OLIVEIRA, F. L. C. D. Análise de Séries Temporais: os Modelos de Amortecimento Exponencial. Rio de Janeiro 2015.

SUDHEER, G.; SUSEELATHA, A. Short term load forecasting using wavelet transform combined with Holt-Winters and weighted nearest neighbor models. International Journal of Electrical Power \& Energy Systems, v. 64, n. 0, p. 340-346, 1// 2015. ISSN 0142-0615. Disponível em: < http://www.sciencedirect.com/science/article/pii/S0142061514004785 >.

TAYLOR, J. W. Exponential smoothing with a damped multiplicative trend. International journal of Forecasting, v. 19, n. 4, p. 715-725, 2003a. ISSN 0169-2070.

- Short-term electricity demand forecasting using double seasonal exponential smoothing. Journal of the Operational Research Society, v. 54, n. 8, p. 799-805, 2003b. ISSN 0160-5682.

Exponentially weighted methods for forecasting intraday time series with multiple seasonal cycles. International Journal of Forecasting, v. 26, n. 4, p. 627-646, 2010a. ISSN 0169-2070.

Triple seasonal methods for short-term electricity demand forecasting. European Journal of Operational Research, v. 204, n. 1, p. 139-152, 2010b. ISSN 0377-2217.

WANG, X.; GUO, P.; HUANG, X. A Review of Wind Power Forecasting Models. Energy Procedia, v. 12, n. 0, p. 770-778, // 2011. ISSN 1876-6102. Disponível em: http://www.sciencedirect.com/science/article/pii/S1876610211019291 >. 
WINTERS, P. R. Forecasting Sales by Exponentially Weighted Moving Averages. Management Science, v. 6, p. 324-342, 1960-04-01 1960. Disponível em: $\langle$ http://pubsonline.informs.org/doi/abs/10.1287/mnsc.6.3.324 >. 